Florida International University FIU Digital Commons

$11-3-2010$

\title{
The Effects of Self-monitoring on Homework Completion and Accuracy Rates of Students with Disabilities in an Inclusive General Education Classroom
}

Carol Ann Falkenberg

Florida International University, carolannfalk@hotmail.com

DOI: $10.25148 /$ etd.FI10112005

Follow this and additional works at: https:// digitalcommons.fiu.edu/etd

Part of the Bilingual, Multilingual, and Multicultural Education Commons, Child Psychology

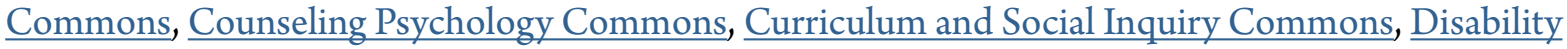
and Equity in Education Commons, Educational Assessment, Evaluation, and Research Commons, Educational Psychology Commons, Elementary and Middle and Secondary Education Administration Commons, Elementary Education and Teaching Commons, Gifted Education Commons, Quantitative Psychology Commons, Social Psychology Commons, Special Education Administration Commons, Special Education and Teaching Commons, and the Student Counseling and Personnel Services Commons

\section{Recommended Citation}

Falkenberg, Carol Ann, "The Effects of Self-monitoring on Homework Completion and Accuracy Rates of Students with Disabilities in an Inclusive General Education Classroom" (2010). FIU Electronic Theses and Dissertations. 298.

https://digitalcommons.fiu.edu/etd/298 


\section{FLORIDA INTERNATIONAL UNIVERSITY}

Miami, Florida

THE EFFECTS OF SELF-MONITORING ON HOMEWORK COMPLETION AND ACCURACY RATES OF STUDENTS WITH DISABILITIES

IN AN INCLUSIVE GENERAL EDUCATION CLASSROOM

A dissertation submitted in partial fulfillment of the

requirements for the degree of

DOCTOR OF EDUCATION

in

EXCEPTIONAL STUDENT EDUCATION

by

Carol Ann Falkenberg

2010 
To: Interim Dean Delia Garcia

College of Education

This dissertation, written by Carol Ann Falkenberg, and entitled The Effects of Self-monitoring on Homework Completion and Accuracy Rates of Students with Disabilities in an Inclusive General Education Classroom, having been approved in respect to style and intellectual content, is referred to you for judgment.

We have read this dissertation and recommend that it be approved.

$\begin{array}{r}\text { Elizabeth Cramer } \\ \hline \text { Maureen Kenny } \\ \hline \text { Lynne Miller } \\ \hline \text { Patricia M. Barbetta, Major Professor }\end{array}$

Patricia M. Barbetta, Major Professor

Date of Defense: November 3, 2010

The dissertation of Carol Ann Falkenberg is approved.

Interim Dean Delia Garcia

College of Education

Interim Dean Kevin O'Shea

University Graduate School

Florida International University, 2010 
C Copyright 2010 by Carol Ann Falkenberg

All rights reserved. 


\section{DEDICATION}

I dedicate this work to Katherine, Edwood, Donald, Anne, Elaine and Arie. Thanks for being so patient and helping me along on this journey. Each one of you inspires me for different reasons, and I am appreciative of all that you have done. I am forever grateful for all of your support throughout this process. I love you all. 


\section{ACKNOWLEDGMENTS}

I would like to thank the members of my committee Major Professor Dr. Patricia Barbetta, Dr. Maureen Kenny, Dr. Elizabeth Cramer, and Dr. Lynne Miller for their continued dedication in this endeavor. This project would not have been possible without them. In particular, I want to extend a very warm and special thanks to Dr. Barbetta, who provided me with much needed feedback every step of the way. Her guidance and continued support and encouragement helped me to fulfill this dream.

I want to thank my family and friends for supporting me through some long nights. I appreciate all you have done for and given to me. All of my wonderful colleagues, leaders and friends at Vineyards Elementary, thank you for your words of encouragement. Thank you to Sheryl, Gina, Lynn, Jennifer, Angeles, Mario and Lisa for your friendship and the laughter. I could never have gotten through this without the

laughter. Finally, I want to thank Collier County Public Schools for allowing me the opportunity to conduct my research in one of their fine schools. It was a privilege. 


\section{ABSTRACT OF THE DISSERTATION \\ THE EFFECTS OF SELF-MONITORING ON HOMEWORK COMPLETION AND \\ ACCURACY RATES OF STUDENTS WITH DISABILITIES IN AN INCLUSIVE \\ GENERAL EDUCATION CLASSROOM \\ by}

Carol Ann Falkenberg

Florida International University, 2010

Miami, Florida

Professor Patricia M. Barbetta, Major Professor

This study investigated the effects of self-monitoring on the homework completion and accuracy rates of four, fourth-grade students with disabilities in an inclusive general education classroom. A multiple baseline across subjects design was utilized to examine four dependent variables: completion of spelling homework, accuracy of spelling homework, completion of math homework, accuracy of math homework. Data were collected and analyzed during baseline, three phases of intervention, and maintenance.

Throughout baseline and all phases, participants followed typical classroom procedures, brought their homework to school each day and gave it to the general education teacher. During Phase I of the intervention, participants self-monitored with a daily sheet at home and on the computer at school in the morning using KidTools (Fitzgerald \& Koury, 2003); a student friendly, self-monitoring program. They also participated in brief daily conferences to review their self-monitoring sheets with the investigator, their special education teacher. Phase II followed the same steps except 
conferencing was reduced to two days a week, which were randomly selected by the researcher and Phase III conferencing was one random day a week. Maintenance data were taken over a two-to-three week period subsequent to the end of the intervention.

Results of this study demonstrated self-monitoring substantially improved spelling and math homework completion and accuracy rates of students with disabilities in an inclusive, general education classroom. On average, completion and accuracy rates were highest over baseline in Phase III. Self-monitoring led to higher percentages of completion and accuracy during each phase of the intervention compared to baseline, group percentages also rose slightly during maintenance. Therefore, results suggest selfmonitoring leads to short-term maintenance in spelling and math homework completion and accuracy.

This study adds to the existing literature by investigating the effects of selfmonitoring of homework for students with disabilities included in general education classrooms. Future research should consider selecting participants with other demographic characteristics, using peers for conferencing instead of the teacher, and the use of self-monitoring with other academic subjects (e.g., science, history). Additionally, future research could investigate the effects of each of the two self-monitoring components used alone, with or without the conferencing. 


\section{TABLE OF CONTENTS}

CHAPTER

PAGE

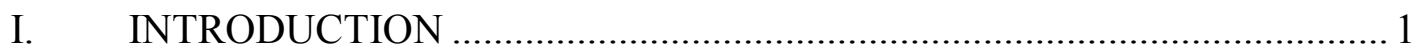

Self-Monitoring Definition and Research................................................ 7

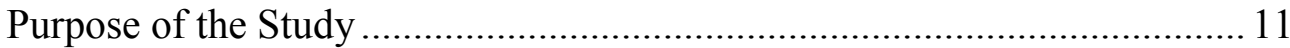

Statement of the Problem......................................................................... 14

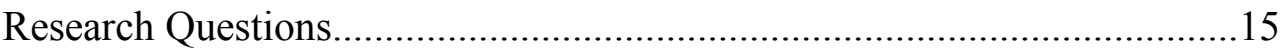

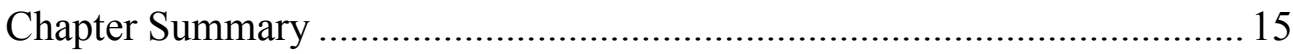

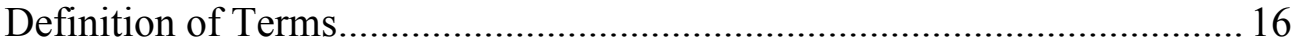

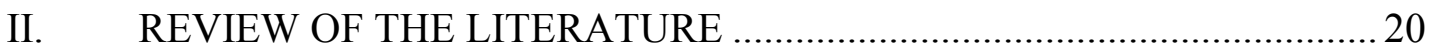

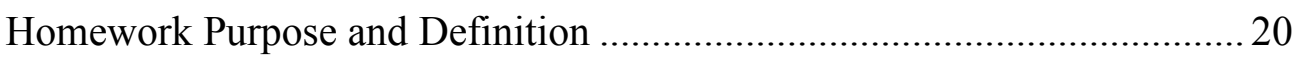

History of Homework in American Schools.................................................. 21

The Benefits of Homework and Homework Strategies ................................ 25

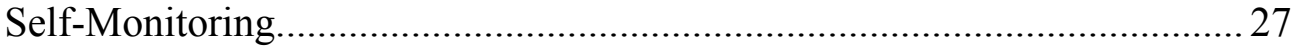

Research on Self-Monitoring ……………................................................. 31

Self-Monitoring with General Education Participants .......................... 32

Self-Monitoring with Students With Disabilities .....................................35

Self-Monitoring and Homework ................................................................ 42

Self-Monitoring Homework with General Education Students ............ 42

Self-Monitoring Homework with Students With Disabilities................ 46

Chapter Summary …………………………………............................. 52

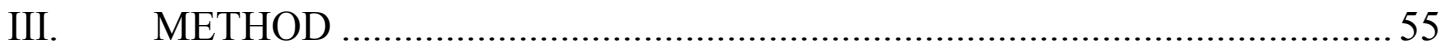

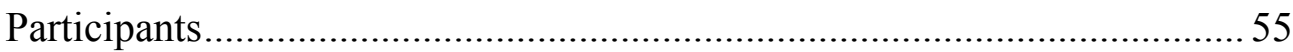

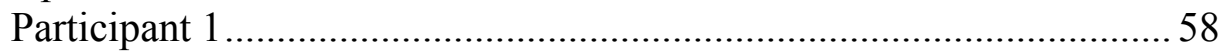

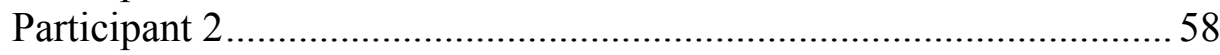

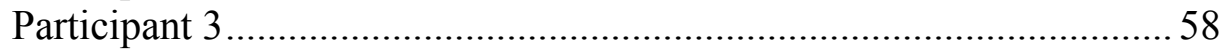

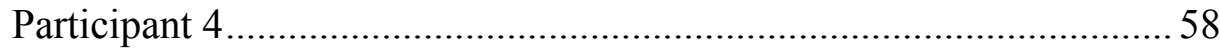

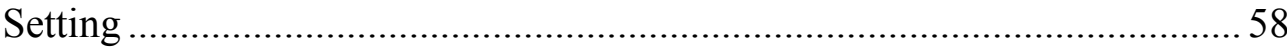

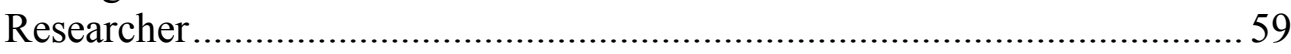

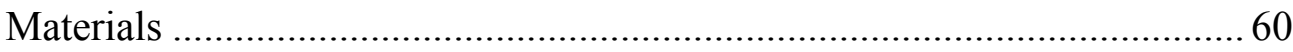

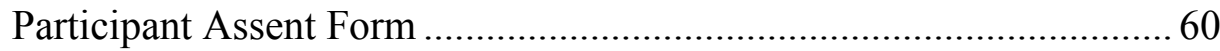

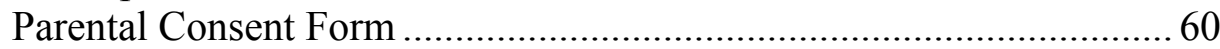

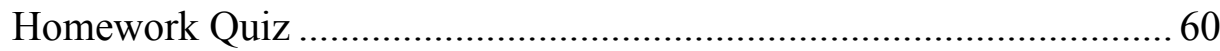

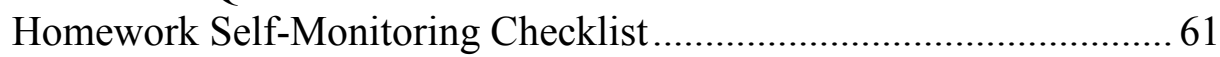

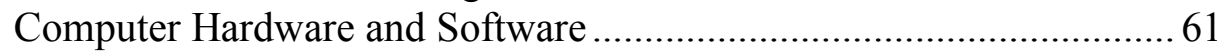

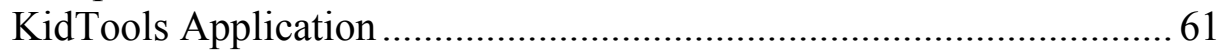

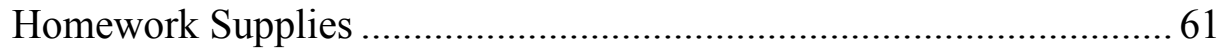

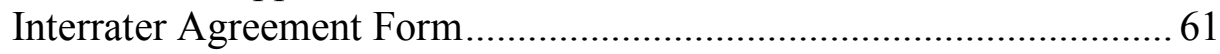

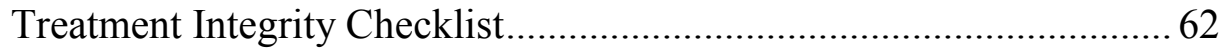

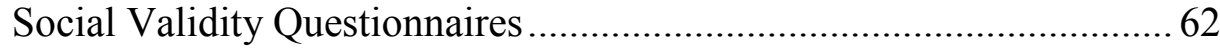

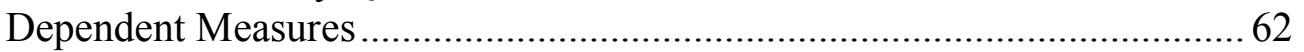




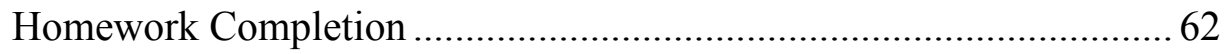

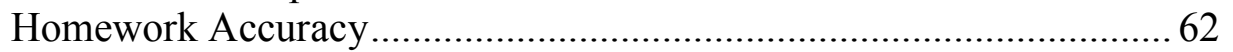

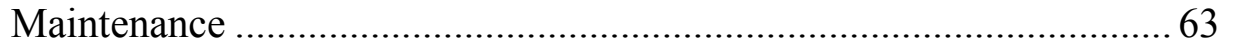

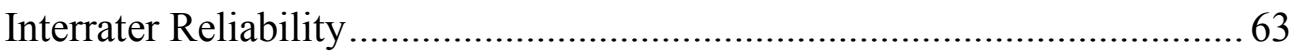

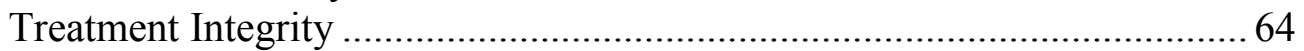

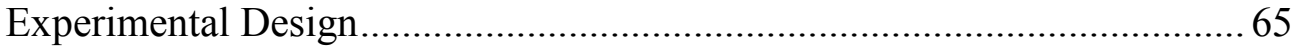

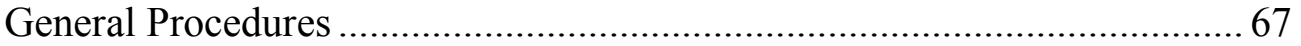

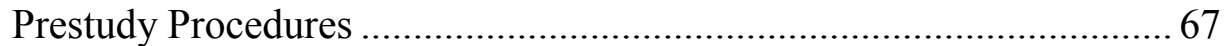

Baseline, Intervention Training, Intervention, and Maintenance .................. 69

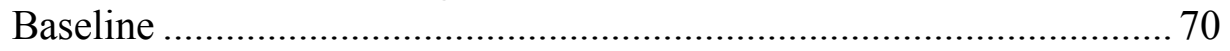

Intervention Training .................................................................... 71

Phase I Intervention ......................................................................... 73

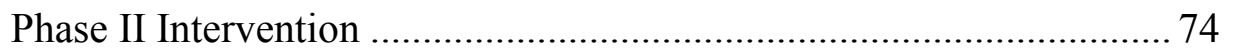

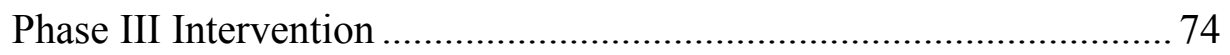

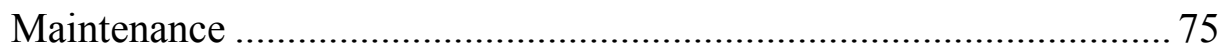

Social Validity Questionnaires ............................................................ 75

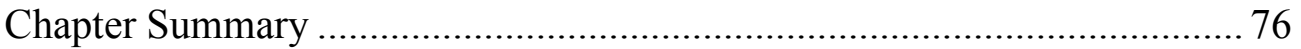

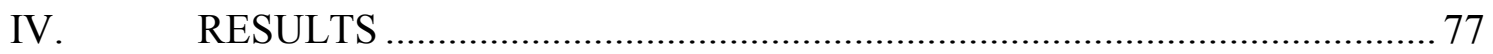

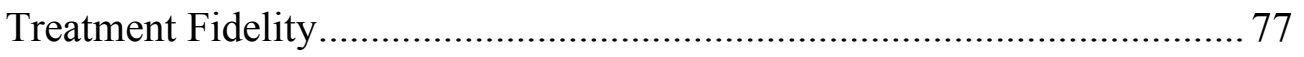

Interrater Agreement ................................................................................. 78

Spelling Homework Completion and Accuracy …………........................... 78

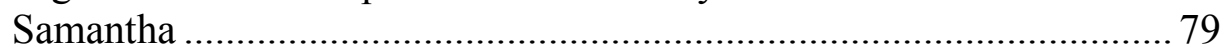

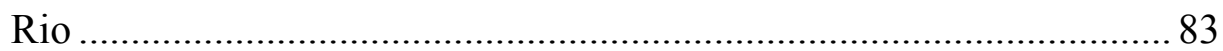

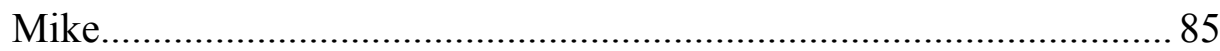

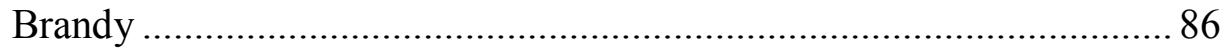

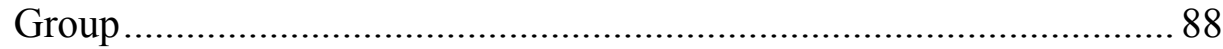

Math Homework Completion and Accuracy ................................................ 89

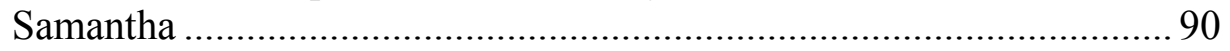

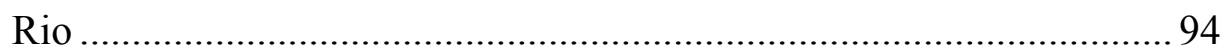

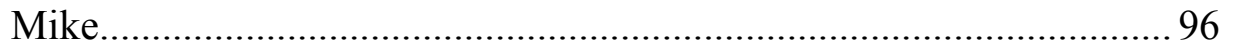

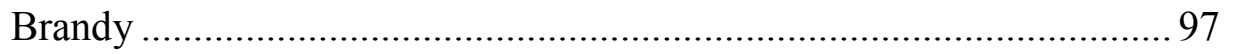

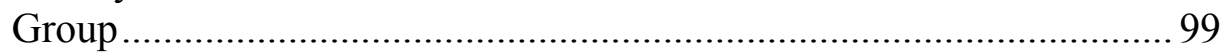

Social Validity Questionnaires ................................................................. 100

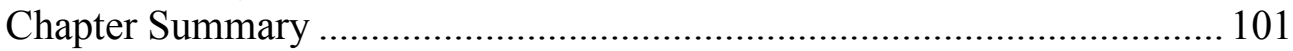

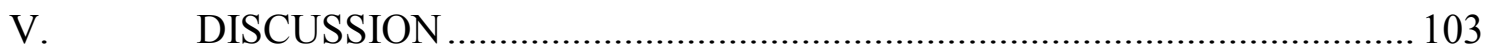

Spelling and Math Homework Completion ..................................................... 104

Spelling and Math Homework Accuracy................................................... 107

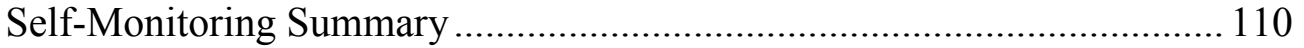

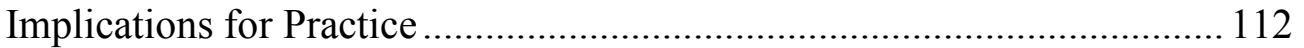

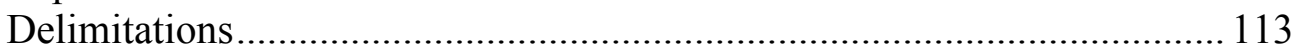

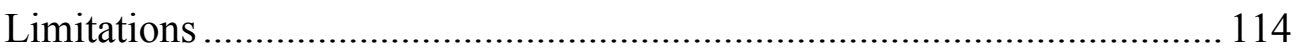

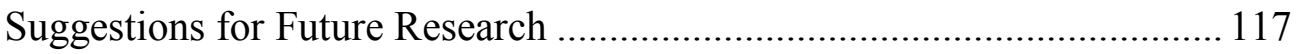

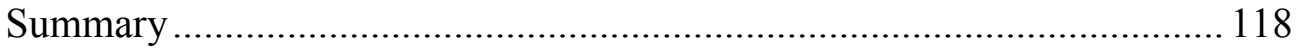




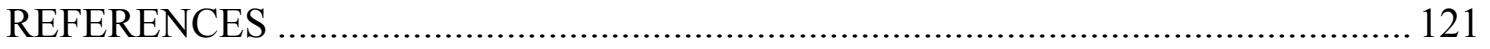

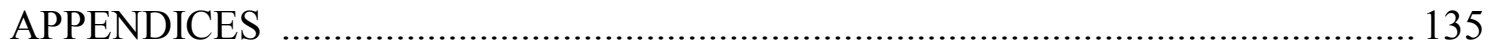

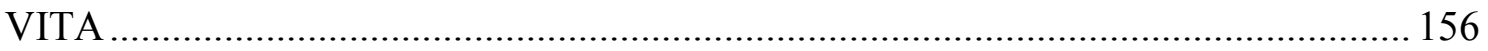




\section{LIST OF TABLES}

TABLE

PAGE

1. Summary of Participant Characteristics......................................................... 59

2. Individual and Group Means and Ranges on Spelling Homework Completion......... 81

3. Individual and Group Means and Ranges on Spelling Homework Accuracy ............ 82

4. Individual and Group Means and Ranges on Math Homework Completion.............. 91

5. Individual and Group Means and Ranges on Math Homework Accuracy ................ 93 


\section{CHAPTER I}

\section{INTRODUCTION}

Since the 1990s, homework has become a standard classroom expectation in American schools at all grade levels including kindergarten (Cooper, Jackson, Nye, \& Lindsay, 2001). Homework is defined as work assigned by the teacher that is to be completed outside of the normal class period (Cooper, 2001). There are at least four purposes for homework: practice and review, preparation for future assignments, transfer of previously learned skills to new conditions, and skill integration (Cooper, 2001; Cooper et al., 2001). In today's schools, most students receive homework with the expectation that it will be completed accurately and in a timely manner. Although homework guidelines vary from district to district, the average amount of homework assigned in the U.S. per night is 10-30 minutes for elementary grades (10 minutes per grade level), 40-60 minutes for intermediate grades, and 60-90 minutes for middle and high school grades (U.S. Department of Education [USDOE], Institute of Education Sciences, 2008b). The reasoning is that younger children have shorter attention spans; therefore, more frequent, concise assignments may be more effective than longer but fewer assignments (USDOE, 2003).

Homework assignments vary throughout a student's school years. In the elementary grades, there is usually one teacher assigning homework for all subjects, as students move to middle and high school, this scenario changes. According to the USDOE Institute of Education Sciences (2008b), elementary teachers typically assign homework for reading and math during the week. In upper grades, as students move from 
class to class, they are typically given various assignments from different teachers, have multiple books to bring home, and diverse expectations from each teacher. However, regardless of how much homework is assigned, in order for homework to be beneficial at any grade level, students need to complete assignments accurately.

Unfortunately, many students do not perform well on their homework assignments, and these poor performances often begin during the elementary school years and continue throughout their education (DuPaul \& Stoner, 2003). During the elementary school years, some students tend to forget to take home their homework assignments, fail to return them to school, or turn them in late or incomplete (Gureasko-Moore, DuPaul, \& White, 2007). During later school years, students have additional challenges with the large number of homework assignments given. A few of the issues include a tendency to neglect to write down their assignments and failure to bring home the additional required materials in order to complete the assignments (DuPaul et al., 2007). Students may complete homework for one class but neglect homework in another class. Researchers have also noted that some students completely avoid academic tasks at home, which produces conflict in many families (Keith \& Keith, 2006).

Research investigating the relationship of homework to achievement indicates that time spent on homework has important and positive effects on learning, whether measured by grades or by test scores (Cooper \& Valentine, 2001; Gettinger \& Seibert, 2002). In fact, homework has been identified as one of the most important practices for establishing a successful academic environment and has been positively correlated with school performance, grades, responsibility, time management, and a student's self-esteem (Coleman, Hoffer, \& Kilgore, 1982; Cooper \& Valentine, 2001; Gleason, Archer, \& 
Colvin, 2002; Hughes, Ruhl, Schumaker, \& Deshler, 2002). Given homework’s importance, effective strategies for timely completion have been a source of concern for both parents and educators alike (Madaus, Kehle, Madaus, \& Bray, 2003).

A review of the literature reveals considerable research on valuable teacher and parental behaviors that influence homework practices (e.g., Hoover-Dempsey et al., 2001; Marzano, 2003). For example, students perform better on their homework assignments when teachers thoroughly explain the assigned homework, check for understanding, and review the homework in class (Stronge, 2002). Goal-setting, recording assignments in planners, communicating to parents about missing assignments, and using the Internet for assistance and communication are also strategies that have been shown to increase homework completion (Bembenutty \& Zimmerman, 2003; Glazer \& Williams, 2001; Salend, Duhaney, Anderson, \& Gottschalk, 2004). Additionally, research suggests that teachers should remind students to check for accuracy and completion before turning in their homework assignments (Cooper, 2007). Making certain that homework is at the appropriate level of difficulty so that it can be completed independently, yet challenging enough to be interesting is also important (Cooper, 2007). Providing opportunities for students to explore topics of their own interest is also beneficial (Cooper, Robinson, \& Patall, 2006; Epstein \& Van Voorhis, 2001). Parents can also positively influence their child's homework success by spending more time overseeing the homework, offering guidance with assignments, providing a distraction free environment, setting up a consistent homework schedule for their child to follow, checking in with teachers, and having an encouraging attitude (Hill \& Tyson, 2009). 
Studies have shown that students perform better on homework by following some basic strategies. For example, homework should be completed at the same time daily in a quiet, well-lit place without the distraction of the television, phone or high-traffic areas (Bempechat, 2004). All the necessary materials for the homework such as paper, pencils, a dictionary, and other special items should be gathered in advance so as not to distract from concentration on the assignment (Cooper, 2007). Additionally, reviewing the homework and prioritizing the assignments helps keep students on task and focused (Corno \& Xu, 2004; Xu, 2007). Adhering to these simple strategies may help increase the achievement of homework for some students (Bempechat, 2004).

Much, if not most, of the research on effective teacher, parental, and student homework strategies has been conducted with general education students. Limited research exists on effective homework strategies for students with disabilities.

Furthermore, no studies were found investigating homework strategies for students with disabilities educated in inclusive general education classrooms, despite the fact that there is a growing number of students with disabilities being educated in inclusive general education classrooms (Florida Department of Education [FLDOE], 2008a). Inclusive classrooms are those in which students with disabilities receive educational services and supports appropriate to their individual needs within the general education classroom setting (Hardman, Drew, \& Egan, 2006). In these inclusive classrooms, most students with disabilities are being required to meet grade level expectations, and homework completion is one of them (Mastropieri et al., 2005). The reauthorized Individuals with Disabilities Education Improvement Act (IDEA, 2004) emphasizes equal access to the general education curriculum for all students; homework is an aspect of this, and yet 
many of our students with disabilities are not prepared to meet these expectations (Bryan \& Burstein, 2004).

Nationally, approximately $56.8 \%$ of students with disabilities are educated in inclusive classrooms for most of the school day (USDOE, Office of Special Education Programs, 2008a). In Florida, approximately $62 \%$ of students with disabilities are receiving their education in inclusive general education classes as compared to $48 \%$ four years previously (FLDOE, 2008a). This increase in the number of students with disabilities in inclusive, general education classrooms grew out of legislation such as the Education for All Handicapped Children Act (PL 94-142), which mandated that public schools provide students with disabilities an appropriately designed education with the same rights as their non-disabled peers (Palmer, Wehmeyer, Gipson, \& Agran, 2004).

Along with the increased presence of many students with disabilities in inclusive settings has come new personal struggles and additional challenges for their teachers and parents. Many students with disabilities have not been prepared to meet grade level expectations (Cooper \& Valentine, 2001) as the result of many factors (DuPaul \& Stoner, 2003). While many of these students were in special education settings, they were typically in classrooms with a lower pupil/teacher ratio, and they received additional academic, social and/or behavioral supports. Once they are placed in inclusive general education classrooms, this additional support is often limited (Redmon, 2007). Overall, in the inclusive general education setting, students with disabilities are required to be more independent and accountable. This shift in accountability can be a difficult adjustment for these students, and consequently they are often unprepared to face the additional 
obstacles. For some students with disabilities, this is particularly true with respect to homework completion and accuracy (Gettinger \& Seibert, 2002; Harvey, 2002).

Frequently, students with disabilities have significant difficulties with homework completion (DuPaul \& Stoner, 2003; Hathaway \& Barkley, 2003; Robin, 1998). Poor performances on homework places students with disabilities at a considerable disadvantage as they often do not successfully use homework to reinforce and extend their classroom learning (Hughes et al., 2002). The result then is that, when homework is counted as a means of assessing progress, the grades of students with disabilities are likely to suffer (Hughes et al., 2002). In order to support students with disabilities who are in inclusive general education settings, additional support, or alternative techniques need to be utilized to maximize their homework success, which in turn will contribute to their full participation in general education classes (Hughes et al., 2002; Hunt \& Goetz, 1997). Such assistance could include students learning to provide some of their own support techniques (Janney \& Snell, 2000).

Researchers have identified some homework strategies that are effective for students with disabilities. These strategies include teachers giving clear and suitable assignments (Meyer \& Kelley, 2007), providing homework accommodations (Bryan \& Burstein, 2004), and permitting alternative responses to assignments (Lee, Palmer \& Wehmeyer, 2009). Assignments are viewed as suitable when they are reviews or extensions of skills learned in class and are tasks students can perform independently (Bryan, Burstein, \& Bryan, 2001). Recommended homework accommodations include shortening the length of the assignment, monitoring the students' homework, and providing peer support (Meyer \& Kelley, 2007). In addition, alternative response formats 
could be considered to demonstrate learning in their homework assignments such as audiotaping, videotaping, and/or drawing to demonstrate (Bryan \& Burstein, 2004).

Along with these effective homework strategies, other techniques such as selfmonitoring have also been studied and shown to be worthwhile. Self-monitoring is one approach that has been shown to support the participation of students with disabilities in general education classrooms without taking too much time away from the teacher (Agran, Snow, \& Swaner, 1999). Successfully implemented with students across a variety of skills, ages, and environments (Patton, Jolivette, \& Ramsey, 2006), selfmonitoring allows students to manage their own behavior rather than relying on the teacher, assistants, or peers to do it. Since research of self-monitoring has been demonstrated to be of value for other skills, this technique may be appropriate in assisting students with disabilities to overcome some of the homework challenges they may face in an inclusive general education classroom.

\section{Self-Monitoring Definition and Research}

Self-monitoring, the practice of observing and recording one's own academic and/or social behaviors (e. g., Vaughn, Bos, \& Schumm, 2000), is a cornerstone of cognitive-behavioral social skills training approaches (e.g., Crum, 2004; Daly \& Ranalli, 2003; Patton et al., 2006). Self-monitoring techniques have been used with students of all ages with and without disabilities (DiGangi, Maag, \& Rutherford, 1991) and have been found to be relatively unobtrusive, cost effective, and fairly easy to implement (Carr \& Punzo, 1993). The use of this technique has shown positive results for general education students in many areas including, but not limited to, writing skills (Santagelo, Harris, \& Graham, 2007), completing social studies assignments for middle school students (Meyer 
\& Kelley, 2007), enhancing music skills (Hayes, 2002), goal attainment (Wehmeyer, Yeager, Bolding, Agran, \& Hughes, 2003), and improving homework completion (Toney, Kelley, \& Lanclos, 2003).

In addition, numerous studies have found self-monitoring to be effective with students with disabilities (Agran, Blanchard, Hughes, \& Wehmeyer, 2002; Peterson, Young, Salzberg, West, \& Hill, 2006). For example, using self-monitoring, students with disabilities have increased behaviors such as following directions and staying on-task (e.g., Agran et al., 2005) and have reduced disruptive classroom behavior (e.g., Harris, Friedlander, Saddler, Frizzelle, \& Graham, 2005). Additionally, self-monitoring has also been beneficial for students with autism in learning social conversation skills (Apple, Billingsley, \& Schwartz, 2005), and for students with learning disabilities to increase their academic performance rate (e.g., Peterson et al., 2006; Smith, 2002; Trammel, Schloss, \& Alper, 1994). Finally, the use of self-monitoring has resulted in behavioral performance improvements for students with disabilities enrolled in self-contained classrooms and mainstreamed into general education classes (Agran et al., 2002; Shimabukuro, Prater, Jenkins, \& Edelen-Smith, 1999).

With respect to the use of self-monitoring and homework performance by general education students, much of the research is dated. For instance, Olympia, Sheridan, Jenson, and Andrews (1994b) taught self-management procedures for math homework completion and accuracy to sixth-grade general education students who made substantial improvements in the amount of homework assignments completed. Further, Carrington, Lehrer, and Wittenstrom (1997) trained two groups of elementary and junior high students with homework difficulties to document their homework assignments. One 
group had parental participation; the other group did not. The homework intervention with the parental involvement led to a significant reduction in parent-reported homework problems within the group. In addition, Bryan and Sullivan-Burstein (1998) used homework planners and completion graphs with spelling and math homework with firstthrough fourth-grade students. The use of planners and self-monitoring of homework through student graphing produced immediate improvements in homework achievement.

Only a few recent studies have investigated the effects of self-management with general education students and homework completion and accuracy. Toney et al. (2003) compared self- and parent-monitoring of homework completion in order to reduce homework-related problems in middle school students. Parent- and self-monitoring significantly increased students' homework completion, and both groups reported fewer homework problems. Meyer and Kelley (2007) conducted a study with 42 students with Attention Deficit Hyperactivity Disorder (ADHD) in sixth to eighth grade, using a selfmonitoring and parent-monitoring intervention to increase their academic achievement in homework completion and study skills. After the intervention, both groups had fewer homework problems. However, although there was no significant difference between the number of homework assignments completed before and after the intervention, the homework grades increased considerably.

As for students with disabilities, limited research on the effectiveness of selfmonitoring of homework completion exists, and much of the existing research is dated. For example, Fish and Mendola (1986) taught three elementary school students with disabilities to self-monitor their homework behavior at home. Results indicated that these students' rate of homework completion significantly improved during the homework 
monitoring intervention. Likewise, Trammel et al. (1994) evaluated the effectiveness of training in self-monitoring, self-evaluation, and goal-setting on homework completion in a resource room with students identified as having learning disabilities and found the interventions successful in improving homework completion and academic performance. In a more recent study, Minzner (2003) attempted to improve homework completion rates and academic grades of high school students classified as learning disabled. The students with learning disabilities were taught to set weekly homework goals, monitor their homework using a planner, and calculate and graph the percentage of homework completed for one class. The results were inconclusive as to the effectiveness of the intervention, and the study had several limitations such as inappropriate referrals of participants.

In sum, studies utilizing self-monitoring have been successful in improving many academic and social performance behaviors for a variety of students across ages and settings (King-Sears, 2006). The limited number of studies conducted on self-monitoring homework have demonstrated that self-monitoring can have a positive effect on the homework performances of students with and without disabilities (Agran et al., 2005). However, most of the studies investigating the effects of self-monitoring on homework have been with general education students or students with disabilities in self-contained classrooms. To date, no published study was found by the researcher that investigates the effects of self-monitoring on the completion and accuracy rate of homework of students with disabilities in general education classrooms. 


\section{Purpose of Study}

According to the latest national statistics from $2007,56.8 \%$ of students with disabilities are spending more than $80 \%$ of their school day in a general education classroom, and $26 \%$ are spending $40 \%$ to $79 \%$ in general education (USDOE, 2008a).

Additionally, as students with disabilities are being educated in general education classes, the demands of organization, time management, and homework completion have increased. Many students with disabilities have difficulty adjusting both socially and academically to the rigorous demands of these general education expectations (Palmer et al., 2004). This includes performance on homework, which is part of grade level expectations (DuPaul \& Stoner, 2003).

Homework is considered important for many reasons. It can improve the comprehension and maintenance of previously learned ideas and concepts (Bryan et al., 2001; Rock, 2005), as well as help students develop lifelong study skill habits that will be of value after they leave school (Rock \& Thead, 2007). By completing homework, students are taught that learning can happen in other places besides the classroom. In addition, homework fosters independence, responsibility, and effective time management (Bryan et al., 2001). Therefore, it is imperative for students to learn the proper homework skills in order for homework to be beneficial. Typically, when students with disabilities participate in the general education curriculum, they are expected to complete homework along with their peers. However, many students with disabilities who are included in general education classes have not been taught these independent study skills (Cooper \& Valentine, 2001). 
There have been many observed problems related to homework completion and accuracy for students with disabilities. For example, these students often overestimate their preparedness for homework completion and accuracy, seem to approach homework haphazardly, have difficulty maintaining attention, and sustaining motivation (Bryan et al., 2001; DuPaul \& Stoner, 2003). This can potentially affect their overall grade for a class, thereby making this a significant research topic to address. Additionally, they may not have been taught particular homework completion strategies, such as working in a quiet space, double-checking their work, and completing it at the same time every day, habits that are necessary in order to be successful in meeting homework demands (Gettinger \& Siebert, 2002).

Although ineffective homework habits are a common problem for some students with disabilities, relatively few studies have addressed the issue (Hoover, 2006). Bryan and Burstein (2004) completed a research synthesis regarding what research has gleaned so far regarding homework completion and academic performance for students with disabilities. The researchers discovered that homework may pose significant challenges for students with disabilities to be successful, particularly since there is an increased reliance on homework as an adjunct to instruction (Bryan \& Burstein, 2004). However, just as students with disabilities may need instructional adaptation and accommodations to be successful in the classroom, they may also need homework accommodations.

For decades, researchers have been studying effective homework practices. These studies have produced findings that assist general education students in progressing more effectively through the curriculum (Bryan \& Burstein, 2004). Yet, there has been minimal research done on understanding how teachers, students, and families can better 
facilitate homework completion and accuracy for students with disabilities. The limited studies that have been completed are dated. No studies have been found that provide the general education teacher with approaches to assist students with disabilities in inclusive general education classrooms with improving their homework completion and accuracy. With the increased movement towards inclusion, the promising use of self-monitoring might be beneficial in improving homework completion and accuracy results for students with disabilities included in general education classes.

Researchers have not investigated the use of self-monitoring strategies by elementary school students with disabilities in general education settings to increase their homework completion and accuracy. Indeed, prior research suggests that instruction in self-monitoring strategies for students with disabilities within general education settings is underutilized (Hughes, Agran, Copeland, Wehmeyer, Rodi, \& Presley, 2002; KingSears, 1999), especially since it is discreet, easily prepared, provides immediate feedback, and is inexpensive. This study was conducted in response to the research void of the effects of self-monitoring on homework completion and accuracy of students with disabilities in an inclusive general education classroom. In order for students with disabilities to fully meet teacher expectations and be successful in the general education classroom, it is imperative that they develop the skills necessary for homework completion and accuracy. Self-monitoring may be one useful, easily implemented tool that enables the student with disabilities to successfully meet the homework expectations in the general education classroom. 


\section{Statement of the Problem}

This study was designed to extend the research of self-monitoring of students with disabilities by exploring the effects of self-monitoring on the spelling and math homework completion and accuracy rates of students with disabilities who are in an inclusive general education classroom. This study adds to the preliminary work of Trammel et al. (1994) and Minzner (2003). Both of these studies investigated the effects of self-monitoring procedures on homework rates for students with disabilities in resource settings. In order to add to the limited body of current research, the present study examined the effects of self-monitoring homework completion and accuracy for elementary school students with disabilities educated in an inclusive general education setting. This study was completed in an elementary school with students with disabilities who were struggling with their spelling and math homework completion and accuracy, a grade level expectation. The students monitored their own homework behavior at home (i. e., have materials, work in a quiet place) with a self-monitoring sheet, monitored their homework behavior at school (i.e., bringing homework to school, giving it to the teacher) using the computer application KidTools (Fitzgerald \& Koury, 2003), and reviewed their monitoring sheets with the researcher during a brief conference. KidTools is a computer program designed especially for students with disabilities to self-monitor various behaviors. No previous study was found that has combined these variables. Thus, the present study can be viewed as taking the first step to bridge this gap in the literature by linking these variables. 


\section{Research Questions}

1. What are the effects of a self-monitoring system with daily, twice-weekly or weekly conferencing on the completion of spelling and math homework for students with disabilities in an inclusive general education classroom?

2. What are the effects of a self-monitoring system with daily, twice-weekly or weekly on the accuracy of spelling and math homework for students with disabilities in an inclusive general education classroom?

3. If there are gains in completion and accuracy of spelling and math homework, will they be maintained 2 and 3 weeks after the intervention has ended?

\section{Chapter Summary}

Homework has been an educational topic of discussion for decades. Generally, it has been agreed upon that homework assists students with their academic achievements (Mendicino, Razzaq, \& Heffernan, 2009). Researchers have examined the positive effects of homework, its usefulness and correlation to grades. Interventions to increase homework completion have included self-monitoring, goal setting, and time management training amongst others. Studies aimed at improving homework completion have targeted students with and without disabilities at the elementary, middle, and high school levels (e.g., Fish \& Mendola, 1986; Flores, Schloss, \& Alper, 1995; Forgatch \& Ramsey, 1994).

Although researchers have undertaken concerns related to homework and how to promote the idea that students with disabilities benefit from it, only a few studies have been conducted on the effects of self-monitoring on homework for students with disabilities. These studies were conducted with the students placed in a resource room setting. No current research was located that investigated the effects of self-monitoring 
on homework completion of students with disabilities in an inclusive general education classroom. Yet, students with disabilities are required to meet homework expectations when placed in an inclusive general education classroom. Considering the increase in students with disabilities educated in a general education classroom, the importance of homework completion and the lack of evidence for effective strategies in this area, additional research is necessary. Therefore, the present study examined the effects of selfmonitoring homework completion and accuracy using a self-monitoring sheet and the computer-based program KidTools for elementary school students with disabilities educated in a general education setting.

\section{Definition of Terms}

In this section, regularly used terms are defined. In addition, other terms that are not frequently used but require definitions are explained.

At Risk refers to a student who is not meeting the requirements necessary for promotion to the next grade level or whose education attainment is below other students of their age or grade level, but who is not receiving academic special education.

Attention-Deficit/Hyperactivity Disorder (ADHD) is a neurobehavioral developmental disorder defined as a persistent pattern of inattention, hyperactivity and/or impulsivity that is more frequently and severely displayed than is observed in typically developing peers.

Emotional and/or Behavioral Disorder (EBD) refers to a condition in which behavioral and/or emotional responses of an individual in school are so different from his/her generally accepted, age appropriate, ethnic or cultural norms that they adversely 
affect performance in such areas as self-care, social relationships, personal adjustment, academic progress, classroom behavior, or work adjustment.

Homework refers to tasks assigned to students by their teachers to be completed mostly outside of class, and derives its name from the fact that most students do the majority of such work at home.

Inclusive setting refers to a classroom where children with disabilities receive their academic and/or related arts instruction in general education classrooms.

Individual Education Plan (IEP) refers to a written plan/program developed for students with disabilities by the special education team with input from the parents, guardians, and the student if applicable. It specifies the student's academic goals and the method by which to obtain these goals. The plan also identifies transition arrangements. The law expects school districts to bring together parents, students, general educators, and special educators to make important educational decisions with consensus from the team for students with disabilities; those decisions are reflected in the IEP.

Interrater reliability is the comparison of at least two independent raters analyzing data on the same target behavior in order to compare results. This procedure helps support reliability in the analysis of data.

KidTools is a computer-based electronic performance software program intended for independent use with elementary school students who have learning disabilities and/or emotional, behavioral, and organizational difficulties. The system includes research based supports that assist children in gaining control of target behaviors. There are 30 templates that can be personalized for individual students to use for selfmonitoring. 
Mainstreamed is used in the context of education, it is the practice of educating students with disabilities in general education classes during specific time periods based on their needs and skills.

Maintenance is the degree to which the student continues to perform the target behavior after the intervention has ceased or decreased (Cooper, Heron, \& Heward, 2007).

Resource Room is a program model in which students with disabilities are taught outside of the general education classroom in a smaller group to receive services in a special education classroom for part of the school day and for a specific need in the area of reading, language arts, or math.

Self-contained is a full-time placement in a special education classroom. In this model, students with disabilities spend no time with typically developing students.

Self-determination is a combination of skills, knowledge, and beliefs that enable a person to engage in goal-directed, self-regulated, autonomous behavior. An understanding of one's strengths and limitations together with a belief in one's self as capable and effective are essential to self-determination (Field, Martin, Miller, Ward, \& Wehmeyer, 1998).

Self-evaluation is part of self-management and refers to the student determining and evaluating whether or not he/she engaged in the target behavior in relation to the goals that have been set. In this study self-evaluation was measured using the KidTools application on the computer at school as well as on a self-monitoring sheet at home. 
Self-reinforcement is part of self-management and refers to self-delivery of rewards for reaching the goals that were set. This helps reinforce that the desired behavior or action will occur.

Self-management describes the process of achieving personal autonomy involving three components of self-management: self-monitoring, self-evaluation, and selfreinforcement.

Self-monitoring is part of self-management and involves self-observation and selfrecording, comparing data about one's self (Fad, Patton, \& Polloway, 2006). In this study, self-monitoring was measured by the use of the KidTools computer based, selfmonitoring software application and the daily self-monitoring sheet.

Specific Learning Disability (SLD). A disorder in one or more of the basic psychological processes involved in understanding or in using language, spoken or written. 


\section{CHAPTER II}

\section{REVIEW OF THE LITERATURE}

The focus of this study was the investigation of the effects of self-monitoring on homework completion and accuracy by students with disabilities educated in an inclusive general education classroom. In order for students with disabilities to be successful in the general education classrooms, it is imperative that they develop and implement the skills necessary for accomplishment in meeting grade level expectations, including homework completion and accuracy. Self-monitoring may be one tool that enables success for meeting these expectations.

This chapter examines various issues in the current theoretical and empirical literature relating to homework self-monitoring in other areas with general education students, self-monitoring with students with disabilities, and self-monitoring of homework. This literature review explores the definition and purpose of homework, strategies for homework, inclusion, self-monitoring, and its effects on students with disabilities included in general education classrooms. The review of literature assisted in developing the research questions that guided the research design, data collection, and analysis. Studies reviewed for this research supported the effectiveness of interventions for teaching self-monitoring of appropriate behavior to children with disabilities (Christensen, Young, \& Marchant, 2004).

\section{Homework Purpose and Definition}

Homework is defined as work assigned by the teacher that is to be completed outside of the normal class period (Cooper, 2001). Cooper (2001) cites four major purposes for the use of homework; (a) practice and review, (b) preparation for future 
assignments, (c) transference of previously learned skills to new conditions, and (d) skill integration. A practice and review assignment requires that the same skills learned in class be demonstrated by the student, often in a redundant fashion (e.g., multiplication drills, writing spelling words). Preparing for future assignments involves the identification and extension of instructional goals in which students take previously learned material and apply it to new situations (Cooper, 2007). In order to demonstrate knowledge of previously learned skills, students are provided with the opportunity to show their comprehension of the material in their own way. As new skills are acquired, a student must integrate and combine a set of learned abilities to create one product. Teachers indicate that the most frequent reason for giving homework is to have students practice a skill learned in class (Cooper, 2007).

Homework can be categorized and/or discussed by the amount, length of the assignment, and frequency with which it is assigned. Some teachers dispense homework with various levels of difficulty depending on its purpose and degree of individualization (Cooper, 2007). Choices for extra-credit homework and whether the homework is required or voluntary are sometimes options. Independent and group projects are also assigned for homework, which may vary in completion deadline (Cooper, 2007).

\section{History of Homework in American Schools}

During the first part of the 20th century, the emergence of movements in child study, child health, parent education, and progressive education essentially altered the perspective for educational dialogue on homework (Gill \& Schlossman, 1996). The chief focal point of concern about homework before 1920 was with children in grammar school (now referred to as elementary and middle school), grades 4 to 8 . Since homework in 
grades 1 through 3 was still uncommon in the early 1900s, there was yet to be a conversation about homework regarding this group of students (Gill \& Schlossman, 2003a). In the early 1900s, the drill/memorization/recitation routine was criticized as a threat to preteens' physical and mental health (Cooper, 1989b). Notably the Parent Teacher Association (PTA) pressed school boards to regulate and minimize how much homework teachers could assign, and many professional, educational periodicals denounced homework (Gill \& Schlossman, 2003a). However, some educators who tried to abolish homework in their schools were met with serious parental opposition. Although parents did not endorse large quantities of daily homework, they wanted their children to spend some time studying at home. According to the popular consensus, homework was expected to begin as early as first grade, if only for 15 minutes a day, and to increase to 1 hour a day in the late elementary grades and middle school (Epps, 1966). Parents began to utilize homework as a tool to maintain some involvement in their children's education and to monitor what was being taught in school (Gill \& Schlossman, 2003a).

There were only a few surveys on homework conducted during the 1920s and 1930s. Therefore, evidence on homework from this period is sparse. There are rough estimates from a few scattered school districts suggesting that fourth- through fifth-grade students averaged around 1 hour per day, seventh- through eighth-grade students, a little more than 1 hour per day, and high school students a little more than that (Gill \& Schlossman, 2003b). What is clear from the limited surveys is that excessive homework was not commonplace at any grade level. 
The first systematic, nationally representative survey of homework practice in the U.S. focused on grades 9 to 12 and was conducted in 1948 by the Purdue Opinion Poll (Gill \& Schlossman, 2003b). The survey revealed that only $8 \%$ of high school students were doing more than 2 hours of homework a night in 1948. On average, high school students were doing less than an hour of homework per day, and girls were completing considerably more homework than boys were (Remmers, Gage, \& Shimberg, 1948).

After the Soviets launched Sputnik in 1957, the entire U.S. educational system and academic disciplines became matters of national attention and scrutiny (Goldstein, 1960; Hill, Spencer, Alston, \& Fitzgerald, 1986; Kralovec \& Buell, 2001). The perception that education in the U.S. could not compete with the Soviets' technological education shifted homework attitudes to a more positive philosophy (Gill \& Schlossman, 2000). Homework became part of an academic excellence movement that commanded higher standards and grounded subject matter instruction in the new strategy that made education central to meeting the threat of Soviet technological superiority (Gill \& Schlossman, 2000). Between 1968 and 1972 with the politics surrounding the Vietnam War and the late Civil Rights movement, attitudes towards homework began to alter once more in anticipation of discovering what would best improve academic achievement (Gill \& Schlossman, 2004). A new commitment to serious homework loads was alleged, and affirmative views of homework began to appear regularly in scholarly educational periodicals in the 1950s and 1960s (Gill \& Schlossman, 2000).

In the 1970s and 1980s, the argument over whether homework was necessary was replaced by an agreement of the necessity for higher academic standards. Since then, researchers have consistently recognized homework as an integral opportunity for 
academic achievement as well as an increased probability to strengthen newly acquired skills (Hughes, Ruhl et al., 2002; Madaus et al., 2003; Olympia et al., 1994b; Walberg, Paschal, \& Weinstein, 1985). Supporters of homework recognized benefits such as the reinforcing of overall academic performance, allowing parents to become more aware of the curriculum, and producing positive attitudes towards school (Hughes et al., 2002; Salend \& Garjria, 1995).

In 1986, the U. S. Department of Education published the article, What Works: Research on Teaching and Learning (USDOE, 1986), which plainly supported homework and gave explicit suggestions to teachers. Schools quickly started to require more homework for younger students (Gill \& Schlossman, 2000).

With the beginning of the 21 st century, homework has once more entered the forefront of educational reform. Gill and Schlossman (2004) propose that the current movement in homework influenced students in the elementary grades. With the focus on state standards, students in these grade levels are expected to complete homework automatically as part of their educational experience. Although homework guidelines vary from district to district, the average amount of homework assigned in the U.S. per night is 10-90 minutes, depending on the grade level (USDOE, 2008b).

Existing research generally supports the relationship of homework completion and accuracy to school achievement. Nevertheless, homework has been an ongoing source of concern for parents and educators alike for many years (Lieberman, 1983; Madaus et al., 2003; Maertens \& Johnson, 1972). Researchers have noted that some children may avoid academic tasks at home, producing conflict in many families (Anesko, Schoiock, Ramirez, \& Levine, 1987; Keith \& Keith, 2006). Difficulties often 
begin during the elementary school years when homework assignments are first required by teachers (Keith, 1986). In order for homework to fulfill its purpose, students need to complete assignments accurately, so these are logical targets for behavior change (Keith \& Keith, 2006; Miller \& Kelley, 1991). Even though most students receive homework, few studies have been directed at improving methods by which children approach or complete homework (Madaus et al., 2003; Miller \& Kelley, 1991).

\section{The Benefits of Homework and Homework Strategies}

Numerous benefits of homework have been identified, making it an imperative part of a student's education (Gettinger \& Seibert, 2002). Research has demonstrated that homework completion could lead to increased speed, mastery, and improved student involvement in other learning tasks, as well as teaching responsibility, perseverance, and time management (Cooper, 1989a; Cooper \& Valentine, 2001; Gettinger \& Seibert, 2002; Olympia, Sheridan, \& Jenson, 1994a). Homework has been shown to strengthen knowledge in that it provides reinforcement of classroom knowledge, it increases students' involvement in learning, helps build personal responsibility, time management skills, and feelings of accomplishment (Epstein \& Van Voorhis, 2001). Well-structured homework assignments promote the goals of increasing the amount of time available for learning and extending content coverage (Good \& Brophy, 2003). In addition, homework can aid in developing independent work habits, encouraging responsibility, and refining study skills (Good \& Brophy, 2003).

Although positive study habits are expected to be a part of a student's homework routine, such skills are rarely taught to general education students or students with disabilities (Gettinger \& Seibert, 2002; Miller, Heafner \& Massey, 2009). Moreover, 
when students are not under the direct guidance of teachers, such as when they are completing their homework, these study skills are often needed most (Wallace \& Kauffman, 1986).

Unfortunately, problems with homework completion are common among students with disabilities (Power, Werba, Watkins, Angelucci, \& Eiraldi, 2006; Robin, 1998). They are too often not turning in homework or turning it in incomplete, which is likely to have an adverse effect on academic achievement (Bryan et al., 2001). Despite the pervasive problems that students with disabilities have with homework completion, little research has been conducted investigating homework interventions (Power, Karustis, \& Habboushe, 2001; Toney et al., 2003). A few studies conducted on homework interventions included writing in a planner, parental monitoring, and self-monitoring of homework (Gettinger \& Seibert, 2002).

Several evidenced-based strategies that appear to improve homework compliance include reinforcements, graphing, cooperative study teams, homework planners, and parent involvement (Bryan \& Burstein, 2004; Bryan \& Sullivan-Burstein, 1998). Positive reinforcement can include sticker charts for younger students and "no homework" passes for older students (Cooper et al., 2006; Dawson \& Guare, 2003). During a 2-year study completed by Bryan and Sullivan-Burstein (1998), when elementary school students were accountable for graphing their homework completion on a daily basis, their homework completion rate increased. Cooper, Horn, and Strahan (2005) conducted a study to promote self-regulation with high school students in seven classes. In their study, increased homework completion rates were observed when the students worked collaboratively with peers, kept a study calendar, had a specific study location, set up 
regular study periods, set realistic goals, prioritized tasks, worked without distractions (i.e., television, computer), and self-rewarded their own successes. Providing homework planners and expecting parents to sign off on completed assignments have also demonstrated to be effective homework strategies as well (Bryan \& Burstein, 2004).

Group contingencies were found to improve the homework of six students in fourth grade and were studied by Reinhardt, Theodore, Bray, and Kehle (2009). Using a "Mystery Motivator" box containing jointly agreed upon rewards and a "Goals Box" with criteria to be met for homework completion and accuracy, the teacher selected one card from each box every day. If the class met the criterion goal, then the reward would be implemented the same day. Overall, participant scores rose significantly on homework completion and accuracy.

In sum, research has acknowledged that students' participation in homework has many potential benefits (Keith \& Keith, 2006), including improved academic achievement (Cooper et al., 2001; Keith, Diamond-Hallam, \& Fine, 2004) and enhanced relationships between school and home (Olympia et al., 1994b). Students with disabilities should be afforded every opportunity to access the tools necessary to successfully complete their homework, which will assist them in meeting grade level expectations. Preliminary research suggests that one easily accessible technique to assist in completion of homework may be self-monitoring.

\section{Self-Monitoring}

Frequently self-monitoring is cited as one of several necessary skills that leads students with disabilities toward being more self-determined individuals who can appropriately and proactively take control of aspects of their life, in and out of school 
settings. Self-monitoring is an element of self-management, which has been widely utilized and is a cornerstone of cognitive-behavioral social skills training approaches (Crum, 2004; Daly \& Ranalli, 2003). Basically, self-management encompasses three elements: self-monitoring, self-evaluation, and self-reinforcement (Fad et al., 2006). Selfmonitoring involves self-observation and self-recording, such as at the sound of a timer, a student records whether or not he or she is on task. Self-evaluation refers to setting personal behavior or academic goals and then comparing the self-monitoring data to the previously set goal. For example, the student may decide to set a goal for the number of times he calls out during a given period of time. Each time he calls out he would record it, then compare the data to the goal and evaluate it. Standards for behavior and selfreinforcement refer to the delivering of a consequence to one's self that has reinforcing powers. For example, after a student completes a certain number of assignments, he selfreinforces by earning time on the computer. Self-monitoring, the focus of this study, is a well-researched technique that has wide applications across students, age levels and behaviors. Students need to be competent in several skills in order to use self-monitoring.

To be successful self-monitors, students need to be able to keep track of what they are doing and how they are thinking so they can adjust their behaviors and thoughts in order to meet goals or complete tasks (Porter, 2002; Smith, 2002). The ability of a student to self-monitor his or her performance is a natural step toward becoming independent, which can only happen when a student takes responsibility for his or her own behavior (Porter, 2002; Rutherford, Quinn, \& Mathur, 1996; Vaughn et al., 2000). Being able to self-monitor reflects a shift from reinforcement by others to self-reinforcement of appropriate behavior (Hallahan \& Kauffman, 2000; Hanson, 1996). In addition, self- 
monitoring actively engages the student as a participant in improving his or her behavior (Blick \& Test, 1987), thereby increasing their investment in the process.

The first step in teaching students to monitor themselves is to select and clearly define a target behavior (Carr \& Punzo, 1993; Stainback \& Stainback, 1980; Vaughn et al., 2000). Next, a student or observer records instances of the behavior to provide evidence of the problem and its frequency (Carr \& Punzo, 1993; Schunk, 1997; Vaughn et al., 2000). Then students set learning and performance goals and identify consequences for meeting or failing to meet their goals (Schunk, 1997; Vaughn et al., 2000). There is also a cognitive component to self-monitoring behavior that requires students to talk to themselves. This is done through a set of instructions (self-talk) for completing a task or to ask themselves questions about their feelings or behaviors (Brophy, 1996; Kamps \& Kay, 2002; Porter, 2002; Smith, 2002). Students can also be taught to ask themselves questions about their academic learning and performance, such as asking, "How many math problems have I completed in the last 10 minutes? How many are correct?” (Carr \& Punzo, 1993). This assists in reinforcing the practice of self-monitoring.

When students with disabilities learn to self-monitor, they are more likely to rely on themselves rather than others for decision making, which has the potential to empower students in controlling their own behaviors. Self-monitoring can be used, independent of adult supervision, as a method to promote student independence and desirable behaviors across a variety of settings (Wood, Murdock, \& Cronin, 2002). However, to reinforce successful self-monitoring, adult involvement would include teaching students to manage their behavior and supervising their self-monitoring performance after instruction (Freeman \& Dexter-Mazza, 2004). 
According to research, there are a number of advantages to teaching students to monitor their behaviors (Freeman \& Dexter-Mazza, 2004; Karvonen, Test, Wood, Browder, \& Algozzine, 2004). First, self-monitoring provides students with concrete illustrations of behavioral improvements, which is rewarding to students and teachers alike. Second, students have prompt feedback on their behavior. Third, students generally enjoy self-monitoring their behavior, particularly when they have a role in choosing the target behaviors and personally deem them important to change. This empowers them to determine areas for improvement, and the need for other adults or peers to assist in controlling their behaviors is minimized or eliminated (Firman, Beare, \& Loyd, 2002; Hughes et al., 2002). Fourth, self-monitoring promotes communication between parents and children as children explain their charts or graphs to their parents. Fifth, selfmonitoring entails self-comparisons rather than comparisons with other students, which fosters intrinsic motivation and defuses competition. Finally, self-monitoring, frees up additional time for the teachers to teach (Freeman \& Dexter-Mazza, 2004).

For self-monitoring to be effective, strategies should be used constantly and overtly at first and then faded to less frequent and more subtle use across time (Craft, Alber, \& Heward, 1998; Stainback \& Stainback, 1980). It is also important to ensure that students understand the skills or behaviors that are to be self-monitored. To help maintain and generalize positive behavioral changes, self-monitoring should be combined with methods that allow students to evaluate themselves against their earlier performances and to reinforce themselves for their successes (Alberto \& Troutman, 2003; Hallahan \& Kauffman, 2000; Porter, 2002; Vaughn et al., 2000). Cognitive strategies such as "selftalk" (e.g., "hey—good job" or "I knew I could do it”) are especially useful (Schunk, 
1997; Smith, 2002). However, students with disabilities are not likely to learn how to self-manage unless their teachers select it as an instructional intervention, and know how to teach self-management to them (Grigal, Neubert, Moon, \& Graham, 2003).

Generally, self-monitoring is a strategy that can be used with students of all ages and disabilities (DiGangi et al., 1991), is relatively unobtrusive, appeals to students, and is inexpensive and reasonably quick to implement (Carr \& Punzo, 1993). The procedure has been shown to be effective in increasing more appropriate behaviors such as on-task behavior, boosting completion of homework assignments, improving both academic performance and social skills, and reducing disruptive behaviors (Agran et al., 2005; Hallahan \& Kauffman, 2000; Rutherford et al., 1996; Schunk, 1997). It has been suggested that self-monitoring can be effective for generalizing and maintaining skills over time, because students can self-monitor any time and in any setting without needing adult assistance (Blick \& Test, 1987; Rutherford et al., 1996).

\section{Research on Self-Monitoring}

Self-monitoring skill sets have been a major topic in special education for decades, but research on how to best combine various components such as goal-setting, self-regulating, choice making, and decision making is still emerging (Karvonen et al., 2004). There exists a multitude of studies using self-monitoring for general education students and students having ADHD or considered "at risk." However, there are far fewer studies with participants with disabilities in a general education classroom. To understand the scope, importance, ease, and relative effectiveness of self-monitoring, this section begins with a review of the literature on self-monitoring with general education students, followed by a review of self-monitoring with students with disabilities. 


\section{Self-Monitoring With General Education Participants}

There are a number of studies using self-monitoring techniques for general education students; however, many of the participants in the studies are considered "at risk" for various reasons such as low academic grades or behavioral difficulties in school.

On-task behavior was a common action that was researched in the studies, therefore only a limited number are included in this review. These studies were conducted across many behaviors, subjects, and settings. The following studies were conducted employing selfmonitoring on academic performance, on-task behaviors, disruptive behavior, and social skills. Each of these studies, which are reviewed from oldest to most recent, produced positive results.

Using a within subjects multiple baseline across subjects design, Moore, Prebble, Robertson, Waetford, and Anderson (2001) examined the impact of self-recording combined with goal setting on the on-task behavior during language lessons for 30 minutes a day for three, eight-year-old boys who were identified by their teacher as spending excessive amounts of time off-task. The intervention involved the selfmonitoring and self-recording of on-task behavior using a tape recorder, a selfmonitoring sheet, graphing, and discussing the data. All three students demonstrated marked improvements in on-task behavior concurring with the inception of the selfmonitoring intervention. The average baseline scores for on-task behavior were $33 \%$, $48 \%$, and $56 \%$. After the intervention those scores rose to $76 \%, 98 \%$, and $98 \%$ respectively. The high levels of on-task behavior were sustained during the follow-up stage. Based on their positive results, Moore et al. (2001) recommend the procedure for students who do not have severe behavior disorders but are working below their potential. 
Using multiple-probe across subjects' research design, Peterson et al. (2006), investigated the effects of a self-management procedure on the classroom social skills of five "at risk" students in seventh- and eighth-grade general education settings. The dependent variables were on-task behavior, off-task behavior, following instructions, accepting "no" for an answer, accepting teacher feedback, and getting teacher attention appropriately. Participants were taught to rate their classroom behavior using a ranking scale. The self-monitoring procedure was simultaneously paired with a student/teacher matching technique and participants earned points if their self-management ratings either matched teachers' ratings exactly or student/teacher ratings differed by only one rating point. Rewards were earned on Fridays based on points for matching the teachers rating.

During baseline, appropriate social skills occurred an average of $40-60 \%$, and ontask an average of $50-55 \%$ of the time. The intervention increased these percentages to $70-100 \%$ for appropriate social skills and to $60-100 \%$ for on-task behavior. According to the results of the study, increases in targeted appropriate social skills and decreases in off-task behavior for all five participants across all settings were positively indicated due to the self-monitoring.

Students identified as having Attention Deficit/Hyperactivity Disorder (ADHD) were a notable population in the research on self-monitoring, and it must be mentioned that although this population is not eligible to be receiving special education services, they still have a medical diagnosis that can require academic accommodations. The following two studies reviewed are with students with ADHD: Barry and Messer (2003); Harris et al. (2005). 
Barry and Messer (2003) used a multiple baseline design across students to investigate the effects of self-monitoring by five Caucasian, sixth-grade, general education male participants who were taking psycho-stimulants for ADHD. In this study, the participants were trained to self-monitor three behaviors: on-task (seated at appropriate place at correct time, paying attention), disruptive behavior (physical play or fighting, loud noises), and academic performance (point system based on correct and completed answers/assignments). The participants self-monitored independently using their own sheet while the teacher concurrently monitored them.

The baseline data for on-task behavior ranged from $0-55 \%$ across participants, compared to $15-100 \%$ with the self-monitoring intervention. Disruptive behavior percentages during baseline ranged from $0-100 \%$ across participants; the self-monitoring intervention reduced those percentages to $0-30 \%$. During baseline, academic performances for complete and correct assignments ranged from 25-80 \%; with selfmonitoring those percentages improved to $65-100 \%$ across participants. Overall, problem behaviors for each participant were reduced, while academic performance was increased during the intervention phases.

Harris et al. (2005) employed a multiple baseline design to compare the utility of self-monitoring of attention (SMA) versus self-monitoring of academic spelling performance (SMP) on the behavior of six, elementary, third- to fifth-grade students diagnosed with ADHD. During self-monitoring of performance (SMP), at the end of the 15-minute spelling lesson, the participants counted and recorded the number of spelling words they practiced correctly. During the same 15-minute period they self-monitored their attention (SMA) by recoding whether or not they were on task. 
As a group, baseline on-task behavior averaged 55\%. During self-monitoring, this average increased to $92 \%$. During the self-monitoring of attention phase, the group's average on-task behavior rose to $94 \%$. Both types of self-monitoring had a positive influence on the students' spelling performance, and both were equally successful in promoting on-task behavior. This study clearly showed that self-monitoring interventions for students with ADHD can be successfully utilized in a general education classroom.

This section presented only a representative sampling of studies that demonstrated the positive effects of self-monitoring on general education students who needed support in some academic or social area. Numerous other studies exist that demonstrate the effectiveness of self-monitoring across a variety of other behaviors including social skills (Agran, Salzberg, \& Stowitschek, 1987), math calculations (Heins, Lloyd, \& Hallahan, 1986), and independent performance (Wood et al., 2002). There have also been selfmonitoring studies conducted for students with disabilities that have further demonstrated its merit.

\section{Self-Monitoring With Students With Disabilities}

Self-monitoring has long been utilized across various behaviors and settings for students with disabilities. Following are a representative sample of studies arranged by date, from earliest to most recent that were conducted in various settings including selfcontained and general education classrooms. Although there was a multitude of studies from which to choose, this sample is the most relevant to the research topic.

Rooney, Hallahan, and Lloyd (1984) conducted an early study of the utilization of self-recording of attention (percentage of time off-task) by four, second-grade students with learning disabilities in the general education classroom. An ABABCBC design was 
utilized with the B phase including the self-monitoring intervention which required participants to record on a sheet whether they were on task or not. The $\mathrm{C}$ phase introduced reinforcement for the use of the self-monitoring. The mean on-task baseline performance across participants was $24 \%$, compared with $60 \%$ in the self-monitoring phase with an increase to $86 \%$ when reinforcement was added to the self-monitoring.

Using a multiple baseline across settings design, Smith and Young (1992) studied the effects of a self-management procedure on the classroom and academic behavior of eight, male, high school participants with mild handicaps, who spent at least half the day in the same general education classroom. Participants were taught to monitor their offtask and academic behavior on a scale of $0-5$, every 10 minutes during a 30-minute time frame. Off-task behaviors were clearly defined, including, but not limited to out of seat without permission, talking to another student, and making noises. Academic behavior was defined as the percentage correct and the percentage complete of independent seatwork assignments. The teacher also rated their behavior and the scores were compared. If the scores matched, the participants earned the points commensurate with the scale plus a bonus point if they matched the teachers' ratings.

During baseline, the average median percentage across the eight participants for correct academic performance and on-task behavior was $42 \%$. This substantially increased to $73 \%$ during the self-monitoring intervention. The use of self-management strategies effectively reduced the incidence of disruptive behaviors and enhanced the participants' attention to task, quality, and quantity of work in high school students with mild handicaps. 
Kim and Sugai (1995) included video self-modeling in their exploration of selfmanagement strategies to reduce classroom disruptive behaviors displayed by students with Emotional Behavioral Disorders. Using a multiple baseline across subjects design, seven primary grade (K-2) participants were assigned to one of three conditions: selfevaluation, self-observation via video modeling, and self-observation plus self-recording. Data for disruptive behaviors were collected throughout all of the phases using direct observation during equal intervals of time. Each participant had his or her own target behaviors and that was recorded as an occurrence or nonoccurrence during each interval.

The combined results demonstrated that the three self-management strategies were appropriate for students across primary grade levels (Kim \& Sugai, 1995). The median baseline across the participants for the percentage of disruptive behaviors throughout the class period during the self-evaluation condition was $60 \%$ and during the intervention changed to $38 \%$. Baseline median across participants for the self-observation only condition was $41 \%$; with the intervention in place it was reduced to $32 \%$. Selfobservation plus self-recording successfully reduced disruptive behaviors in participants using the enhanced intervention from a baseline median of $47 \%$ to a decreased amount of $34 \%$ with the intervention. Kim and Sugai (1995) proposed that the self-recording procedure enhances the participants' awareness of their inappropriate behavior and the consequences for such behavior.

A study utilizing self-monitoring for students with developmental disabilities to improve performance in general education middle school classes was carried out by Hughes, Ruhl; et al. (2002). Four participants in grades 7 and 8, diagnosed with autism, intellectual disabilities, or multiple disabilities that were included in general education 
classes and/or activities (i.e., lunch, recess) for part of their school day were involved in the single-subject multiple-baseline across subjects study. The process consisted of three steps: establish a goal, take action, and adjust the goal or plan. Each student learned a different self-monitoring technique that correlated with his or her individual target behavior.

The results of the self-monitoring were significant. Each student improved performance from baseline data by a considerable percentage: increasing from a range of 0\%-7\% during baseline across subjects to a $58 \%-100 \%$ range across subjects during maintenance. Hughes, Ruhl et al. (2002) cautioned that the results were confined to the target behavior; however, they emphasized that the maintenance of the behavior beyond the training sessions make a strong case for the effectiveness of self-monitoring techniques as reinforcement for students with disabilities. This presents further evidence that self-monitoring is an additional support tool for students with disabilities to employ in the general education setting to assist in their own success.

Zlomke and Zlomke (2003) investigated the impact of self-monitoring combined with a token economy on the behavior of a 13-year-old boy who received instruction in a self-contained classroom for students with Emotional Behavioral Disorders. Data were collected at the group home where he lived and in school settings. During baseline, minor behaviors produced verbal warnings, disruptive behaviors resulted in a short time-out, and aggressive behaviors caused the participant to return to the group home for the remainder of the day. The second condition included the token economy, which consisted of a teacher-implemented point system. The third condition continued the token economy and added self-monitoring. At the end of each 15-minute interval, the teacher and 
participant compared their recordings. An exact match earned the participant an additional point. In the final (reversal) phase of this study, the intervention returned to the token economy alone.

During baseline, data were collected for five, 15-minute intervals throughout the day for 3 weeks. The mean occurrence of target negative behaviors during baseline was 118 (range $=115-123$ ) which continued to decrease throughout the initial token economy phase with a mean of 63 (range $=40-101)$. The addition of self-monitoring to the token economy intervention resulted in a further reduction in the target negative behaviors with a mean of 7.75 (range $=3-20)$. With the return to just the token economy, an increase in the number of target behaviors was observed increasing the mean to 12 (range=8-15). Throughout periodic maintenance data probes taken over 4 weeks, the incidence of the target behaviors remained low with a mean of $13($ range $=11-15)$ compared to baseline levels. The participant's behavior pattern confirmed the effectiveness of token economies for changing behavior and demonstrated that self-monitoring made a substantial contribution to the token economy in decreasing the target behaviors (Zlomke \& Zlomke, 2003). The results of this study replicated previous research on the effectiveness of token economies in reducing minor, disruptive, and aggressive classroom behaviors in youth with disabilities (Zlomke \& Zlomke, 2003).

Rock (2005) explored the effects of a strategic self-monitoring program using a multiple baseline across subjects with an embedded reversal design. The program called ACT-REACT, is an acronym for a six-step intervention combining self-monitoring of attention with self-monitoring of performance. The steps are: Articulate your goals, Create a work plan, Take pictures, Reflect using self-talk, Evaluate your progress, and 
ACT again. Of the nine participants, one student was gifted, two students were considered average, and six represented a range of students with disabilities. The participants were divided into three equal groups, all enrolled in general education classes consisting of a teacher and an assistant. They were trained to use a self-monitoring think sheet and booklets, which included academic performance prompts, academic attention, and performance goal evaluation prompts.

During baseline, the mean rate per minute of disengagement across subjects for group 1 was .73, for intervention 1; this decreased to a significantly lower rate of .18. When the return-to-baseline condition was implemented, a substantial increase occurred to .57 , while the reinstatement of the intervention decreased the rate again to .11 . For group 2, the baseline data of the mean percentage of engagement across subjects was $19 \%$; intervention 1 produced an increase to $87 \%$. Baseline 2 reduced engagement time to $44 \%$ and the second intervention generated increased results again to $86 \%$. Group 3 presented similar results. The positive behavioral gains were maintained over time thereby providing additional evidence of the effectiveness of the intervention. The success of ACT-REACT with a diverse group of young learners illustrates the utility of a well-designed, self-monitoring intervention for creating inclusive learning environments and for tailoring interventions to students' individual needs.

In a more recent study, a single-subject withdrawal study conducted by Gulchak (2008) used a mobile handheld computer to teach an eight-year-old student with Emotional Behavioral Disorders educated in a self-contained classroom, to self-monitor attention to task. The dependent variable was on-task behavior defined as keeping hands away from face, completing work, and raising his hand to be called upon. During the 
intervention, the participant collected self-monitoring data on his handheld computer every 10 minutes for 1 hour throughout the reading period. The participant was required to remain on-task for the full duration of the interval in order to receive credit for being on-task; otherwise the result was zero for that interval period. At the end of the reading period, the student would print a report on the handheld computer that summarized the number of on-task behavior intervals that were recorded and then graph these on a spreadsheet.

Results for the first baseline indicated the mean for on-task behavior was $64 \%$; the first self-monitoring phase with the handheld computer increased on-task behavior to $90 \%$. The second baseline decreased the on-task behavior to $70 \%$, and the second selfmonitoring phase displayed another improvement of on-task behavior to $98 \%$. This study was different in that it verified self-monitoring with a handheld computer and proved just as effective as previous studies conducted using pen and paper.

Reviewed in this section was a representative sample of the self-monitoring research completed with students with disabilities. Numerous other studies have been conducted with students with disabilities in the areas of math fluency (McDougall \& Brady, 1998), disruptive behavior (Du Paul \& Hoff, 1998), behavioral expectations (Clees, 1994), and class preparation (Gilberts, 2000). There was also a host of other studies with self-monitoring on-task behavior (e.g., Hughes \& Boyle, 1991; Mathes \& Bender, 1997; Shimabukuro et al., 1999).

Fewer studies have been conducted on self-monitoring and homework completion and none on students with disabilities in an inclusive general education classroom. 
Following is a review of these studies. The self-monitoring and homework studies are being reviewed separately as they relate more directly to this study.

\section{Self-Monitoring and Homework}

A limited number of studies have been employed related to self-monitoring and homework for students with and without disabilities. In this section the studies with general education students are reviewed first, followed by those with students with disabilities. Note that no self-monitoring and homework study conducted in the general education setting was found. More detail is included in the studies to follow since they are more specifically related to the proposed research topic.

\section{Self-Monitoring Homework With General Education Students}

Olympia et al. (1994b) investigated the effectiveness of self-management on improving the completion and accuracy rates of math homework assignments. The researchers taught self-management within a single-subject reversal design to 16 , sixth graders of randomly selected teams of four. The teams were taught to self-monitor, selfinstruct, self-evaluate, and self-reinforce. There were two teams under each condition, one being with a student-selected goal, the other with a teacher-selected goal. Scoring templates were available to the teams for self-scoring of homework. Daily points were earned for each homework assignment turned in by a team member. For the first 3 days

of the intervention, participants on both teams were required to return homework with at least $80 \%$ correct to receive individual reinforcement and teams needed to average at least $80 \%$ correct to receive team reinforcement. Additional points were awarded for accuracy levels of $81 \%$ and higher. 
The participants made substantial improvements in the number of assignments completed (an average increase of $33.5 \%$ ), but the results for accuracy were mixed. The mean percentage across participants of homework turned in during baseline 1 was $39.4 \%$, and the accuracy was $47.3 \%$. For the first intervention phase, the mean percentage across participants of homework turned in improved to $74.4 \%$ with the accuracy also rose up to $76.5 \%$. There was a sharp decline again in baseline 2 to $41.9 \%$ for the mean across participants of homework turned in and $72.4 \%$ for accuracy. There was another jump during the intervention to $73.9 \%$ across participants for homework turned in and $82.9 \%$ for accuracy. The study indicated that completion and accuracy rates of homework clearly increased when self-management was employed.

Carrington et al. (1997) used a multiple baseline design to train two groups of elementary and junior high school participants, 42 in all, to record completion of homework assignments at home on a chart and alternate homework time with "play" sessions. They used the "Winning at Homework" package (Carrington et al., 1997), which combines brief periods of play immediately following homework goals reached. Participants were randomly assigned to Group 1 or Group 2, with Group 2 being the control-waiting group. After baseline, Group 1 learned the technique, followed 6 weeks later by Group 2 . The participants, with the parent as a facilitator, primarily implemented the strategy at home. For example, the participants kept a chart at home as to when they would do homework and when they had a "play" period. As they worked on their homework and the timer went off to indicate a "play" period, the parent could remind the participant to go play. After a brief "play" period, homework was continued and charted 
until it was completed. To assess the results of the technique the homework problem severity scale was utilized to assess the severity of participants' homework difficulties.

At 6 weeks, Group 1 showed a significant reduction in their severity ratings from 8.9 as the mean baseline, reduced to 4.9 at the end of treatment (12 weeks) and again to 4.7 at the follow-up (11 months). Group 2 showed a similar significant reduction in severity rating scoring 8.3 at baseline, 5.5 at the end of the treatment, and 5.4 at the follow-up. Ratings suggest this technique may have a lasting effect on children's ability to assume responsibility for their independent work. Moreover, the homework intervention led to a significant reduction in parent reported homework problems. It should be noted that participants who selected their own target goals sustained greater gains than those who were given a target goal by the classroom teacher.

Toney et al. (2003) compared self- and parent-monitoring of homework completion in order to reduce homework related problems in middle school students. Participants were 37 middle school students ( 24 boys, 13 girls) who had difficulty completing homework, their parents also participated. There were three randomly selected experimental groups: parental monitoring, self-monitoring, and a wait-control list. Participants and parents in both treatment groups received information regarding the importance of homework, training in organizing materials, recording assignments, and developing a homework routine. The study utilized the 20 -item Homework Problem Checklist (HPC), which appraises parents' perceptions of homework problems (Anesko et al., 1987) as a pre- and post-treatment measure of success. Examples of items on the HPC include "My child denies having homework assignments," and "My child refuses to do homework." Participants of families assigned to self-monitoring were responsible for 
completing the checklists and turning them in each day. In the parent-monitoring group, parents were trained to complete the checklist daily and were required to look for proof that the behavior was performed. Participants in both groups received a daily reward for compliance and checklist completion, but the parent-monitoring group was required to show proof they completed the target behaviors in order to earn rewards.

Results on the HPC pre-treatment revealed the parent-monitoring group reported 33 (out of 60) homework problems on the checklist, post treatment was 13 (out of 60), and 14 (out of 60) respectively on the follow-up. The self-monitoring group recorded similar results with 31 on the pre-treatment HPC and 16 on both the post treatment and on the follow-up. The wait-list control group reported 32 on both the pre- and posttreatment HPC and a 30 during follow-up. Compared to the control group, results showed both treatment groups reported decreased homework problems and improvements were maintained at a 2-week follow-up. Toney et al. (2003) found parent monitoring of homework completion significantly increased participants' homework completion and parents reported fewer homework problems.

In a more recent study, Gureasko-Moore et al. (2007) completed an investigation which evaluated the effectiveness of a self-management intervention package that enhanced the classroom preparation skills and homework behavior of six adolescent boys aged 11-12 years, diagnosed with ADHD and learning difficulties. Two multiple-baseline across-subjects designs were utilized, with two groups of three participants. The intervention involved training in self-management procedures focusing on the improvement of classroom preparation skills. Every day the participants completed their 
self-management checklist and met with the school psychologist after school to review it. Following the intervention, the training process was systematically faded.

Results were consistent across all participants in enhancing classroom preparation behaviors. The median percentage of classroom preparation behaviors during baseline ranged from $40 \%$ to $50 \%$; after intervention the median percentage ranged from $75 \%$ to 94\% across participants. The study demonstrated that the implementation of the selfmanagement strategies was successful in improving participants' organizational skills related to classroom preparation and homework completion. In addition, the participants, their parents, and their teachers rated the intervention as acceptable and effective in enhancing the participants' organizational skills (Gureasko-Moore et al., 2007). Thus, self-monitoring procedures can offer an alternative homework intervention for participants.

\section{Self-Monitoring Homework With Students With Disabilities}

A dated study using self-monitoring of homework with students with disabilities was conducted by Fish and Mendola (1986), who taught three elementary school participants, enrolled in a special education class for children identified as emotionally disturbed, to self-monitor their homework behavior at home. Using a multiple baseline across subjects design, math, reading and language arts homework completion was selfmonitored for 14 consecutive weeks and 4 weeks at follow-up. The participants were taught to self-monitor using self-talk. This was modeled by saying out loud "Now what time is it? Time for me to do my homework. Where am I going to do it? I know I'll do it in the . Now what homework do I have for tonight? Ok, first I'll do

then___and then___. Good! It looks like I have a lot to do. I'll do the best I can. If my 
mind wonders, I'll tell myself 'back to work.' When I am finished I can play." First, this was said aloud, then in a whisper, then self-talk.

Results indicated that participants' rate of homework completion improved from a baseline mean across participants of $25-50 \%$ to $75-100 \%$ during the intervention. These positive results carried over into the follow-up phase and into the next school year. Accuracy data for the homework assignments were not presented.

Using a multiple baseline design across subjects, Glomb and West (1990) taught self-instruction and self-evaluation skills to two middle school students with learning and behavior problems. Using a strategy called "WATCH," an acronym for (a) Write down the assignment when it is given and write a due date, (b) Ask for clarification or help on the assignment if needed, (c) Task-analyze the assignment and schedule the tasks over the days available to complete the assignment, and (d) Check all work for completeness, accuracy, and neatness. Data were collected on the completeness, accuracy, and neatness of participants' creative writing homework assignments for one week prior to the start of the study. The baseline and intervention data for each participant improved from $22 \%$ to $87 \%$ for one participant and from $62 \%$ to $89 \%$ for the other. Overall, the intervention effectively increased neatness, accuracy, and completeness of creative writing homework assignments.

Trammel et al. (1994) examined the effects of self-monitoring on the number of homework assignments completed for eight students with learning disabilities in grades 7 through 10. Using a multiple-baseline design across subjects, who ranged in age from 13.9 to 16 years old, the experimental procedure required the use of a sheet listing all daily assignments given by regular classroom teachers as well as a self-recording chart 
for self-graphing daily homework completed. The participants were included in 7th- to 10th-grade general education classes during part of the day and received special education services in a resource room for up to $42 \%$ of the remainder of their day. In the resource room, participants were taught to chart their homework completion each day. The assignment sheet was marked with a check if they completed and turned in their homework, an " $\mathrm{X}$ " was marked if it was not completed and an "O" if no assignment was given for that class. Each day, if students' recording of homework assignments matched the teacher's record of homework assignments, participants were then given verbal praise and a piece of bubble gum from the general education teacher. The latter reward was phased out after the 10th day of intervention. In the next phase, self-graphing their homework completion data and goal setting were also taught to the participants. Graphs were then displayed in the resource room, showing 3 days worth of data. Participants were then taught to set goals for homework completion for the next 3 days. Participants were required to set goals at or above the previous goal level. The final phase of the study included discontinuing the homework sheets and graphing, but they were permitted to complete the homework sheets at their own discretion.

During baseline, the average homework completion rate was two completed assignments. This increased to five completed assignments during the intervention and continued during both follow-up probes. Results indicated that the intervention was effective in improving participants' homework completion.

In another study, Bryan and Sullivan-Burnstien (1998) investigated the use of homework planners and completion graphs in spelling and math homework in firstthrough fourth-grade classrooms with a single subject alternating condition design. There 
were four groups, which included participants with specific learning disabilities and homework problems, participants with specific learning disabilities and no homework problems, participants who were average achieving without homework problems, and participants who were average achieving with homework problems. For one of the conditions, participants were taught to write their homework in their planner and graph their spelling and math homework completion on a daily basis. This was reviewed every 2 weeks with a possible percentage score of 200.

The researchers reported that self-monitoring of homework completion through student graphing and use of planners produced immediate improvements in homework achievement (Bryan \& Sullivan-Burnstein, 1998). The graphing intervention increased average math and spelling completion scores for three of the four groups. Participants with specific learning disabilities and homework problems scored 96\% up 32\% from baseline. Those with specific learning disabilities without homework problems scored $87 \%$ up $21 \%$ from baseline. The average achieving participants without homework problems scored 91\%, which was consistent with baseline data of 91\%. Finally, the average achieving participants with homework problems scored $77 \%$ with the intervention, up $17 \%$ from baseline. The only group that remained the same was the group without problems at baseline, which was $91 \%$.

Minzner (2003) conducted a study using a multiple baseline design to measure the homework completion rates and academic grades of six, 11th- and 12th-grade high school participants classified as learning disabled (one girl, five boys). Three simultaneous experiments using two-student multiple baseline designs were conducted. Each participant was taught to set weekly homework goals, calculate, and graph the 
percentage of homework completed for one class in which the student was not completing homework. Participants were taught, through modeling and guided practice, to record homework assignments in their planners, to calculate and graph weekly homework data, and to use a system to indicate completion of their homework. The participants chose which class to use for the self-monitoring; the second class was also monitored by the researcher for completion and accuracy of homework in order to determine generalization. Each week the participants met with the researcher and calculated their percentage of completed homework for the previous week then recorded the percentage on a graph. The graph was stapled to their planner, which was provided to all participants at the commencement of the school year. Inappropriate referrals resulted in a ceiling effect for three participants who began the intervention with high rates of homework completion (means of $97 \%, 87 \%$, and $88 \%$ respectively) during baseline. The remaining participants failed to show consistent improvement in rates of homework completion between the monitored class and the unmonitored comparison class for either baseline or intervention. Overall, the completion rates did not improve with initiation of the intervention for any participant. The mean homework completion rate during baseline across participants was $75 \%$, and during the intervention was $63 \%$. Although the intervention seems to have lowered the percentages, the researcher deemed the study's results as inconclusive. The rationale for this was that there were unsuitable referrals (i.e., the students had high baselines) and this resulted in a ceiling effect for three of the participants.

Cancio, West, and Young (2004) used a multiple baseline design across subjects to assess treatment effects of self-monitoring math homework accuracy and completion 
with participants who received special education services in a resource and a selfcontained classroom. The participants included six male participants who had poor organization and time management skills, ages 11 to 15 years, in sixth to eighth grades, with EBD, and their parents. During their special education class time, training was received on how to document homework and daily "matching" procedures using a checklist. Matching included items such as time homework began, length of time to complete, and where the homework was completed. Parents also filled out a checklist and then checked to verify if they "matched" with the participant's checklist. Points were awarded according to how close the match was with the parent. Reinforcers were a major component of the process. Participants earned points for all the homework completed and were able to turn them in for rewards from their own reinforcement menu.

The average baseline level across subjects for assignment completion was $2 \%$, which increased by $90 \%$ during the intervention. Participant accuracy of homework average during baseline across subjects was $2 \%$, which also substantially increased by $87 \%$ during the intervention. The self-management techniques in this study were successfully utilized with participants with EBD, but could be easily adapted for other participants with disabilities.

Overall, the self-monitoring studies investigating homework have shown positive results. Regardless of whether they took place with students with disabilities or without, in self-contained classrooms or general education classroom, and across all grade levels, self-monitoring was effective. 


\section{Chapter Summary}

Despite the terminology employed, overall literature reviews of research acknowledged positive effects for self-management components including selfinstruction, self-reinforcement, and self-monitoring (Bryan \& Sullivan-Burstein, 2004).

Outcomes from discrete studies also verified that self-monitoring enhanced an assortment of skills, such as on-task behavior (Amato-Zech, Hoff, \& Doepke, 2006; McCarl \& Hallahan, 1991); social skills (Agran et al., 1987; Peterson et al., 2006); classroom disruptions (Kehle, Clark, Jenson, \& Wampold, 1986; Todd, Horner, \& Sugai, 1999); spelling performance (Harris et al., 2005); math calculations (Heins et al., 1986; Lannie \& Martens, 2008); homework completion (Fish \& Mendola, 1986; Meyer \& Kelley, 2007); independent performance (Rock \& Thead, 2007; Wood et al., 2002); and creative writing (Glomb \& West, 1990; Santangelo et al., 2007).

The primary beneficial goal of self-monitoring strategies is their independent use across contexts, settings, and materials. When devising individualized support plans for students in managing their behavior, self-monitoring is an effective and regularly utilized instructional strategy in the classroom (Todd et al., 1999). The clear advantage of selfmonitoring is that it endorses autonomy, responsibility, and personal control over behavior by teaching students how to employ behavioral interventions for self-treatment (Hong, Peng, \& Rowell, 2009).

Self-monitoring promotes communication between teachers, parents, and children by actively engaging the student as a participant in improving his or her behavior (Blick \& Test, 1987), which increases their investment in the process. For students requiring individualized programs, self-monitoring procedures provide the prompts required for a 
student to independently accomplish a task or routine (Craft et al., 1998). Self-monitoring can be utilized in all areas including homework completion, monitoring appropriate behavior, and academic progress (Hughes \& Boyle, 1991; Shimabukuro et al., 1999). Combining self-management strategies produces more resilient behavioral change and facilitates enduring interventions rather than solely employing any one technique independently(Alberto \& Troutman, 2003; Todd et al., 1999). Furthermore, once taught, self-monitoring techniques can be effective tools for generalizing and maintaining skills since students can perform them anytime and anywhere, with minimal or no assistance (Rutherford et al., 1996). Self-monitoring necessitates self-comparisons rather than comparisons with other students, which promotes intrinsic motivation and defuses competition.

Overall, self-monitoring interventions produced significant results regardless of the nature or degree of the participants' disabilities. Also, the literature reveals numerous self-monitoring strategies that can be effectively and unobtrusively utilized with students in general education classrooms (Lee et al., 2009). However, the existing research lacks evidence of the effects of self-monitoring techniques on homework for students with disabilities who are in general education classrooms. While effective homework interventions have been utilized, they are not designed specifically for the population of students with disabilities (Power et al., 2001). Studies aimed at improving homework completion have targeted students with and without disabilities at the elementary and middle school levels with a few studies at the high school level (Fish \& Mendola, 1986; Flores et al., 1995; Forgatch \& Ramsey, 1994; Glomb \& West, 1990). Furthermore, no studies on self-monitoring and homework for students with disabilities in inclusive 
general education settings were found. In particular, no current research was located to determine if homework completion and accuracy will improve for students with disabilities in a general education setting if self-monitoring is employed.

In sum, when self-monitoring is utilized systematically in a classroom setting, it has been a verifiable and powerful technique for changing behavior. This has been shown with general education students, as well as students with disabilities in a self-contained setting. No research has been found to date that utilized self-monitoring to improve homework completion and accuracy for students with disabilities educated in a general education classroom. Therefore, in light of the efficacy and practical utility of selfmonitoring, it would be sensible to investigate its effectiveness with homework accuracy with this population. Taking this into account, the intent of the present study was to investigate the effects of self-monitoring on improving spelling and math homework completion and accuracy rates. It was designed to examine whether self-monitoring techniques in this milieu are congruous with previous studies and is intended to add to the current literature on homework strategies. 


\section{CHAPTER III}

\section{METHOD}

This study investigated the effects of a self-monitoring system on the completion and accuracy of spelling and math homework for students with disabilities included in a general education classroom. This chapter presents information about the participants, setting, dependent measures, materials, experimental design, and general procedures that were utilized in this study. A summary of the method section is provided at the end of the chapter.

\section{Participants}

Participants were four, fourth-grade elementary school students with disabilities enrolled in a public school in Collier County who received their academic instruction in a general education classroom. Each student with disabilities met eligibility criteria for Exceptional Student Education in the state of Florida. These eligibilities included Specific Learning Disabilities (SLD), Language Impaired (LI), and Other Health Impaired (OHI). In order for students to be classified as eligible for Exceptional Student Education services, there is a multiple step process. Initially, those students thought to have SLD in Collier County Public Schools (CCPS) are recommended for testing by a teacher, parent, or specialist. Two parent conferences and alternate strategies for assisting the student learn must be conducted prior to this recommendation. Next, the CCPS evaluation procedures include the use of current, valid verbal and non-verbal tests and evaluation materials, administered and interpreted by a certified, school psychologist. In order for a student to meet the eligibility criterion for SLD the following must be documented: (a) general education strategies must have been tried and found to be 
ineffective, (b) there must be a disorder in one or more basic psychological processes, (c) there must be a discrepancy of one standard deviation or more between an intellectual standard score and achievement standard score, (d) vision and hearing screenings for the purpose of ruling out sensory deficits that may interfere with the student's academics, and (e) there must be learning problems that are not due primarily to other handicapping conditions (Collier County Public Schools, 2009).

Similarly, for a student to be eligible for Language Impaired (LI) classification, there are actions that must first be undertaken. First, information is gathered from the student's parent or guardian, teachers, and the student (when appropriate), regarding the concerns and a description of language skills (using interviews, checklists, and/or questionnaires). Next, documented observations of the student's language skills must be conducted by the speech-language pathologist in one or more settings. The speechlanguage pathologist must administer and interpret one or more standardized normreferenced, county approved instruments designed to measure language skills. It must be determined that the language impairment is not primarily the result of factors related to age, gender, culture, ethnicity, or limited English proficiency.

Finally, before a student is classified as OHI, the following process takes place. To meet eligibility for OHI, there are two components of minimum evaluation. First, students must have a report of a medical examination within the previous 12-month period by a Florida-licensed physician qualified to assess the student's physical condition (Florida Department of Education [FLDOE], 2005). This report must show references to Attention Deficit Disorder (ADD), Attention Deficit with Hyperactivity Disorder (ADHD), Tourette syndrome, an acquired brain injury, or some other physical 
impairment. Second, an educational evaluation that identifies educational and environmental needs for the student who are not commensurate with the needs of their same aged peers. These two combined factors make them eligible for an $\mathrm{OHI}$ qualification in CCPS.

The participants' fourth-grade general education teacher recommended the study participants. Teacher nominations were considered a beneficial contribution because the teacher can provide invaluable information regarding their students (Abidin \& Robinson, 2002). Therefore, it is an optimum process for discovering the participants who could most profit from the intervention (Cooper et al., 2007; Tam, Heward, \& Heng, 2006). The teacher was asked to recommend students with disabilities who regularly have difficulty completing their homework accurately, do not complete it, or do not turn it in at all. In this study, students struggling with their math and spelling homework were defined as those who do not turn in their homework on time; consistently complete it incorrectly, turn it in incomplete, or turned it in $75 \%$ or less of the time each week.

Additionally, once the participants were identified, their parents were given informed written consent to sign prior to the commencement of the study (see Appendix A). Each student was taught by the researcher how to self-monitor his or her homework completion and accuracy on a daily basis using their self-monitoring sheet (see Appendix B) at home and their KidTools self-monitoring sheet (see Appendix C) on the computer (Whitby \& Miller, 2009). A description of each participant and a summary table of characteristics in Table 1 follows. 


\section{Participant 1}

Samantha (pseudonym) was a 10-year-old, fourth-grade Caucasian girl who met eligibility criteria for the Language Impaired program. She accessed the language arts and math general education curriculum in a general education setting with in-class support. She had a full scale IQ of 105.

\section{Participant 2}

Rio (pseudonym) was a 10-year-old, fourth-grade Hispanic boy who met eligibility criteria for the Specific Learning Disability program. He accessed the language arts and math general education curriculum in a general education setting with in-class support. He had a full scale IQ of 112.

\section{Participant 3}

Mike (pseudonym) was a 10-year-old, fourth-grade African-American boy who met eligibility criteria for the Specific Learning Disability program. He accessed the language arts and general education curriculum in a general education setting with inclass support. He had a full scale IQ of 85.

\section{Participant 4}

Brandy (pseudonym) was an 11-year-old, fourth-grade Caucasian girl who met eligibility criteria for the Other Health Impaired program. She accessed the language arts and math general education curriculum in a general education setting with in-class support. She had a full scale IQ of 103.

\section{Setting}

The study was conducted in a fourth-grade general education classroom of a large, public elementary school located in Naples, Florida. The racial/ethnic 
make-up of the group of 832 students enrolled at the school was as follows: $63.2 \%$

Caucasian, 26.0\% Hispanic, 3.0\% African American, 1.0\% Haitian, 1.0\% Asian, 4.4\%

Multi-Racial, and $0.4 \%$ Indian.

Table 1

Summary of Participant Characteristics

\begin{tabular}{|c|c|c|c|c|c|}
\hline Participant & Grade/Age & $\begin{array}{l}\text { Gender/Race/ } \\
\text { Ethnicity }\end{array}$ & IQ & $\begin{array}{l}\text { Educational } \\
\text { Placement }\end{array}$ & Disability \\
\hline Samantha & $4 \mathrm{th} / 11$ & $\mathrm{~F}, \mathrm{~W}$ & 105 & $\begin{array}{l}\text { General Ed. } \\
\text { w/In-class } \\
\text { ESE support }\end{array}$ & LI \\
\hline Rio & $4 \mathrm{th} / 10$ & $\mathrm{M}, \mathrm{H}$ & 112 & $\begin{array}{l}\text { General Ed. } \\
\text { w/In-class } \\
\text { ESE support }\end{array}$ & SLD \\
\hline Mike & $4 \mathrm{th} / 10$ & $\mathrm{M}, \mathrm{B}$ & 85 & $\begin{array}{l}\text { General Ed. } \\
\text { w/In-class } \\
\text { ESE support }\end{array}$ & SLD \\
\hline Brandy & $4 \mathrm{th} / 11$ & $\mathrm{~F}, \mathrm{~W}$ & 103 & $\begin{array}{l}\text { General Ed. } \\
\text { w/In-class } \\
\text { ESE support }\end{array}$ & $\mathrm{OHI}$ \\
\hline
\end{tabular}

Note: $\mathrm{F}=$ Female, $\mathrm{M}=$ Male, $\mathrm{B}=\mathrm{Black}, \mathrm{H}=$ Hispanic, $\mathrm{W}=$ White

Source: Participants' school records.

Of the total population, $19 \%$ were students with disabilities. The students with

disabilities who participated in the study were part of a general education classroom with approximately 22 students. Throughout the study, participants sat at their assigned desks that were not next to one another in the general education classroom.

\section{Researcher}

The researcher is an Exceptional Student Education (ESE) teacher working for 4 years at the school where the study took place. During the current study, the researcher was the 
ESE inclusion teacher who worked for approximately 2 hours a day in the general education classroom where the study took place. The researcher was in the classroom during part of the reading and math content.

\section{Materials}

The following is a list of materials that were utilized in the investigation. Descriptions of the consent forms, checklists, and all other materials are given.

\section{Participant Assent Form}

Students whose parents signed the consent form were read the participant's assent to participate in the research study form (see Appendix D). This form provided a brief description of the study, duration and the expectations for the researcher and participant. The researcher answered all questions the participants had regarding the form and the study. Researcher and university contact information were provided on the form. The participants were given a signed copy of the form.

\section{Parental Consent Form}

Parents were provided with a consent form regarding student participation in the research study (see Appendix A). This consent form provided a concise description of the study, information regarding the study's duration, expectations for student commitment and researcher contact information.

\section{Homework Quiz}

Following the initial meeting with the participants about appropriate homework behaviors and settings, a homework quiz was given. This was completed by the participants prior to baseline (see Appendix E). 


\section{Homework Self-Monitoring Checklist}

A homework self-monitoring checklist was employed for each participant to selfmonitor his/her homework completion behaviors at home (see Appendix B). They were to be returned each day.

\section{Computer Hardware and Software}

Hewlett Packard desktop computers, equipped with a 19" liquid crystal display (LCD) monitor, standard keyboard, mouse, and headphones were used for this study. They were accessible to the students each day.

\section{KidTools Application}

KidTools is a free electronic performance software program downloadable from the Internet (http://kidtools.missouri.edu/FreeDownloads.php). It is designed for elementary and middle school students who have specific learning disabilities and/or emotional and behavioral problems to utilize independently. The purpose is for participants to create, review, print, and save their personalized self-monitoring documents (see Appendix C).

\section{Homework Supplies}

Supplies for homework were used such as a daily planner, books (i.e., math book, spelling book), pencils, and paper.

\section{Interrater Agreement Form}

An interrater agreement form was used to compare homework completion and accuracy scores obtained by the researcher with those of the independent rater (see Appendix F). 


\section{Treatment Integrity Checklist}

A treatment integrity checklist, which lists all the steps completed along with dialogue scripts, was implemented to improve procedural reliability (see Appendix G).

\section{Social Validity Questionnaires}

Two informal social validity questionnaires were designed by the researcher and used to solicit responses to the self-monitoring of spelling and math homework. One was used for parental responses (see Appendix H), the other for participant responses (see Appendix I).

\section{Dependent Measures}

Dependent variables were measured in this study were: completion of spelling homework, accuracy of spelling homework, completion of math homework, accuracy of math homework and maintenance of homework completion, and accuracy. Following are the definitions of the dependent variables.

\section{Homework Completion}

Homework completion was measured as a percentage of questions/prompts/steps answered or completed compared to the possible number of questions/prompts/steps available to answer or complete. Included in the possible number of questions/prompts/steps available was the student's name, date, and heading if required for the assignment along with homework questions.

\section{Homework Accuracy}

Homework accuracy was measured as a percentage of questions/prompts answered/steps answered correctly compared to the possible number of questions/prompts available to answer. Included in the possible number of 
questions/prompts available as accurate was the student's name, date, and heading if required for the assignment along with homework questions. Writing of a name was scored as correct if spelled correctly and date accuracy was defined as accurate if it included the month, day, and year in words or numbers. If a heading was required for the assignment and it was written correctly, it was scored as correct. Each problem was scored as accurate if the answer was identical or acceptable compared to the answers in the teacher's edition or on the scoring rubric for that assignment.

\section{Maintenance}

Maintenance was defined as completion and accuracy performance on spelling and math homework assignments given for 3 weeks after the study was concluded for the first two participants and for 2 weeks after the study was concluded for the other two participants. Maintenance procedures included comparison of data collection of percentage of completion and accuracy of spelling and math homework assignments from baseline and the three self-monitoring phases.

\section{Interrater Reliability}

Two independent raters were trained to check completion and accuracy of the homework and carry out interrater reliability. This addressed the consistency of the rating system. Training of the raters was provided by the researcher and took place in one session. One of the raters was the general education teacher, the other was another special education teacher who taught the fourth-grade participants in the study. During the training session, raters were given oral and written procedures on how to check the participants' homework using the teacher's edition or grading rubric provided on-line by the school district. The raters were considered sufficiently trained when they 
demonstrated comprehension of the grading systems. To be considered trained, the independent rater's scores needed to match the trainer's scores with at least $90 \%$ accuracy. Their understanding was shown by correctly grading completed homework samples. The homework samples were considered correctly graded if they matched the answers in the teacher's edition of the assigned homework and the heading on the paper was written and graded accurately (correct spelling and heading).

Throughout the study, interrater data were collected for 33\% (122 of 370) of all spelling and math homework assignments across all the study's conditions and phases. Interrater agreement compared the researcher's scores with the independent rater's scores and was obtained by dividing the number of agreements by the number of agreements plus disagreements then multiplying by 100 . Interrater reliability analysis did not fall below $90 \%$, so retraining of the raters did not occur. Note that although two individuals were trained for interrater data collection, only one participated throughout the study (see Appendix F).

\section{Treatment Integrity}

To attest to the accuracy of the appropriate procedural design, the researcher collected treatment integrity data (see Appendix G). The researcher used the checklist to support that all components of the baseline and intervention conditions were implemented as planned. An independent observer also filled out this form for 31 of the $121(25.7 \%)$ homework conferencing sessions across all conditions and participants, and 4 of the $16(25 \%)$ of the meetings with each participant to validate that the researcher implemented the proper procedures. Two independent observers were trained to collect treatment integrity data to help validate accuracy of the procedural implementation as 
designed. In one session, the observers were trained to use the treatment integrity checklist. Note that although two individuals were trained to collect treatment integrity data, only one participated throughout the study. Training involved reviewing the treatment integrity checklist and explaining that each item needed to be checked either yes or no to indicate the occurrence or non-occurrence of the procedure. Following the training session, the independent observers were asked to watch the researcher executing the steps. Prior to the commencement of the study with participants, the researcher completed a "practice session" with the observers present using the checklist. The researcher also used a checklist. Afterwards, there was a comparison of the researcher's and observers' checklists. There was a $100 \%$ reliability check, so the observers were considered appropriately trained.

\section{Experimental Design}

To investigate the effects of self-monitoring on the homework completion and accuracy rate of elementary students with disabilities educated in an inclusive general education classroom, data were collected using a single subject, multiple baseline across subjects design (Cooper et al., 2007). The multiple baseline design is appropriate since there are several subjects displaying the same problems with completion and accuracy of spelling and math homework within the same setting and the withdrawal of intervention is not necessary (Cooper et al., 2007). In a multiple baseline across subjects design, an intervention is introduced progressively for different participants who exhibit similar target behaviors in the same setting. After steady state of responding has been achieved under baseline conditions, the intervention is applied to one of the participants, while the others remain under baseline. When criterion or steady state responding has been 
achieved in the first participant, the independent variable is applied to another participant and so on.

The multiple baseline across subjects design was chosen since it allows for both evaluations as well as causal inference. This is helpful for evaluating situations where an intervention would be likely to bring about enduring changes in the dependent variable (homework completion and accuracy). Other advantages include: (a) data can be recorded during the same time period for different lengths of time, (b) repeated measurement of the dependent variables continues, (c) provides a standard for evaluating the effect of independent variable, (d) there is no withdrawal of treatment, and, (e) replication and verification can be noted in comparable data paths (McMillan, 2004).

Experimental control demonstrated by the multiple baseline across subjects design can be described using three elements of baseline logic (Cooper et al., 2007; Johnston \& Pennypacker, 1993). First, repeated measures can establish the prediction of a baseline's data path into the subsequent intervention phase, allowing the detection of a difference between the actual data path during intervention and the path predicted from baseline. Second, the effects of the intervention are verified by demonstrating that it changed one participant's behavior without influencing the remaining participants' behavior while they remain in baseline. Finally, the effects of the independent variable are replicated across the additional participants if a change in behavior is observed when and only when the intervention is implemented. When all three aspects of single-case design logic are demonstrated, the multiple baseline across subjects design controls for at least two of the primary threats to internal validity, including (a) historical events (e.g., a 
curriculum or personnel change in a classroom setting) that might concurrently affect multiple participants and (b) participant maturation (Kazdin, 1982).

\section{General Procedures}

The following section explains the procedures employed in this investigation. The prestudy portion describes the preparation that took place prior to commencing the study. In the general study section, a description of baseline and intervention condition procedures is presented. Finally, there is a description of how the maintenance procedures were measured to examine the effects of this study.

Prestudy procedures. The following is a description of the proceedings that were executed preceding the launch of this study. This includes the selection of participants, the preparation that occurred prior to the commencement of the study, obtaining parental permission, and rater training.

Selection of participants. The researcher, a special education teacher at the selected school, scheduled a meeting with the fourth-grade general education teachers who work with students with disabilities in their classes. At the meeting, the researcher described the study and the implications for the students with disabilities. Criteria for participation in the study were discussed along with the expectations of the teachers (see Appendix J). In addition to having a disability, the study participants were students who completed their math and spelling homework less than $75 \%$ of the time and/or scored less than an average of $75 \%$ on the homework assignments that were completed (see Appendix J). Additionally, the participants had to be able to navigate a computer program independently. The general education and special education teachers (including the researcher) nominated participants for the study who met these criteria. The researcher 
met with the teachers again the next week and collected nominations and discussed potential participants for the study. Upon recommendation of the general education and special education teachers who work with the students, participants who needed improvement with their spelling and math homework completion and accuracy were selected by the committee.

Parental consent. The parents of potential participants were invited to an informative meeting explaining the purpose of the investigation, the procedures, and the commitment involved by the parent and student. Answers to any questions or concerns the parents had were provided. All the participants' parents spoke English so a translator was not necessary for the meeting. At the meeting, the consent form was provided and reviewed with the parents/guardians. The parents were asked to review, sign, and return the consent form within a week.

Participant assent. A form similar to the parent consent was read to and discussed with the student participants. This occurred during a one-on-one meeting with the researcher. This form was developed in English only since all the participants spoke and read English. The researcher answered all participant questions. The participants were asked to sign the form assenting to participate in the study and were given a copy of the signed form.

Selection of homework. The homework selected for the study was from the books adopted by the district and followed a mandated curriculum map and guideline, which designates the specific homework. All students in that classroom were assigned the same daily homework. Spelling and math homework consisted of approximately two 
assignments every day Monday through Thursday. This consisted of approximately 20 minutes each of a math and spelling assignment four nights a week.

Independent raters' selection and training. One general education teacher and one special education teacher who work with the fourth-grade participants were both trained as independent raters. The researcher completed training of the independent raters in one session. During training, the raters were provided oral, written and visual explanations for scoring the homework including the requirement that participants have their name, date and heading correctly spelled on their papers. The raters were provided with a sample of completed homework and were taught how to use the Teacher's Edition and the rubrics to score the paper. Further, an explanation and example of the treatment integrity checklist was provided. Both the homework scores and treatment integrity checklist scores obtained by the raters were compared to the homework and integrity checklist scores the researcher obtained. The raters and the researcher had $100 \%$ agreement on the homework samples and the treatment integrity checklist, so the raters were considered adequately trained.

Research site preparation. The researcher prepared the classroom by checking that all hardware, software, electronics, and materials needed were available and working. During the intervention phase, for the first few days, the researcher prepared the computer in the classroom prior to the participants' arrival by opening the KidTools document that contains their individual monitoring sheet.

\section{Baseline, Intervention Training, Intervention, and Maintenance}

This section will describe the baseline conditions, the training intervention procedures, and a thorough explanation of the intervention. The maintenance section 
describes how measures were obtained to explore the effects of this study. There is also a summary of the method chapter.

\section{Baseline}

Baseline needs to be established in order to evaluate the effects of an intervention (Cooper et al., 2007). Baseline data were collected and recorded daily on the completion and accuracy of each participant's homework without the use of self-monitoring until a relative stable baseline was observed. Ideally, baseline was to be considered stable if participants consistently had homework completion and accuracy rates fall within a $15 \%$ range. This did not occur for three of the four participants. Since there was a consistent variability observed for multiple baseline sessions for these three participants, the researcher chose to intervene where it seemed appropriate. That is, given the considerable baseline data collected, it seemed unlikely that any stable baseline would develop, only that a consistently variable baseline would maintain.

To assist in creating a more valid study, certain issues were addressed prior to baseline. First, participants were given tips to facilitate homework completion (see Appendix L, USDOE, 2003). Further, the same list of homework tips was also sent home for parents of the participants to review with their children.

During baseline, the participants followed their typical daily morning routine. This routine began when the first bell rang and participants entered the classroom, unpacked their book bags and took out their homework to give to the teacher. Homework assignments were written in their daily planners, which were provided for each student in the school at the start of the school year. Teachers selected daily homework assignments. They were required to follow a CCPS' specific curriculum map, which adheres to state 
academic guidelines. This curriculum map outlines all class and homework assignments to be covered by the instructor for each subject at every grade level throughout the school year. The teacher checked that the spelling and math homework was completed and collected the homework. Later, the homework was graded and recorded in the electronic grade book and on the Teacher Checklist (see Appendix K).

Data were collected and recorded on whether the students handed in their homework, on percentage of completion and accuracy. After the homework was collected and copied, both the researcher and one of the raters scored the homework independently. The raters did this for 33\% of the time. Standard classroom procedure was that in order for a student to participate in the grade level Friday afternoon activities, termed "Fun Friday" (movie day, kickball game, garage sale, etc.), they must have turned in their homework for the week. If the homework was not turned in, then that student would go to study hall in another designated classroom. As a result, there was already a built in reward, although not necessarily a reinforcer, in the typical classroom procedure.

\section{Intervention Training}

Based on the data, the researcher determined when to intervene with each participant. Each student participant was trained in a staggered fashion just prior to their moving to the intervention phase. The training took place inside the researcher's resource room in one session on the day the intervention began (see Appendix M). No other students were in the room during this training. The researcher showed the participant how to complete the self-monitoring sheet using a sample and then completing one together. The researcher fully explained the meaning of each item on the monitoring sheet. For example, one of the items on the sheet was, "Worked in a clear area." The researcher 
discussed with the participant what that meant by demonstrating how much cleared space is needed to perform homework. The participant was shown by demonstration that the book and paper need to be on the table with ample room to write, etc. The researcher did this for each item on the training sheet. After each item on the training sheet, the participant colored, shaded, checked or circled the smiley face for a "yes" response or the sad face for a "no" response. For instance, the self-monitoring sheet asked if homework directions were read, the participant had to think about it and responded by marking the smiley for a "yes" or the sad face to indicate a "no." There was not a "correct" answer on the self-monitoring sheet. The participants were not rewarded or reinforced extrinsically in any way for answering "yes" to the questions. The researcher answered any questions the student had about the self-monitoring sheet; which was to be completed every day at home, initialed by an adult and brought back to school each day.

Further, in one session the researcher taught the participants to operate the KidTools self-monitoring program on the computer each day in the classroom. Training began by telling the participants to click on the KidTools icon that was previously installed on the computers. Once it was opened, there was a cartoon guide that verbally directed them to type in their name and then pick a tool. Participants were instructed to select the button that says "monitoring cards" and then push the return key, select the "checking card" (see Appendix C). Next, the participants were instructed to type in the two behaviors they monitored on their cards. The questions were "Did I bring my homework to school?" and "Did I turn in my homework?" which they typed on the spaces provided. After the first time, their personalized information was saved for future use, so it did not have to be typed again, and the program automatically entered the date 
for them. While the participants worked with KidTools, there was a program cartoon guide present during each step that prompted participants after a few seconds if no action was taken. There were faces on this sheet from which they needed to pick either the smiley face for a "yes" response, or a sad face for a "no" response. The participants were not rewarded or reinforced extrinsically in any way for answering "yes" to the questions. When they were finished, they just exited the program. Then they printed their selfmonitoring sheet and brought it with them later in the day when meeting with the researcher. The participants' data were saved each time they exited the program and could be retrieved and printed anytime. This also created a permanent record for the researcher to use for data collection.

Each day the participants logged into the KidTools program, accessed their individualized self-monitoring sheet, answered the questions, printed their sheet and exited. They were considered appropriately trained if they independently logged onto the computer, correctly filled out a practice self-monitoring sheet, gave an explanation or demonstration of each item, and answered the questions on that monitoring sheet on their own or with the assistance of the KidTools guide. An affirmative answer did not earn them any extrinsic rewards or reinforcers.

\section{Phase I Intervention}

During Phase I of the intervention, the participants filled out their self-monitoring sheet at home while they were doing their homework at home. Once it was filled out and initialed by an adult, they put the self-monitoring sheet in their planner and brought their planner with the sheet inside and their homework, back to school. Each day when the general education teacher asked for the students to take out their homework, they turned 
in their homework as required, to their general education teacher. They were responsible for their student planner and kept it at their desks until it was needed. Additionally, the participants logged onto the KidTools application in the morning at school, filled out their individual self-monitoring sheet, printed it and saved it at school each day. Later in the day, participants reviewed both their self-monitoring sheets with the researcher. They came to the researcher's office individually and privately to discuss their self-monitoring and KidTools sheets just before their lunch time.

\section{Phase II Intervention}

Throughout Phase II of the intervention, participants continued to self-monitor their homework completion and accuracy, but met with the researcher only twice a week. Prior to the implementation of Phase II of the intervention, the researcher met with each participant and explained that while they were still responsible for self-monitoring their

spelling and math homework completion and accuracy, they would only be meeting with the researcher two times a week (see Appendix N). The meeting days were Friday and another day that was randomly selected. Friday was selected as a constant, unbeknownst to the participants. Subsequently, the participants were unaware of which days they would be checked each week.

\section{Phase III Intervention}

During Phase III of the intervention, participants continued to self-monitor their spelling and math homework completion and accuracy, but met with the researcher only once a week. Prior to the implementation of Phase III of the intervention, the researcher met with each participant and explained that while they were still responsible for selfmonitoring their spelling and math homework completion and accuracy, they would only 
be meeting with the researcher once per week (see Appendix O). The meeting day was a randomly selected day, so the participants were unaware of which day they would be meeting with the researcher each week.

\section{Maintenance}

Throughout the maintenance phase, participants continued to write down their homework in their daily planner and turn it in to the classroom teacher every day. They were asked to continue to fill out their KidTools sheet on the computer at school if they chose to, but the researcher no longer reviewed the sheets with the participants (see Appendix P). Nor were they reminded in any way. However, they did turn in the sheets to the researcher if they completed them. Data on spelling and math homework completion and accuracy were collected daily for two of the participants for 3 weeks after the end of Phase III of the intervention and for 2 weeks for the other two participants. The end of the school year prohibited maintenance data from being collected for all four participants for longer periods of time.

\section{Social Validity Questionnaires}

After maintenance, an informal social validity measure was administered separately to both the parents (see Appendix H) and the participants (see Appendix I) involved. The questionnaires were used to assess social acceptability of the intervention and to ensure that relevant parties (e.g., teachers, parents, participants) agreed the procedure was reasonable. Participants and parents were interviewed individually in relation to their experience with the self-monitoring intervention. More specifically, participants and parents were asked open-ended questions about what they enjoyed, disliked or would change about the self-monitoring intervention. Both participants and 
parents were invited to supply truthful responses and were ensured no negative consequences would result from off-putting answers. The researcher wrote down the responses to the questionnaires.

\section{Chapter Summary}

Using a single subject, multiple baseline across subjects design, this study examined the effects of self-monitoring on the homework accuracy and completion rate of students with disabilities included in a general education classroom. The multiple baseline design was chosen since it allows for evaluation across participants and causal inference. Participants included four students with disabilities enrolled in a public elementary school. The researcher conducted the study in a fourth-grade general education classroom. The study was conducted partly during the participants' morning work routine in the general education classroom and partly in the researcher's office. Materials used in the study included a computer, homework, books, Teacher's Edition, self-monitoring sheets, KidTools and other relevant academic materials.

Dependent measures for this study were completion and accuracy of spelling and math homework. Baseline and all conditions of the intervention consisted of participants turning in their homework and checking for completion and accuracy. Aside from the written homework tips given to participants and parents prior to baseline, there were no changes in the daily homework routine during baseline. During intervention, participants self-monitored completion and accuracy of their spelling and math homework at home and at school using the KidTools application. Maintenance data on spelling and math homework completion and accuracy were collected daily for two of the participants for 3 weeks after completion of the study and for 2 weeks for the other two participants. 


\section{CHAPTER IV}

\section{RESULTS}

This chapter presents the findings of a study that used a multiple baseline design across subjects to investigate the effects of self-monitoring on the completion and accuracy rates of spelling and math homework for students with disabilities who are in an inclusive general education classroom. During baseline, other than an instructional session on best practices in homework given to the participants, all homework procedures remained the same. The self-monitoring intervention condition consisted of three phases. During the first phase of the intervention, the participants self-monitored their homework at home and in school and a brief, individualized daily conference occurred between the researcher and the participants to review their self-monitoring sheets. During the second intervention second phase, conferences occurred twice weekly, and they occurred once a week during the third intervention phase. In addition, this study examined whether the participants maintained any observed gains over a 2- to 3-week period, following the final phase of the intervention.

Initially, treatment fidelity and interrater agreement data are presented. Next, is a presentation of the effects of the intervention on the completion and accuracy of spelling homework by individual participants and the group means, followed by data on completion and accuracy of math homework. Finally, this chapter concludes with a synopsis of the results.

\section{Treatment Fidelity}

To facilitate that procedures were followed as designed, one trained independent observer collected treatment fidelity data. Procedural data were collected on 31 of the 121 
(25.7\%) homework conferencing session across all conditions and participants, and 4 of the $16(25 \%)$ meetings with each participant to explain the self-monitoring condition and each phase thereafter, prior to each phase. Independent observer data indicated that procedures were followed with $100 \%$ consistency on all observed sessions.

\section{Interrater Agreement}

One trained rater, along with the researcher, collected interrater agreement data for 33\% (122 of 370) of all spelling and math homework assignments across all the study's conditions and phases. For spelling homework completion and accuracy, the mean interrater agreement was $99.87 \%$ (range $95-100 \%$ ) and $100 \%$ (range $100-100 \%$ ) respectively. The mean interrater agreement for math homework completion and accuracy was $100 \%$ (range 100-100\%) and 99.80\% (range 95-100\%), respectively.

\section{Spelling Homework Completion and Accuracy}

This study examined the effects of self-monitoring on the completion and accuracy rate of the spelling homework given Monday through Thursday for students with disabilities in an inclusive, general education classroom. Completion was measured by the number of answers provided divided by the number of possible answers including name, date and heading, if applicable. Accuracy was defined by the number of correct answers divided by the number of possible correct answers for the daily spelling homework assignments.

Daily homework completion and accuracy percentage data are visually presented in a multiple baseline figure. Presented in tables are individual and group mean and range data across baseline and the three phases of the self-monitoring condition (daily conferencing, twice weekly conferencing, weekly conferencing). Also, presented in the 
table are individual and group mean and range maintenance data (when no conferencing occurred) compared to the mean spelling completion and accuracy performance on the last phase of the intervention.

Maintenance mean scores were compared to the mean performance of spelling completion and accuracy during the intervention. During maintenance, participants no longer had access to their daily self-monitoring sheet used during the intervention at home, reviewed, and signed by a parent. However, if they chose to, they were able to continue to self-monitor on the computer using KidTools, but there were no homework conference meetings with the researcher to review their self-monitoring sheets. The maintenance condition was conducted after the final phase of self-monitoring following the last intervention day for each participant.

\section{Samantha}

Figure 1 and Tables 2 and 3 display Samantha's spelling homework completion and accuracy performances during baseline, the three phases of the self-monitoring condition (daily conferencing, twice-weekly conferencing, once-weekly conferencing) and during the maintenance condition with no self-monitoring form used at home or conferencing with the researcher. During baseline, Samantha's mean spelling homework completion was $76 \%$ (range $70-80 \%$ ). After self-monitoring with daily conferencing was introduced, Samantha's mean spelling homework completion increased to $96.05 \%$ (range $90-100 \%$ ). This represents a mean increase of $20.05 \%$ of spelling homework completed from baseline to Phase I of the self-monitoring intervention. When self-monitoring with daily conferencing was reduced to twice a week, Samantha's mean spelling homework 


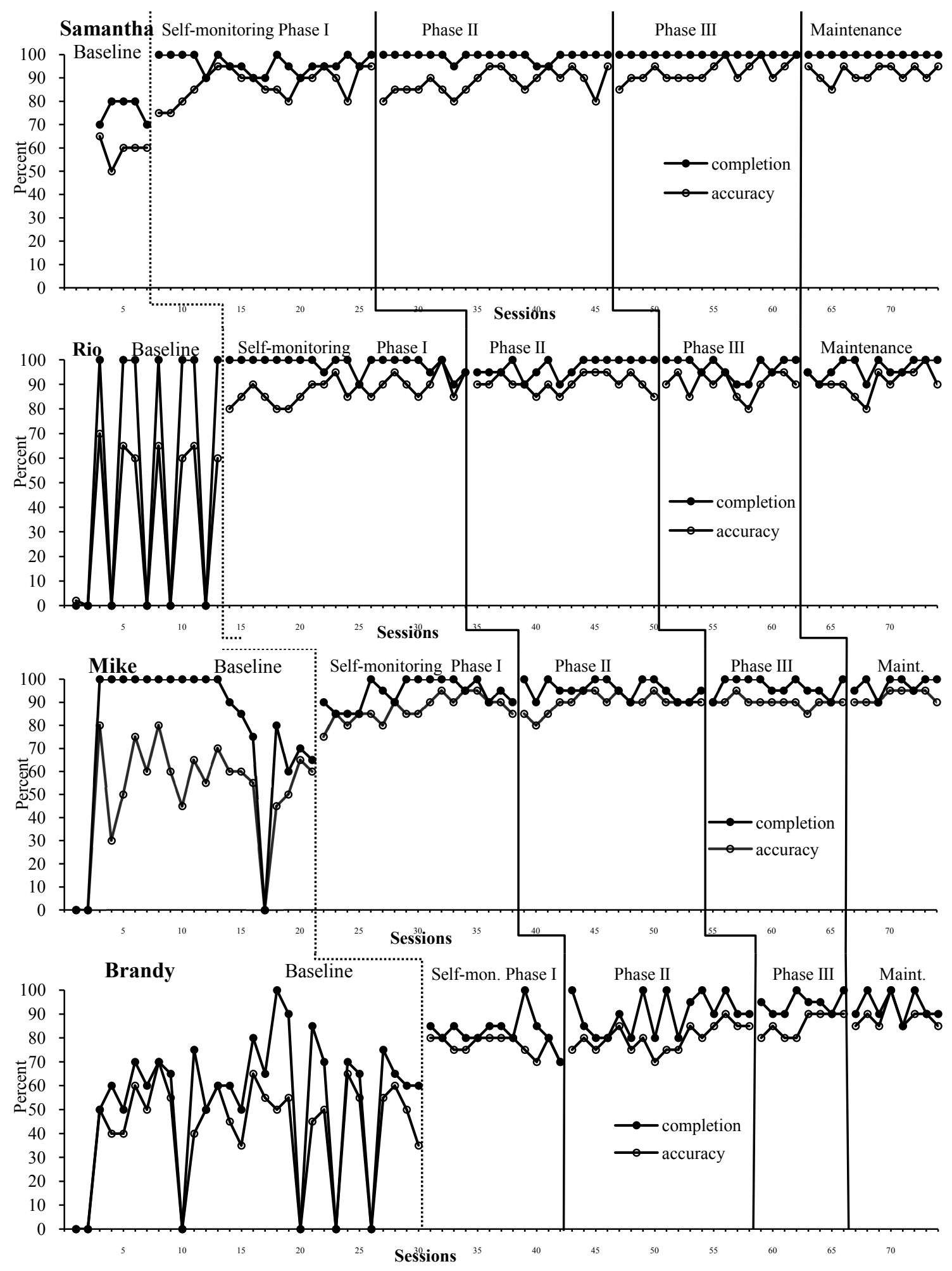

Figure 1. Spelling homework completion and accuracy. 
completion continued to increase with a mean performance of 99.25\% (range $95-100 \%$ ). With self-monitoringreduced to once a week conferencing, Samantha's mean spelling homework completion increased further to a mean of 100\% (range 100-100\%).

During maintenance, Samantha's mean spelling homework completion remained at the high rate of $100 \%$ (range 100-100\%). Spelling homework completion was greatest, during the self-monitoring with weekly conferencing and sustained during maintenance, with a mean increase of $24.0 \%$ percent over baseline (see Figure $1 \&$ Table 2 ).

Table 2

Individual and Group Means and Ranges in Percentages on Spelling Homework Completion

\begin{tabular}{lccccc}
\hline Participant & Baseline & $\begin{array}{c}\text { Self-Monitoring: } \\
\text { daily conferencing }\end{array}$ & $\begin{array}{c}\text { Self-monitoring: } \\
\text { twice-weekly } \\
\text { conferencing }\end{array}$ & $\begin{array}{c}\text { Self-monitoring: } \\
\text { weekly } \\
\text { conferencing }\end{array}$ & Maintenance \\
\hline Samantha & 76.0 & 96.05 & 99.25 & 100 & 100 \\
& $(70-80)$ & $(90-100)$ & $(95-100)$ & $(100-100)$ & $(100-100)$ \\
Rio & 53.84 & 98.33 & 97.18 & 97.81 & 96.6 \\
& $(0-100)$ & $(90-100)$ & $(90-100)$ & $(90-100)$ & $(90-100)$ \\
Mike & 77.38 & 94.11 & 95.66 & 96.53 & 97.5 \\
& $(0-100)$ & $(85-100)$ & $(90-100)$ & $(90-100)$ & $(90-100)$ \\
& & & & & \\
Brandy & 53.5 & 82.91 & 90.0 & 94.37 & 93.12 \\
& $(0-100)$ & $(70-100)$ & $(80-100)$ & $(90-100)$ & $(85-100)$ \\
& & & & & \\
Group & 65.18 & 93.12 & 95.43 & 97.17 & 96.80 \\
& $(0-100)$ & $(70-100)$ & $(80-100)$ & $(90-100)$ & $(85-100)$ \\
\hline
\end{tabular}

Note. Top numbers indicate mean of spelling homework completion. Bottom rows of numbers represent the range of scores.

With respect to spelling homework accuracy during baseline (see Figure $1 \&$ Table 3), Samantha's mean spelling homework accuracy was 59\% (range 50-65\%). After self-monitoring with daily conferencing was introduced, Samantha's mean spelling 
homework accuracy increased to $87.36 \%$ (range $75-95 \%$ ). This represents a mean increase of $28.36 \%$ of spelling homework accuracy from baseline to Phase I of the selfmonitoring intervention. When self-monitoring with daily conferencing was reduced to twice a week, Samantha's mean spelling homework accuracy continued to increase with a mean performance of $88.25 \%$ (range $80-95$ ). With self-monitoring with once a week conferencing, Samantha's mean spelling homework accuracy increased further to a mean of $92.81 \%$ (range $85-100 \%$ ).

Table 3

Individual and Group Means and Ranges in Percentages on Spelling Homework Accuracy

\begin{tabular}{lccccc}
\hline Participant & Baseline & $\begin{array}{c}\text { Self-Monitoring: } \\
\text { daily } \\
\text { conferencing }\end{array}$ & $\begin{array}{c}\text { Self-monitoring: } \\
\text { twice weekly } \\
\text { conferencing }\end{array}$ & $\begin{array}{c}\text { Self-monitoring: } \\
\text { weekly } \\
\text { conferencing }\end{array}$ & Maintenance \\
\hline \multirow{2}{*}{ Samantha } & 59.0 & 87.36 & 88.25 & 92.81 & 92.08 \\
& $(50-65)$ & $(75-95)$ & $(80-95)$ & $(85-100)$ & $(85-95)$ \\
Rio & 34.38 & 88.09 & 90.62 & 90.31 & 91.25 \\
& $(0-70)$ & $(80-100)$ & $(85-95)$ & $(80-95)$ & $(80-100)$ \\
Mike & 50.71 & 87.05 & 90.0 & 90.0 & 92.5 \\
& $(0-80)$ & $(75-95)$ & $(80-95)$ & $(85-95)$ & $(90-95)$ \\
Brandy & 41.16 & 77.0 & 80.35 & 85.62 & 88.75 \\
& $(0-70)$ & $(70-80)$ & $(70-90)$ & $(80-90)$ & $(85-100)$ \\
Group & 46.31 & & & & \\
& $(0-80)$ & $(70-100)$ & $(70-95)$ & $(80-100)$ & $(80-100)$ \\
\hline
\end{tabular}

Note. Top numbers indicate individual mean of spelling homework accuracy.

Bottom rows of numbers represent the range of scores.

During the maintenance condition, Samantha's mean spelling homework accuracy decreased slightly to $92.08 \%$ (range $85-95 \%$ ). Spelling homework accuracy was greatest, 
but only minimally, during the self-monitoring intervention Phase III, with a mean increase of $33.81 \%$ over baseline (see Figure $1 \&$ Table 3 ).

Samantha was in maintenance for 3 weeks. Her mean spelling homework completion rate was $24.0 \%$ higher during maintenance than baseline (see Figure $1 \&$ Table 2,). Compared to baseline, Samantha's spelling homework accuracy rate was $33.08 \%$ higher during maintenance (see Figure $1 \&$ Table 2).

\section{Rio}

Figure 1 and Tables 2 and 3 display Rio's spelling homework completion and accuracy performances during baseline, and the three phases of the self-monitoring condition (daily conferencing, twice-weekly conferencing, once-weekly conferencing) and during the maintenance condition with no self-monitoring sheet from the intervention used at home or conferencing with the researcher.

During baseline, Rio's mean spelling homework completion was 53.84\% (range 0-100\%). After self-monitoring with daily conferencing was introduced, Rio's mean spelling homework completion increased to $98.33 \%$ (range $90-100 \%$ ). This represents a mean increase of $44.49 \%$ of spelling homework completed from baseline to Phase I of the self-monitoring intervention. When self-monitoring with daily conferencing was reduced to twice a week, Rio's mean spelling homework completion slightly decreased with a mean performance of $97.18 \%$ (range 90-100). When self-monitoring with conferencing was reduced to once a week, Rio's mean spelling homework completion minimally increased to a mean of $97.81 \%$ (range $90-100 \%$ ).

During the maintenance condition, Rio's mean spelling homework completion remained at a high rate of $96.6 \%$ (range $90-100 \%$ ). Spelling homework completion was 
greatest, during the self-monitoring with daily conferencing and remained high during maintenance, with a mean increase of $42.76 \%$ percent over baseline (see Figure $1 \&$ Table 2).

With respect to Rio's spelling homework accuracy performance during baseline, Rio's mean spelling homework accuracy was 34.38\% (range 0-70\%). After selfmonitoring with daily conferencing was introduced, Rio's mean spelling homework accuracy increased to $87.09 \%$ (range $80-100 \%$ ). This represents a mean increase of $53.71 \%$ of spelling homework accuracy from baseline to Phase I of the self-monitoring intervention. When self-monitoring with daily conferencing was reduced to twice a week, Rio's mean spelling homework accuracy continued to increase with a mean performance of $90.62 \%$ (range $85-95 \%$ ). When self-monitoring conferencing was reduced to once a week, Rio's mean spelling homework accuracy decreased slightly to a mean of $90.31 \%$ (range $80-95 \%$ ).

During the maintenance condition, Rio’s mean spelling homework accuracy increased somewhat to $91.25 \%$ (range $80-100 \%$ ). Spelling homework accuracy was greatest, but only minimally, during the maintenance condition, with a substantial mean increase of $56.87 \%$ over baseline (see Figure $1 \&$ Table 2 ).

Rio was in maintenance for 3 weeks. His spelling homework completion rate was $42.76 \%$ higher during maintenance than in baseline (see Figure $1 \&$ Table 2). Compared to baseline, Rio's spelling homework accuracy rate was $56.87 \%$ higher during maintenance (see Figure $1 \&$ Table 2). 


\section{Mike}

Figure 1 and Tables 2 and 3 display Mike's spelling homework completion and accuracy performances during baseline, and the three phases of the self-monitoring condition (daily conferencing, twice-weekly conferencing, once-weekly conferencing) and during the maintenance condition with no self-monitoring sheet from the intervention used at home or conferencing with the researcher. During baseline, Mike's mean spelling homework completion was 77.38\% (range 0-100\%). After self-monitoring with daily conferencing was introduced, Mike's mean spelling homework completion increased to $94.11 \%$ (range $85-100 \%$ ). This represents a mean increase of $16.73 \%$ of spelling homework completed from baseline to Phase I of the self-monitoring intervention. When self-monitoring with daily conferencing was reduced to twice a week, Mike's mean spelling homework completion slightly increased with a mean performance of $95.66 \%$ (range 90-100). When self-monitoring with conferencing was reduced to once a week, Mike's mean spelling homework completion continued to increase slightly to a mean of $96.53 \%$ (range $90-100 \%)$.

During the maintenance condition, Mike's mean spelling homework completion continued at a high rate of $97.5 \%$ (range 90-100\%). Spelling homework completion was greatest, during the maintenance condition, with a mean increase of $20.12 \%$ percent over baseline (see Figure $1 \&$ Table 2).

With respect to Mike's spelling homework accuracy performance during baseline, Mike's mean spelling homework accuracy was 50.71\% (range50-65\%). After selfmonitoring with daily conferencing was introduced, Mike's mean spelling homework accuracy increased to $87.05 \%$ (range $75-95 \%$ ). This represents a mean increase of 
$36.34 \%$ of spelling homework accuracy from baseline to Phase I of the self-monitoring intervention. When self-monitoring with daily conferencing was reduced to twice a week, Mike's mean spelling homework accuracy continued to increase with a mean performance of $90.0 \%$ (range $80-95$ ). When self-monitoring with conferencing was reduced to once a week, Mike's mean spelling homework accuracy remained steady at a mean of $90.0 \%$ (range $85-95 \%$ ).

During the maintenance condition, Mike's mean spelling homework accuracy continued to increase slightly to $92.50 \%$ (range $90-95 \%$ ). Spelling homework accuracy was greatest, during maintenance, with a mean increase of $41.79 \%$ over baseline (see Figure $1 \&$ Table 2).

Mike was in maintenance for 2 weeks. His spelling homework completion rate was $20.12 \%$ higher during maintenance than in baseline (see Figure $1 \&$ Table 2). Compared to baseline, Mike's spelling homework accuracy rate was $41.79 \%$ higher during maintenance than in baseline (see Figure $1 \&$ Table 2).

\section{Brandy}

Figure 1 and Tables 2 and 3 display Brandy's spelling homework completion and accuracy performances during baseline, and the three phases of the self-monitoring condition (daily conferencing, twice-weekly conferencing, once-weekly conferencing) and during the maintenance condition with no self-monitoring sheet from the intervention used at home or conferencing with the researcher. During baseline, Brandy's mean spelling homework completion was $53.50 \%$ (range $0-100 \%$ ). After self-monitoring with daily conferencing was introduced, Brandy's mean spelling homework completion increased to $82.91 \%$ (range $70-100 \%$ ). This represents a mean increase of $29.41 \%$ of 
spelling homework completed from baseline to Phase I of the self-monitoring intervention. When self-monitoring with daily conferencing was reduced to twice a week, Brandy's mean spelling homework completion increased with a mean performance of $90.0 \%$ (range $80-100 \%$ ). When self-monitoring with conferencing was reduced to once a week, Brandy's mean spelling homework completion continued to increase to a mean of 94.37\% (range $90-100 \%$ ).

During the maintenance condition, Brandy's mean spelling homework completion remained at a high rate of $93.12 \%$ (range $85-100 \%$ ). Spelling homework completion was greatest, during the self-monitoring with weekly conferencing and remained high during maintenance, with a mean increase of $39.62 \%$ percent over baseline (see Figure $1 \&$ Table 2).

With respect to Brandy's spelling homework accuracy performance during baseline, Brandy's mean spelling homework accuracy was $41.16 \%$ (range 0-70\%). After self-monitoring with daily conferencing was introduced, Brandy's mean spelling homework accuracy increased to $77.08 \%$ (range $70-80 \%$ ). This represents a mean increase of $35.92 \%$ of spelling homework accuracy from baseline to Phase I of the selfmonitoring intervention. When self-monitoring with daily conferencing was reduced to twice a week, Brandy's mean spelling homework accuracy continued to increase with a mean performance of $80.0 \%$ (range $70-90$ ). When self-monitoring with conferencing was reduced to once a week, Brandy's mean spelling homework accuracy increased further to a mean of $85.62 \%$ (range $85-100 \%)$.

During the maintenance condition, Brandy's mean spelling homework accuracy continued to increase to $88.75 \%$ (range $85-100 \%$ ). Spelling homework accuracy was 
greatest during the maintenance condition with a mean increase of $47.59 \%$ over baseline (see Figure $1 \&$ Table 2).

Brandy was in maintenance for 2 weeks. Her spelling homework completion rate was $39.62 \%$ higher during maintenance than in baseline (see Figure $1 \&$ Table 2). Compared to baseline, Brandy's spelling homework accuracy rate was $47.59 \%$ higher during maintenance (see Figure $1 \&$ Table 2).

\section{Group}

Figure 1 and Tables 2 and 3 display group means for spelling homework completion performance during baseline, self-monitoring with daily conferencing, twiceweekly conferencing, once-weekly conferencing, and during the maintenance condition without any conferencing. During baseline, the group mean percentage of spelling homework completion was $65.18 \%$ (range 0-100\%). After self-monitoring with daily conferencing was introduced, the mean spelling homework completion rate increased to $93.12 \%$ with a (range $70-100 \%$ ). This represents a mean increase of $27.94 \%$ of spelling homework completed from baseline to Phase I of the self-monitoring intervention. When self-monitoring with daily conferencing was reduced to twice a week, the group's mean spelling homework completion continued to increase with a mean performance of $95.43 \%$ (range $80-100 \%$ ). When self-monitoring with daily conferencing was reduced to once a week, the group's mean spelling homework completion increased further to a mean of $97.17 \%$ (range $90-100 \%)$.

During the maintenance condition, the group mean on spelling homework completion decreased slightly to $96.80 \%$ (range $85-100 \%$ ). Spelling homework 
completion was greatest during weekly conferencing in Phase III with a mean increase of $31.99 \%$ over baseline (Table 2).

Table 3 displays group means for spelling homework accuracy performance during baseline, self-monitoring with daily conferencing, twice-weekly conferencing, once-weekly conferencing, and during the maintenance condition without any conferencing. During baseline, the group mean percentage of spelling homework accuracy was $46.31 \%$ (range $0-80 \%$ ). After self-monitoring with daily conferencing was introduced, the mean spelling homework accuracy rate increased to $84.87 \%$ with a (range $70-100 \%$ ). This represents a mean increase of $38.56 \%$ of spelling homework accuracy rate from baseline to Phase I of the self-monitoring intervention. When self-monitoring with daily conferencing was reduced to twice a week, the group mean spelling homework accuracy continued to increase with a mean performance of $87.30 \%$ (range $70-95 \%$ ). When self-monitoring with conferencing was reduced to once a week, the group mean spelling homework accuracy increased further to a mean of $89.68 \%$ (range $80-100 \%$ ).

During the maintenance condition, the group mean on spelling homework accuracy continued to increase to $91.20 \%$ (range $80-100 \%$ ). Spelling homework accuracy was greatest during maintenance condition with a mean increase of $44.89 \%$ over baseline (Table 3).

\section{Math Homework Completion and Accuracy}

This study was also conducted to examine the effects of self-monitoring on the completion and accuracy of the math homework given Mondays through Thursdays of students with disabilities in an inclusive, general education classroom. Completion was measured by the number of answers provided divided by the number of possible answers 
including name, date and heading if applicable. Accuracy was defined by the number of correct answers given divided by the number of possible correct answers for the daily math homework assignments.

Daily homework completion and accuracy percentage data are visually presented in a multiple baseline figure. Also, presented in tables are individual and group means and range data across baseline and the three phases of the self-monitoring condition (daily conferencing, twice-weekly conferencing, weekly conferencing). Also, presented are individual and group means and range maintenance data (when no conferencing occurred) compared to the mean math completion and accuracy performance during the last phase of the intervention.

Maintenance mean scores were compared to the mean performance of math completion and accuracy during the intervention. During maintenance, participants no longer had access to their daily self-monitoring sheet used during the intervention at home nor were there individual conferences with the researcher. However, if they chose to, they were able to continue to self-monitor on the computer using KidTools, but there was no conference meeting with the researcher to review their self-monitoring sheet, they just turned it into the researcher. The maintenance condition was conducted after the final phase of self-monitoring following the last intervention day for each participant.

\section{Samantha}

Figure 2 and Tables 4 and 5 display Samantha's math homework completion and accuracy performances during baseline, and the three phases of the self-monitoring condition (daily conferencing, twice-weekly conferencing, once-weekly conferencing) and during the maintenance condition with no conferencing. During baseline, Samantha's 
mean math homework completion was 74\% (range 70-80\%). After self-monitoring with daily conferencing was introduced, Samantha's mean math homework completion increased to $95.26 \%$ (range $90-100 \%$ ). This represents a mean increase of $21.26 \%$ of math homework completed from baseline to Phase I of the self-monitoring intervention.

Table 4

Individual and Group Means and Ranges in Percentages on Math Homework Completion

\begin{tabular}{lccccc}
\hline Participant & Baseline & $\begin{array}{c}\text { Self-Monitoring: } \\
\text { daily } \\
\text { conferencing }\end{array}$ & $\begin{array}{c}\text { Self-monitoring: } \\
\text { twice-weekly } \\
\text { conferencing }\end{array}$ & $\begin{array}{c}\text { Self-monitoring: } \\
\text { weekly } \\
\text { conferencing }\end{array}$ & Maintenance \\
\hline Samantha & 74.0 & 95.26 & 99.25 & 100 & 99.28 \\
& $(70-80)$ & $(90-100)$ & $(95-100)$ & $(100-100)$ & $(90-100)$ \\
Rio & 100 & 99.52 & 97.0 & 96.15 & 97.08 \\
& $(100-100)$ & $(95-100)$ & $(90-100)$ & $(90-100)$ & $(90-100)$ \\
Mike & 55.0 & 89.66 & 96.87 & $95-0$ & 98.12 \\
& $(0-75)$ & $(80-100)$ & $(90-100)$ & $(90-100)$ & $(95-100)$ \\
Brandy & 64.0 & 85.33 & 88.57 & 90.0 & 91.87 \\
& $(0-100)$ & $(80-100)$ & $(80-100)$ & $(80-100)$ & $(85-100)$ \\
Group & 73.25 & 92.44 & 95.42 & 95.28 & 96.58 \\
& $(0-80)$ & $(70-100)$ & $(80-100)$ & $(80-100)$ & $(85-100)$ \\
\hline
\end{tabular}

Note. Top numbers indicate mean of math homework completion.

Bottom numbers represent the range of scores.

When self-monitoring with daily conferencing was reduced to twice a week, Samantha's mean math homework completion continued to increase with a mean performance of $99.25 \%$ (range $95-100 \%$ ). When self-monitoring with conferencing was reduced to once a week, Samantha's mean math homework completion increased further to a mean of $100 \%$ (range $100-100 \%)$. 


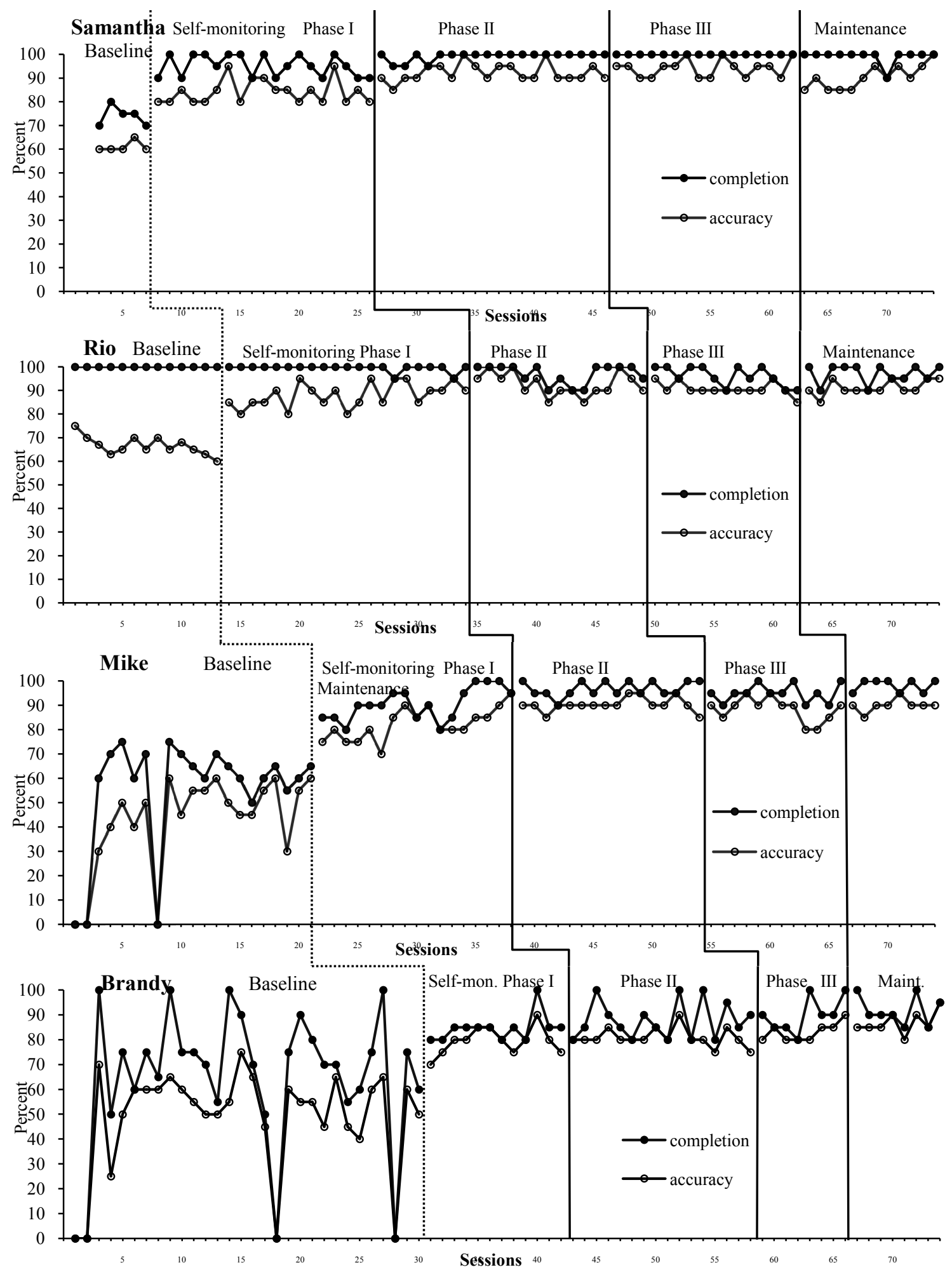

Figure 2. Math homework percentage complete and correct. 
During the maintenance condition, Samantha's mean math homework completion remained at the high rate, but decreased slightly to $99.28 \%$ (range $90-100 \%$ ). Math homework completion was greatest, during the self-monitoring with weekly conferencing and remained high during maintenance, with a mean increase of $25.28 \%$ percent over baseline (see Figure $1 \&$ Table 2).

Table 5

Individual and Group Means and Ranges in Percentages on Math Homework Accuracy

\begin{tabular}{lccccc}
\hline Participant & Baseline & $\begin{array}{c}\text { Self-Monitoring: } \\
\text { daily } \\
\text { conferencing }\end{array}$ & $\begin{array}{c}\text { Self-monitoring: } \\
\text { twice-weekly } \\
\text { conferencing }\end{array}$ & $\begin{array}{c}\text { Self-monitoring: } \\
\text { weekly } \\
\text { conferencing }\end{array}$ & Maintenance \\
\hline Samantha & 61.0 & 84.21 & 92.25 & 94.06 & 91.07 \\
& $(60-65)$ & $(80-95)$ & $(85-100)$ & $(90-100)$ & $(85-100)$ \\
Rio & 66.61 & 88.09 & 92.66 & 90.76 & 91.25 \\
& $(60-75)$ & $(80-95)$ & $(85-100)$ & $(85-95)$ & $(85-95)$ \\
Mike & 42.14 & 82.35 & 90.31 & 88.33 & 90.0 \\
& $(0-60)$ & $(70-95)$ & $(85-95)$ & $(80-95)$ & $(85-95)$ \\
Brandy & 48.16 & 79.66 & 81.07 & 83.12 & 86.87 \\
& $(0-75)$ & $(70-85)$ & $(75-90)$ & $(80-90)$ & $(85-95)$ \\
& & & & & \\
Group & 54.47 & 83.57 & 89.07 & 89.06 & 89.79 \\
& $(0-75)$ & $(70-95)$ & $(75-100)$ & $(80-100)$ & $(85-100)$ \\
\hline
\end{tabular}

Note. Top numbers indicate mean of math homework accuracy.

Bottom numbers represent the range of scores.

With respect to math homework accuracy performance during baseline, Samantha's mean math homework accuracy was 61\% (range 60-65\%). After selfmonitoring with daily conferencing was introduced, Samantha's mean math homework accuracy increased to $84.21 \%$ (range $80-95 \%$ ). This represents a mean increase of $23.21 \%$ of math homework completed from baseline to Phase I of the self-monitoring intervention. When self-monitoring with daily conferencing was reduced to twice a week, 
Samantha's mean math homework accuracy continued to increase with a mean performance of $92.25 \%$ (range $85-100 \%$ ). When self-monitoring with conferencing was reduced to once a week, Samantha's mean math homework accuracy increased further to a mean of $94.06 \%$ (range $90-100 \%)$.

During the maintenance condition, Samantha's mean math homework accuracy decreased to $91.07 \%$ (range $85-100 \%$ ). Math homework accuracy was greatest, during the self-monitoring intervention with weekly conferencing, with a mean increase of $33.06 \%$ over baseline (see Figure $1 \&$ Table 2).

Samantha was in maintenance for 3 weeks. Her math homework completion rate was $25.28 \%$ higher during maintenance than baseline (see Figure $1 \&$ Table 2). Compared to baseline, Samantha's math homework accuracy rate was $30.07 \%$ higher during maintenance (see Figure $1 \&$ Table 2).

\section{Rio}

Figure 2 and Tables 4 and 5 display Rio's math homework completion and accuracy performances during baseline, and the three phases of the self-monitoring condition (daily conferencing, twice-weekly conferencing, once-weekly conferencing) and during the maintenance condition with no conferencing. During baseline, Rio's mean math homework completion was $100 \%$ (range 100-100\%). After self-monitoring with daily conferencing was introduced, Rio's mean math homework completion slightly decreased to $99.52 \%$ (range $95-100 \%$ ). This represents a slight mean decrease of $.48 \%$ of math homework completed from baseline to Phase I of the self-monitoring intervention. When self-monitoring with daily conferencing was reduced to twice a week, Rio's mean math homework completion continued to decrease with a mean performance of $97 \%$ 
(range 90-100). When self-monitoring with conferencing was reduced to once a week, Rio's mean math homework completion decreased even more to a mean of $96.15 \%$ (range 90-100\%).

During the maintenance condition, Rio's mean math homework completion remained at a high rate of $97.08 \%$ (range 90-100\%). Math homework completion was greatest during baseline and during the self-monitoring with daily conferencing, but remained high during maintenance, even though there was a slight mean decrease of $.48 \%$ percent over baseline (see Figure $1 \&$ Table 2 ).

With respect to math homework accuracy performance during baseline during baseline, Rio’s mean math homework accuracy was 66.61\% (range 60-75\%). After selfmonitoring with daily conferencing was introduced, Rio's mean math homework accuracy increased to $88.08 \%$ (range $80-95 \%$ ). This represents a mean increase of $21.48 \%$ of math homework completed from baseline to Phase I of the self-monitoring intervention. When self-monitoring with daily conferencing was reduced to twice a week, Rio's mean math homework accuracy continued to increase with a mean performance of $92.66 \%$ (range 85-100). When self-monitoring with conferencing was reduced to once a week, Rio's mean math homework accuracy decreased slightly to a mean of $90.76 \%$ (range 85-95\%).

During the maintenance condition, Rio's mean math homework accuracy increased slightly to $91.25 \%$ (range $85-95 \%$ ). Math homework accuracy was greatest, during the self-monitoring intervention with twice-weekly conferencing, with a mean increase of $26.05 \%$ over baseline (see Figure $1 \&$ Table 2 ). 
Rio was in maintenance for 3 weeks. His math homework completion rate was $2.92 \%$ lower during maintenance than in baseline (see Figure $1 \&$ Table 2). Compared to baseline, Rio's math homework accuracy rate was $24.64 \%$ higher during maintenance (see Figure $1 \&$ Table 2).

\section{Mike}

Figure 2 and Tables 4 and 5 display Mike's math homework completion and accuracy performances during baseline, and the three phases of the self-monitoring condition (daily conferencing, twice-weekly conferencing, once-weekly conferencing) and during the maintenance condition with no conferencing. During baseline, Mike's mean math homework completion was 55\% (range 0-75\%). After self-monitoring with daily conferencing was introduced, Mike's mean math homework completion increased to $89.66 \%$ (range $80-100 \%$ ). This represents a mean increase of $44.49 \%$ of math homework completed from baseline to Phase I of the self-monitoring intervention. When self-monitoring with daily conferencing was reduced to twice a week, Mike's mean math homework completion continued to increase with a mean performance of $96.87 \%$ (range 90-100\%). When self-monitoring with conferencing was reduced to once a week, Mike's mean math homework completion slightly decreased to a mean of $95 \%$ (range $90-100 \%$ ).

During the maintenance condition, Mike's mean math homework completion increased to a high rate of $98.12 \%$ (range $95-100 \%$ ). Math homework completion was greatest, during the maintenance condition, with a mean increase of $43.12 \%$ over baseline (see Figure $1 \&$ Table 2).

With respect to math homework accuracy performance during baseline, Mike's mean math homework accuracy was $42.14 \%$ (range $0-60 \%$ ). After self-monitoring with 
daily conferencing was introduced, Mike's mean math homework accuracy increased to $82.35 \%$ (range $70-95 \%$ ). This represents a mean increase of $40.21 \%$ of math homework accuracy from baseline to Phase I of the self-monitoring intervention. When selfmonitoring with daily conferencing was reduced to twice a week, Mike's mean math homework accuracy continued to increase with a mean performance of $90.31 \%$ (range $85-95 \%)$. When self-monitoring with conferencing was reduced to once a week, Mike's mean math homework accuracy slightly decreased to a mean of $88.33 \%$ (range $80-95 \%$ ).

During the maintenance condition, Mike's mean math homework accuracy increased slightly to $90 \%$ (range $85-95 \%$ ). Math homework accuracy was greatest, but

only minimally, during the self-monitoring intervention with twice-weekly conferencing, with a mean increase of $48.17 \%$ over baseline (see Figure $1 \&$ Table 2).

Mike was in maintenance for 2 weeks. His math homework completion rate was 43.12\% higher during maintenance than baseline (see Figure $1 \&$ Table 2). Compared to baseline, Mike's math homework accuracy rate was $47.86 \%$ higher during maintenance (see Figure $1 \&$ Table 2).

\section{Brandy}

Figure 2 and Tables 4 and 5 display Brandy's math homework completion and accuracy performances during baseline, and the three phases of the self-monitoring condition (daily conferencing, twice-weekly conferencing, once-weekly conferencing), and during the maintenance condition with no conferencing. During baseline, Brandy's mean math homework completion was $64 \%$ (range $0-100 \%$ ). After self-monitoring with daily conferencing was introduced, Brandy's mean math homework completion increased to $85.33 \%$ (range $80-100 \%$ ). This represents a mean increase of $21.33 \%$ of math 
homework completed from baseline to Phase I of the self-monitoring intervention. When self-monitoring with daily conferencing was reduced to twice a week, Brandy's mean math homework completion increased with a mean performance of $88.57 \%$ (range 80 100). When self-monitoring with conferencing was reduced to once a week, Brandy's mean math homework completion continued to increase slightly to a mean of $90 \%$ (range $80-100 \%)$.

During the maintenance condition, Brandy's mean math homework completion continued to a high rate of $91.87 \%$ (range $85-100 \%$ ). Math homework completion was greatest, during maintenance, with a mean increase of $27.87 \%$ percent over baseline (see Figure $1 \&$ Table 2).

With respect to math homework accuracy performance during baseline, Brandy's mean math homework accuracy was $48.16 \%$ (range $0-75 \%$ ). After self-monitoring with daily conferencing was introduced, Brandy's mean math homework accuracy increased to $79.66 \%$ (range $70-85 \%$ ). This represents a mean increase of $31.5 \%$ of math homework completed from baseline to Phase I of the self-monitoring intervention. When selfmonitoring with daily conferencing was reduced to twice a week, Brandy's mean math homework accuracy continued to increase with a mean performance of $81.07 \%$ (range 75-90\%). When self-monitoring with conferencing was reduced to once a week, Brandy's mean math homework accuracy increased further to a mean of $83.12 \%$ (range $80-90 \%$ ).

During the maintenance condition, Brandy's mean math homework accuracy continued to increase to $86.87 \%$ (range $85-95 \%$ ). Math homework accuracy was greatest during baseline with a mean increase of $38.71 \%$ over baseline (see Figure $1 \&$ Table 2). 
Brandy was in maintenance for 2 weeks. Her math homework completion rate was $38.71 \%$ higher during maintenance than baseline (see Figure $1 \&$ Table 2). Compared to baseline, Brandy's math homework accuracy rate was $38.71 \%$ higher during maintenance (see Figure $1 \&$ Table 2).

\section{Group}

Table 4 displays group means for math homework completion performance during baseline, self-monitoring with daily conferencing, twice-weekly conferencing, once-weekly conferencing, and during the maintenance condition without any conferencing. During baseline, the group mean percentage of math homework completion was $73.25 \%$ (range $0-100 \%$ ). After self-monitoring with daily conferencing was introduced, the group mean math homework completion rate increased to $92.44 \%$ with a (range $70-100 \%$ ). This represents a mean increase of $19.19 \%$ of math homework completed from baseline to Phase I of the self-monitoring intervention. When selfmonitoring with daily conferencing was reduced to twice a week, the group mean math homework completion continued to increase with a mean performance of $95.42 \%$ (range $80-100 \%)$. When self-monitoring with conferencing was reduced to once a week, the group mean math homework completion decreased slightly to a mean of $95.28 \%$ (range $80-100 \%)$.

During the maintenance condition, the groups mean on math homework completion increased to $96.58 \%$ (range $85-100 \%$ ). Math homework completion was greatest during the maintenance condition with a mean increase of $23.33 \%$ over baseline (see Table 4). 
Table 5 displays group means for math homework accuracy performance during baseline, self-monitoring with daily conferencing, twice-weekly conferencing, onceweekly conferencing, and during the maintenance condition without any conferencing. During baseline, the group mean percentage of math homework accuracy was $54.47 \%$ (range $0-75 \%$ ). After self-monitoring with daily conferencing was introduced, the mean math homework accuracy rate increased to $83.57 \%$ with a (range $70-95 \%)$. This represents a mean increase of $29.1 \%$ of math homework accuracy rate from baseline to Phase I of the self-monitoring intervention. When self-monitoring with daily conferencing was reduced to twice a week, the group's mean math homework accuracy continued to increase with a mean performance of $89.07 \%$ (range $75-100 \%$ ). When selfmonitoring with conferencing was reduced to once a week, the group's mean math homework accuracy decreased slightly to a mean of $89.06 \%$ (range $80-100 \%$ ).

During the maintenance condition, the groups mean on math homework accuracy increased to $89.79 \%$ (range $85-100 \%$ ). Math homework accuracy was greatest during maintenance condition with a mean increase of $35.32 \%$ over baseline (see Table 5).

\section{Social Validity Questionnaires}

Participants and parents were both given similar social validity questionnaires (see Appendix H and I) after the last of the maintenance data were collected. According to the questionnaire, all four of the participants found self-monitoring helpful in completing their spelling and math homework. Additionally, all participants considered the procedure to be easy to accomplish. Interestingly, each participant liked the selfmonitoring for different reasons. One participant enjoyed the computer aspect, while another appreciated his improved grades and family approval; a third took pleasure in the 
attention from others; and one participant liked the individual conferencing. When asked if they would continue to self-monitor, three of the four indicated that they would, and one explained it depended on his grades next year and that he may not need it. The final question asked what changes they would make with the self-monitoring. Two would like to compete with other children in the class, one would like stickers added to the chart, and one would like to be paid or maybe have extra computer time for improved grades.

Parents had similar responses to a questionnaire. All four parents agreed that the self-monitoring was helpful for their child. One said it assisted her daughter in keeping track of what to do, one noticed it kept her son from being anxious, another appreciated that she did not have to nag her son anymore, and one was just happy to have any assistance. All four thought it was easy to help implement. Equally, all four would support further use of self-monitoring. Finally, none of the four parents offered any suggestions about changing the self-monitoring, but two mentioned implementing rewards at home.

\section{Chapter Summary}

The results of this study signify that the participants enhanced their spelling and math homework completion and accuracy rates using self-monitoring techniques. Individual means for the self-monitoring intervention at each phase, as well as maintenance consistently remained higher than the individual baseline means. For spelling completion, the individual baseline percentage was as much as $44 \%$ lower than in Phase III self-monitoring. Also, the variability in the range of performance decreased substantially. Similarly, for spelling accuracy, individual Phase III self-monitoring 
percentages were up to $55 \%$ higher than in baseline and the variability in the range decreased substantially.

For math completion, individual Phase III self-monitoring percentages were up to $40 \%$ higher than in baseline. Also, the variability in the range of performance decreased by $80 \%$. Similarly, for math accuracy, individual Phase III self-monitoring scores were up to $46 \%$ higher compared to baseline. The range decreased by $50 \%$ as well. Further, during maintenance the mean percentage rates across all phases, all participants and dependent variables was still higher than the comparison score taken on the last day of intervention.

Maintenance data for each of the dependent variables demonstrated that the maintenance means remained above the mean levels of baseline across all participants and phases. When compared to baseline, participants' accuracy rates were highest on math homework assignments in maintenance. Further, participants completed more math homework assignments during maintenance than in any other phase. On average, participants succeeded in self-monitoring with only one conference per week as well as during maintenance. 


\section{CHAPTER V \\ DISCUSSION}

This chapter provides a discussion on the results of this study. A brief study overview is followed by a summary of the results with respect to relevant literature on self-monitoring. Delimitations and limitations of this study, as well as implications for practice and suggestions for future research are also included.

This study utilized a multiple baseline across subjects design to investigate the effects of self-monitoring on the completion and accuracy rates of spelling and math homework for students with disabilities who are educated in an inclusive, general education classroom. The participants were four, fourth-graders with various disabilities (e.g., SLD, OHI, LI). Data were collected and analyzed on baseline, self-monitoring intervention sessions across three phases (daily conferencing, twice-weekly conferencing, weekly conferencing), and maintenance sessions on the dependent variables: spelling homework completion and accuracy, math homework completion and accuracy. Maintenance data on spelling and math homework completion and accuracy were taken over a 2- to 3-week period after the end of the implementation of the intervention.

Although outcomes varied for individual participants, overall the results demonstrated that self-monitoring had a positive influence on participants' rates of spelling and math homework completion and accuracy. Mean percentages of homework completion and accuracy were higher for three participants in all three self-monitoring intervention phases than during baseline. However, Rio had a math completion rate of $100 \%$, so there was no improvement to be made. Additionally, the maintenance data of homework completion and accuracy show that all participant scores consistently 
remained well above their baseline levels. During baseline, participants followed their normal classroom homework routine as discussed earlier. The self-monitoring interventions involved 3 components of self-monitoring including home, computer program and individual conferencing which varied throughout the phases. The results of this study support the literature that consistently demonstrates the effectiveness of selfmonitoring on a multitude of school and home behaviors (e.g. Bryan \& Burstein, 2004; Cooper et al., 2005; Freeman \& Dexter-Mazza, 2004). A detailed analysis of the results for each dependent variable, along with comparisons to previous research follows.

\section{Spelling and Math Homework Completion}

For the current study, all four participants demonstrated substantial improvements in their spelling and math homework completion in each phase of the self-monitoring condition compared to baseline. There are a number of more than notable results for all data. For instance, during Phase III of the spelling completion intervention, which only included random once-a-week conferencing, Samantha, Rio, Mike, and Brandy produced a mean of $24 \%, 43.97 \%, 19.15 \%$, and $40.87 \%$ higher rates respectively compared to baseline. In addition, self-monitoring of math homework completion also led to a marked improvement during each phase of the self-monitoring condition compared to baseline for three of the participants, and decreased only slightly for one participant. Samantha, Mike, and Brandy increased their math homework completion by $26 \%, 40 \%$ and $22.03 \%$ higher respectively from baseline compared to self-monitoring intervention Phase III with random once-a-week monitoring. One participant, Rio, decreased his rate of math homework completion rates from baseline to Phase III of self-monitoring by $3.85 \%$, but still maintained a high average of $97.08 \%$. His baseline completion rate was maintained 
at $100 \%$, so it could not have increased. Since his accuracy rate increased substantially, his slight decrease in completion rate was not a concern, as during baseline he already was completing a $100 \%$ of his homework, which created a ceiling effect, so there was no way to increase his completion rate.

Overall, maintenance scores showed variability among all four participants. However, the participants had a higher percentage of spelling and math homework completion during maintenance than they did during baseline (except for Rios' math completion, as previously discussed). Notably, Samantha's and Mike's completion of spelling homework assignments were in the 70th percentiles during baseline and increased into the 90th percentiles and above during maintenance. Rio and Brandy each had means in the 50th percentiles which also increased into the 90th percentiles during maintenance. Given overall performance improvements in spelling and math homework completion, the data demonstrated that self-monitoring had a positive effect on the ability of students with disabilities included in general education to complete spelling and math homework more effectively. Furthermore, those improvements were maintained once the intervention was removed.

The results of the current study support several previous studies that found selfmonitoring of homework to be beneficial. Both the Trammel et al. (1994) and Fish and Mendola (1986) studies were successful in teaching students with disabilities to selfmonitor their homework. Similar to the current study, the results from Fish and Mendola (1986) demonstrated a considerable improvement in the rate of homework completion from baseline to intervention (baseline, $25-50 \%$ to intervention $75-100 \%$ ). The Trammel et al. (1994) study showed marked increases in homework completion rates. From a mean 
of two completed assignments during baseline to five completed assignments during the self-monitoring intervention.

The results of this study also supports the successful outcome of the work of Toney et al. (2003), who compared self- and parent-monitoring of homework completion in order to reduce homework-related problems in middle school students. In addition, the results of this study provide further support to the investigation by Glomb and West (1990), who taught self-instruction and self-evaluation skills on neatness, accuracy, and completeness of creative writing homework assignments to middle school students with learning and behavior problems. The results of their study showed substantial improvements from baseline and intervention for both participants on all three components.

However, the results of this study did not lend support to the work of Minzner (2003), who used self-monitoring to measure the homework completion rates and academic grades of high school participants with LD. Overall, the completion rates for the participants did not improve with the initiation of the self-monitoring. Although the intervention seems to have lowered the percentages of homework completion, the researcher deemed the study's results as inconclusive. This may be due to inappropriate referrals of students who were already performing well on homework completion, which resulted in a ceiling effect.

The current study extends the previous literature on self-monitoring in numerous ways. First, it incorporates the effects of self-monitoring by investigating the rates of spelling and math homework completion and accuracy for students with disabilities who are educated in an inclusive general education classroom. Prior to this study, no studies 
were found that included participants with disabilities included full-time in general elementary school education classes. Second, the participants to keep track of their homework, as part of the intervention, used technology in the form of a simple online computer program. Only one other study was found that utilized technology as part of the self-monitoring and the technology was in the form of a hand-held device, not an online computer program. Finally, this study implemented a three-phase intervention system in which the individual conferencing sessions were reduced from daily, to twice weekly, then once a week, and finally, to none at all. No other study was found that reduced the frequency of the teacher-participant interactions during the intervention phases.

In summary, the results suggest that for students with disabilities included in general education classes, self-monitoring should be considered as a strategy to increase spelling and math homework completion. While self-monitoring led to higher percentages of spelling and math homework completion during the intervention compared to baseline, the group percentages also rose slightly during maintenance. Therefore, the results also suggest that self-monitoring leads to maintenance in spelling and math homework completion once the intervention concludes. While self-monitoring greatly improved spelling and math homework completion rates for the participants, previous studies did not investigate its effects with students with disabilities in general education classes. The results of this study should be viewed in this context.

\section{Spelling and Math Homework Accuracy}

With some variation, all four participants attained remarkable improvements of spelling and math homework accuracy during each phase of the self-monitoring condition than during baseline. More specifically, Samantha, Rio, Mike, and Brandy produced a 
mean of $33.81 \%, 55.93 \%, 39.29 \%$, and $44.46 \%$ higher rates respectively in Phase III intervention with random once-a-week conferencing on spelling homework accuracy than in baseline. All four participants' mean baseline data were too low to be considered passing grades for spelling homework accuracy. During Phase III of the intervention and continuing in maintenance, scores rose to well above average for all four participants. Rio's baseline spelling homework accuracy was exceptionally low; his increase in spelling accuracy was so substantial that it completely altered his grade in spelling.

These results support the work of Bryan and Sullivan-Burnstien (1998) who studied the use of homework planners and completion graphs in spelling and math homework grades in first- through fourth-grade classrooms with students with disabilities. Immediate improvements in homework achievement were reported in the Bryan and Sullivan-Burnstein study, where participants with learning disabilities and homework problems scored $96 \%$ during the intervention, up 32\% from baseline. In the present study, participants spelling homework was more accurate when self-monitoring was introduced and practiced, with a group mean score of $43.37 \%$ over baseline in Phase III. This is substantial since there was only one conference per week with each participant during this phase, which made the intervention more independent. Similarly, in 2003, Barry and Messer (2003) investigated the effects of self-monitoring by five, sixth-grade, general education male participants with ADHD. During baseline data collection for academic performance, the range across participants for complete and correct assignments was $25-80 \%$; self-monitoring significantly raised the numbers to $65-100 \%$ across participants. 
Maintenance scores for spelling homework accuracy in the current study presented variability among all four participants. All four, however, obtained means of more than $33 \%$ gains during maintenance compared to baseline. Mike had the highest maintenance scores, as well as significant gains from baseline from $50.7 \%$ to $92.5 \%$ in maintenance. On the other hand, Brandy's spelling homework accuracy maintenance scores were the lowest at $88.75 \%$, but her mean percentage of spelling accuracy was still 44.89\% higher than baseline.

During the self-monitoring of math homework accuracy intervention, all four participants acquired higher percentages of math homework accuracy during each phase of the self-monitoring condition than during baseline. Samantha, Rio, Mike, and Brandy increased their math homework accuracy by $33.06 \%, 24.15 \%, 46.19 \%$ and $34.96 \%$ respectively from baseline when compared to self-monitoring intervention in Phase III.

For math homework accuracy, three of the four participants had higher percentage rates during maintenance than during the intervention phases. Brandy obtained the lowest percentage during maintenance at $89.79 \%$, but was still a substantial increase from her baseline of $48.16 \%$. The highest percentage of math homework accuracy maintained was by Rio at $91.25 \%$, which was also a noteworthy increase from his $66.61 \%$ baseline percentage. Although, maintenance scores displayed some variability, Brandy demonstrated a higher percentage during maintenance than the other phases. Brandy's rates of math homework accuracy continued to increase from the first day of the intervention, but remained highest during maintenance. However, the average maintenance scores indicated a very slight reduction in accuracy rates across the other three participants. 
This study was on par with Cancio et al. (2004), who assessed treatment effects of self-monitoring math homework completion and accuracy on participants with Emotional Behavioral Disorders, ages 11 to 15 years. The average baseline level across subjects for assignment completion and accuracy in their study increased substantially for both participants. Also, the results of the current study are similar to Olympia et al. (1994b) who investigated the effectiveness of self-management on improving the completion and accuracy rates of math homework assignments with sixth graders. The participants of that study averaged an overall increase of $33.5 \%$ in the number of math homework assignments completed and an increase of over $10 \%$ for accuracy.

The results of the current study indicate that for these four participants, selfmonitoring led to an increase in the accuracy of spelling and math homework assignments. Taken judiciously, results of this study suggest that self-monitoring leads to improvements in accuracy of spelling and math homework, and short-term maintenance once the intervention concludes. Subsequently, self-monitoring should be considered as a strategy to increase spelling and math homework accuracy. However, no other study was found that examined the effects of self-monitoring on the spelling and math homework accuracy of students with disabilities educated in general education classrooms. Subsequently, the results of this study should be interpreted as preliminary.

\section{Self-Monitoring Summary}

Overall, the results of this study lend further support to the limited research that has demonstrated that self-monitoring has a positive impact on the homework completion and accuracy rates of students with disabilities in an inclusive general education classroom. In this study, when self-monitoring was implemented, participants typically 
increased their spelling and math homework completion and accuracy rates during each phase of the intervention. Even as the time with the researcher decreased, percentage rates continued to increase. Additionally, participants were able to maintain much higher rates in spelling and math homework completion and accuracy during maintenance than in baseline. These continued improved performances with reduced researcher attention and during maintenance is likely due to the naturally existing contingencies of reinforcement, such as positive teacher attention and better grades on homework, maintaining the improved performances. In other words, the typical reinforcers that likely maintain homework performances were now maintaining the participants' performances. The results of this study support the existing literature (e.g., Cancio et al.; Olympia et al., 1994b; Toney et al., 2003) which suggests that a self-monitoring intervention has positive outcomes on homework completion and accuracy rates for students with disabilities. No previous research was found that specifically targeted students with disabilities included full-time in general elementary school education classrooms.

The current study added to the literature by providing an analysis of three phases of the self-monitoring condition with students with disabilities in general education in which teacher involvement in the intervention was decreased throughout the phases. Previous research on self-monitoring has been conducted with general education students in higher grades, different subjects, and on students with disabilities in self-contained classrooms (e.g., Cooper et al., 2007; Tam et al., 2006). This study extends the literature in that it examined the effects of self-monitoring on spelling and math homework completion and accuracy, and it further extends the literature by utilizing technology at school, as well as individual conferencing. 


\section{Implications for Practice}

The results of this study have potentially important implications for classroom practice, particularly in the inclusive educational settings. The results suggest that selfmonitoring can be an effective tool for teachers to employ with their students with disabilities or other students in need of additional assistance with homework. Furthermore, it is highly cost efficient and simple for teachers to implement and can be performed anytime and anywhere with little to no assistance necessary. Teachers may execute this method with one student, a small group of students, or the entire class. At home, the participants reviewed their sheet on their own and then had a parent initial it. Parents can also be taught to participate in the self-monitoring procedures with their children at home, including the technology-based component. Once a student learns how to navigate the computer program on his or her own, it is relatively an independent task.

Previous research has shown that students with disabilities benefit from selfmonitoring interventions which actively engage the participant in improving their own behaviors (e.g., Blick \& Test, 1987) and increases their investment in the process (e.g., Lee et al., 2009, Zlomke \& Zlomke, 2003). The results of this study may also have implications for teaching students with disabilities strategies for homework management. This study used brief daily conferencing sessions in which gains in spelling and math homework completion and accuracy were immediately noted when the self-monitoring condition was introduced. Although, there was a self-monitoring component at home, as well as at school throughout the phases, during maintenance only the school piece was in place and the participants continued to perform at high rates. Subsequently, teachers may want to assign solely the KidTools component of the self-monitoring to allow for more 
student independence and responsibility and less teacher required time during the school day. Also, as self-monitoring has been shown to foster self-comparisons rather than comparisons with other students, which may promote intrinsic motivation and defuse competition (Freeman \& Dexter-Mazza, 2004), teachers may encourage students to chart their own homework completion and accuracy rates to see their progress for themselves.

Further, self-monitoring may promote communication between teachers, parents, and children and can be utilized in all academic areas and settings. The current study used an intervention method that encompassed those fundamentals resulting in improved spelling and math homework completion and accuracy rates across intervention phases and maintenance for students with disabilities in general education classes. Additionally, these results further maintain the necessity for structured research based interventions to be used with students who are struggling with homework in general and students with disabilities in particular.

\section{Delimitations}

The sample size used in single subject design research is small by the nature of the design and therefore limits the generalization of its findings. In order to further determine the effects of self-monitoring on the rates of spelling and math homework completion and accuracy for students with disabilities who are education in a general education classroom, direct and systematic replications are needed. For example, this study included only fourth-grade students with disabilities from one general education classroom. Therefore, the results may not be generalized to participants at other grade levels, or with other abilities or disabilities or those educated in other types of classrooms. The present study was limited to only spelling and math homework, so 
results may not be generalized to other homework subjects such as science or social studies. Further, if a student did not understand the homework, it is possible that his or her participation was negatively impacted. While all assignments were of the same grade level and ability, each had a variety of topics that may or may not have been fully understood by the participants. This being said, no participant expressed any confusion about any of the assignments given to them.

An additional delimitation was that participants in this study were participating during the course of a normal school day. Participants were pulled from their classrooms to have conference meetings with the investigator who was their special education inclusion teacher. Each participant met at the same time for every conference, but this may have occurred at times when the students either wanted to or did not want to leave the classroom. Although no participant ever verbalized feelings of not wanting to participate in the conference, no data were collected on this. This may have had effects on the participants' level of performance. Lastly, this study did not investigate the effects of self-monitoring spelling and math homework completion and accuracy without any parent support or assistance, therefore, the impact of their participation is unknown. However, during maintenance when there was no parent involvement or conferencing, the participants still performed well above baseline levels. Since the study only investigated the effects of spelling and math homework completion and accuracy, the results may not be generalized to other forms of homework.

\section{Limitations}

Several study limitations in this investigation should be noted. Though participants met with the researcher prior to the start of the study, both the self- 
monitoring and conferencing with the researcher during the day were novel to all four participants. Given this, it may have taken some time for the participants to become comfortable with the new situation. Also, the additional adult attention, by both the researcher and the parent, required by the intervention may have positively or negatively impacted the results. Further, although there was a thorough review of the data, time constraints needed to be taken into consideration in determining when to implement some of the phases of the self-monitoring condition with specific participants. Specifically, Brandy only had 8 days of the self-monitoring Phase III intervention with weekly conferencing. Had time not been a factor, Brandy's intervention phase may have been extended until more stability was observed. While Brandy's limited exposure to the Phase III self-monitoring intervention may be a limitation to the study, her prolonged baseline phase, as well as her adequate time in Phase I with daily conferencing and Phase II with twice weekly conferencing actually demonstrates the strength of the intervention. Brandy's performance in baseline was continuously unstable, even though she was required to complete spelling and math homework and hand it in each day to the classroom teacher. Although, Brandy's performance remained unstable with daily conferencing in Phase I of the intervention, the variability decreased substantially from baseline. Also, maintenance data in this study were collected for a fairly short period of time due to end of the school year. Subsequently, it is unknown how long the positive effects may have lasted.

Another factor that needs discussion is the lack of a stable baseline for most participants prior to intervening. Usually the greater stability in the baseline condition promotes greater confidence that changes in responding are due to the application of the 
intervention. However, for this study participants were chosen specifically due to their inconsistency in completing or turning in homework. So the lack of stability in the baseline is not that surprising. Therefore, the researcher began the self-monitoring when it seemed appropriate. Subsequently, the intervention produced almost immediate and substantial changes in the stability of the data trend for each participant.

A few other issues need to be addressed in this study. This study did not have a specific procedure for whether or not the participants had their homework selfmonitoring sheet signed by a parent. Some days the parents signed the sheet, while other days they did not. Each participant met with the researcher regardless of whether his or her sheet was signed by a parent. The participants all brought their sheets back to school each day; but again, there was no procedure in place for what would happen if they did not return it. Subsequently, no data were collected on this. Also, due to the end of the school year, time constraints required the maintenance period in this study to be shorter than desired.

Another limitation of this study is that there were no procedures in place if the participants did not complete their computer self-monitoring sheet on KidTools. Each participant filled one out as expected, so the issue never needed to be addressed. Further, all three of the self-monitoring components; self-monitoring at home, self-monitoring on the computer program and meeting with the researcher were in place for each phase, excluding the maintenance phase. Therefore, it was undetermined which component, if any, played a stronger role in the outcomes any of the dependent variables. 


\section{Suggestions for Future Research}

The results of this study suggest several possible areas for future research. The demographic characteristics of the participants were restricted to fourth-grade students who were labeled as having a disability and included in the general education classroom. In future research, participants with other demographic characteristics should be considered for this intervention. Demographics to be considered could include students differing in abilities and disabilities, students at different grade levels, various school settings, diverse school locations as well as students living with or without parents. Additionally, the homework subjects chosen in this study were spelling and math, future research can investigate other homework subjects related to grade levels, such as science or language courses.

Future research could monitor the math and spelling instruction taking place in the classroom during the study to determine if the homework topics were covered in class. Homework should be an extension of the material learned in class, used as practice at home. It should not be new material the student has not previously been exposed to (Hardman et al., 2006). This study included parental involvement; further investigation should also examine the use of peers instead of parents in support of the self monitoring. Although this study targeted students who were below average in spelling and math homework completion and accuracy, future studies could examine participants at higher levels to determine if their scores would also increase. Additionally, maintenance data in this study were collected for a fairly short period of time due to time constraints, future research could extend the time period. 
This study also combined many components of self-monitoring. Future research could assess the use of just one part of this study. Assessments using the home and parental involvement element could be investigated. Or just the technology or conferencing portions of the self-monitoring may be examined. Additionally, rather than have a teacher conferencing with the participants, a peer may be employed instead. Moreover, three phases were used in this study with various amounts of conferencing in each one, future research could focus on just one.

Although outcomes have varied for individual participants, data demonstrated that self-monitoring had a positive impact on participant spelling and math homework completion and accuracy as measured by the dependent variables. The results demonstrated that for students with disabilities in general education classrooms, selfmonitoring increased spelling and math homework completion and accuracy. However, given the nature of single subject design research, there is a need for direct and systematic replications of this research.

\section{Summary}

The results of this study suggest that self-monitoring has a positive impact on the spelling and math homework completion and accuracy rates of students with disabilities enrolled in inclusive general education classes. Spelling and math homework completion and accuracy rates rose substantially when the self-monitoring condition was employed in the first phase and for each subsequent phase of the intervention.

Maintenance data were taken over a 2- to-3-week period, following the final phase of the intervention. Compared to baseline, results indicate that participants completed more spelling and math homework once the self-monitoring condition was 
introduced, as well as during maintenance. Results also showed that participants produced more accurate spelling and math homework during each phase of the selfmonitoring condition and even after the intervention ceased.

The overall results of this study suggest that self-monitoring could support student with disabilities in general education classes who are struggling with spelling and math homework completion and accuracy. This study adds to the limited research on selfmonitoring interventions on students with disabilities in general education classes by providing an analysis of a self-monitoring homework strategy for students with disabilities included in general education classes.

Since this study explored the effects of fourth-grade students with disabilities in general education, results may not be generalized beyond this population. Future research should explore its efficacy with diverse participant populations and other subject areas. Furthermore, future research should investigate the effects of self-monitoring on homework completion and accuracy rates on students with various other disabilities, in other grades levels or placements. Various components of this intervention could also be modified and investigated in future research.

This study determined that self-monitoring had positive effects on the spelling and math homework completion and accuracy rates of students with disabilities in general education. Therefore, this strategy should be considered as a tool to assist these students in improving these skills. No previously known study had specifically targeted this population of students using the methods in this study. The sample size is small by the nature of the design and therefore limits the generalization of its findings. 
Over the years, the use of self-monitoring interventions has produced noteworthy results regardless of the nature or degree of the participants' disabilities. Studies aimed at improving homework completion have targeted students with and without disabilities at the elementary and middle school levels, with a few studies at the high school level (e.g., Fish \& Mendola, 1986; Flores et al., 1995; Forgatch \& Ramsey, 1994; Glomb \& West, 1990). Prior to this study, the research lacked studies investigating the effects of selfmonitoring on the homework completion and accuracy of students with disabilities in general education classrooms. The current study begins to fill this void. Additional research is needed to extend its results. 


\section{REFERENCES}

Abidin, R., \& Robinson, L. (2002). Stress, biases, or professionalism: What drives teachers' referral judgments of students with challenging behaviors? Journal of Emotional and Behavioral Disorders, 10, 204-12.

Agran, M., Blanchard, C., Wehmeyer, M., \& Hughes, C. (2002). Increasing the problem solving skills of students with severe disabilities participating in general education. Remedial and Special Education, 23, 279-288.

Agran, M., Salzberg, C. L., \& Stowitschek, J. J. (1987). An analysis of the effects of a self-instructional training program on the acquisition and generalization of social behaviors in a work setting. The Journal of the Association for Persons with Severe Handicaps, 12, 131-139.

Agran, M., Sinclair, T., Alper, S., Cavin, M., Wehmeyer, M., \& Hughes, C. (2005). Using self-monitoring to increase following-direction skills of students with moderate to severe disabilities in general education. Education and Training in Developmental Disabilities, 40, 3-13.

Agran, M., Snow, K., \& Swaner, J. (1999). Teacher perceptions of self-determination: Benefits, characteristics, strategies. Education and Training in Mental Retardation and Developmental Disabilities, 34, 293-301.

Alberto, P. A., \& Troutman, A. C. (2003). Applied behavior analysis for teachers (6th ed.). Upper Saddle River, NJ: Merrill/Prentice-Hall.

Amato-Zech, N. A., Hoff, K. E., \& Doepke, K. J. (2006). Increasing on-task behavior in the classroom: Extension of self-monitoring strategies. Psychology in the Schools. $43(2), 211-221$.

Anesko, K., Schoiock, G., Ramirez, R., \& Levine, F. (1987). Homework problems checklist: Assessing children's homework difficulties. Journal of Applied Behavioral Assessment, 9, 179-185.

Apple, A., Billingsley, F., \& Schwartz, I. (2005). Effects of video modeling alone and with self-management on compliment-giving behaviors of children with highfunctioning ASD. Journal of Positive Behavior Interventions, 7, 33-46.

Barry, L., \& Messer, J. (2003). A practical application of self-management for students diagnosed with attention-deficit/hyperactivity disorder. Journal of Positive Behavior Interventions, 5, 238-248. 
Bembenutty, H., \& Zimmerman, B. (2003, April). The relation of motivational beliefs and self-regulatory processes to homework completion and academic achievement. Paper presented at the annual meeting of the American Educational Research Association, New York.

Bempechat, J. (2004). The motivational benefits of homework: A social-cognitive perspective. Theory into Practice, 43, 189-196.

Blick, D., \& Test, D. (1987). Effects of self-recording on high-school students' on-task behavior. Learning Disability Quarterly, 10, 203-213.

Brophy, J. (1996). Teaching problem students. New York, NY: The Guilford Press.

Bryan, T., \& Burstein, K. (2004). Improving homework completion and academic performance: Lessons from special education. Theory into Practice, 43, 213-219.

Bryan, T., Burstein, K., \& Bryan, J. (2001). Students with learning disabilities: Homework problems and promising practices. Educational Psychologist, 36, $167-180$.

Bryan, T., \& Sullivan-Burstein, K. (1998). Teacher selected strategies for improving homework completion. Remedial and Special Education, 19, 263-275.

Cancio, E., West, R., \& Young, K. (2004). Improving mathematics homework completion and accuracy of students with EBD through self-management and parent participation. Journal of Emotional and Behavioral Disorders, 12, 9-22.

Carr, S., \& Punzo, R. (1993). The effects of self-monitoring of academic accuracy and productivity on the performance of students with behavioral disorders. Behavior Disorders, 18, 241-250.

Carrington, P., Lehrer, P., \& Wittenstrom, K. (1997). A children's self-management system for reducing homework-related problems: Parent efficacy ratings. Child and Family Behavior Therapy, 19, 1-22.

Christensen, L., Young, K., \& Marchant, M. (2004). The effects of a peer-mediated positive behavior support program on socially appropriate classroom behavior. Education and Treatment of Children, 27, 199-234.

Clees, T. (1994). Self-recording of students' daily schedules of teachers' expectancies: Perspectives on reactivity, stimulus control, and generalization. Exceptionality, 5(3), 113-129. 
Coleman, J., Hoffer, T., \& Kilgore, S. (1982). High school achievement: Public, catholic, and private schools compared. New York, NY: Basic Books.

Collier County Public Schools. (2008). Exceptional student education programs. Retrieved from http://collier.k12.fl.us/ese/ebd.htm

Cooper, H. (1989a). Homework. White Plains, NY: Longman.

Cooper, H. (1989b). Synthesis of research on homework. Educational Leadership, 47, 85-91.

Cooper, H. (2001). Homework for all in moderation. Educational Leadership, 58, 34-38.

Cooper, H. (2007). The battle over homework: Common ground for administrators, teachers, and parents. Thousand Oaks, CA: Corwin Press.

Cooper, H., Robinson, J., \& Patall, E. (2006). Does homework improve academic achievement? A synthesis of research, 1987-2003. Review of Educational Research, 76(1), 1-62.

Cooper, H., \& Valentine, J. (2001). Using research to answer practical questions about homework. Educational Psychologist, 36(3), 143-153.

Cooper, J., Heron, T., \& Heward, W. (2007). Applied behavior analysis (2nd ed.). Upper Saddle River, NJ: Pearson/Merrill-Prentice Hall.

Cooper, J., Horn, S., \& Strahan, D. (2005). "If they would only do their homework": Promoting self-regulation in high school English classrooms. The High School Journal, 88(3), 10-25.

Cooper, J., Jackson, K., Nye, B., \& Lindsay, J. (2001). A model of homework's influence on the performance evaluations of elementary school students. Journal of Experimental Education, 69,181-199.

Corno, L., \& Xu, J. (2004). Homework as the job of childhood. Theory into Practice, 43, $227-233$.

Craft, M. A., Alber, S. R., \& Heward, W. L. (1998). Teaching elementary students with developmental disabilities to recruit teacher attention in a general education classroom: Effects on teacher praise and academic productivity. Journal of Applied Behavior Analysis, 31, 399-415.

Crum, C. (2004). Using a cognitive-behavioral modification strategy to increase on-task behavior of a student with a behavior disorder. Intervention in School and Clinic, 39, 305-309. 
Daly, P., \& Ranalli, P. (2003). Using countoons to teach self-monitoring skills. Teaching Exceptional Children, 35(5), 30-35.

Dawson, P., \& Guare, R. (2003). Executive skills in children and adolescents: A practical guide to assessment and interventions. New York, NY: Guilford.

DiGangi, S., Maag, J., \& Rutherford, R. (1991). Self-graphing of on-task behavior: Enhancing the reactive effects of self-monitoring of on-task behavior and academic performance. Learning Disability Quarterly, 14, 221-230.

DuPaul, G., \& Hoff, K. (1998). Attention/ concentration problems. In S. Watson and F. Gresham (Eds.), Handbook of child behavior therapy: Ecological considerations in assessment, treatment, and evaluation (pp. 99-126). New York, NY: Plenum Press.

DuPaul, G. J., \& Stoner. G. (2003). ADHD in the schools: Assessment and intervention strategies (2nded.). New York, NY: Guilford Press.

Epps, M. (1966). Homework. Washington, DC: National Education Association.

Epstein, J., \& Van Voorhis, F. (2001). More than minutes: Teachers' roles in designing homework. Educational Psychologist, 36, 181-193.

Fad, K., Patton, J., \& Polloway, E. (2006).Behavioral intervention planning: A comprehensive guide for completing a functional behavioral assessment and developing a behavioral intervention plan (3rd ed.). Austin, TX: PRO-ED

Field, S., Martin, J., Miller, R., Ward, M., \& Wehmeyer, M. (1998). A practical guide for teaching self-determination. Reston, VA: Council for Exceptional Children.

Firman, K., Beare, P., \& Loyd, R. (2002). Enhancing self-management in students with mental retardation: Extrinsic versus intrinsic procedures. Education and Training in Mental Retardation and Developmental Disabilities, 37, 163-71.

Fish, M., \& Mendola, L. (1986). The effect of self-instruction training on homework completion in an elementary special education class. School Psychology Review, $15,268-276$.

Fitzgerald, G., \& Koury, K. (2003). The KidTools support system. U.S. Department of Education Grant No. H327A000005. Available: http://kidtools.missouri.edu

Flores, D., Schloss, P., \& Alper, S. (1995). The use of a daily calendar to increase responsibilities fulfilled by secondary students with special needs. Remedial and Special Education, 16, 38-43. 
Florida Department of Education. (2005). Exceptional education and student services. Retrieved from www.fldoe.org/ese/pdf/eserulesada.pdf

Florida Department of Education. (2010). Bureau of exceptional education and student serivices, students with disabilities enrollment, ages 6-21, 2008-09. Retrieved from http://www.fldoe.org/ese/pdf/b-621.pdf

Forgatch, M., \& Ramsey, E. (1994). Boosting homework: A videotape link between families and schools. School Psychology Review, 23, 472-484.

Freeman, K., \& Dexter-Mazza, E. (2004). Using self-monitoring with an adolescent with disruptive classroom behavior. Behavior Modification, 28, 402-419.

Gettinger, M., \& Seibert, J. K. (2002).Contributions of study skills to academic competence. School Psychology Review, 31, 350-366.

Gilberts, G. (2000). The effects of peer-delivered self-monitoring strategies on the participation of students with disabilities in general education classrooms. (ERIC Document Reproduction Service No. ED439871)

Gill, B., \& Schlossman, S. (1996). 'A sin against childhood': Progressive education and the crusade to abolish homework, 1897-1941. American Journal of Education, $105,27-66$.

Gill, B., \& Schlossman, S.(2000). The lost cause of homework reform. American Journal of Education, 109, 27-62

Gill, B., \& Schlossman, S. (2003a). Homework and the elusive voice of parents: Some historical perspectives. Teachers College Record, 105, 846871.

Gill, B., \& Schlossman, S. (2003b). A nation at rest: The American way of homework. Educational Evaluation and Policy Analysis, 25, 319-337.

Gill, B., \& Schlossman, S. (2004). Villain or Savior? The American discourse on homework, 1850-2003. Theory Into Practice, 43, 174-181.

Glazer, N., \& Williams, S. (2001). Averting the homework crisis. Educational Leadership, 58, 43-45.

Gleason, M., Archer, A., \& Colvin, G. (2002). Interventions for improving study skills. In M. A. Shinn, H. M. Walker \& G. Stoner (Eds.), Interventions for academic and behavior problems II: Preventive and remedial approaches (pp.651-680).

Bethesda, MD: National Association of School Psychologists. 
Glomb, N. \& West, R.P. (1990). Teaching behaviorally disordered adolescents to use self-management skills for improving the completeness, accuracy, and neatness of creative writing assignments. Behavior Disorders, 15, 233-242.

Goldstein, A. (1960). Does homework help? A review of research. Elementary School Journal, 60, 212-224

Good, T., \& Brophy, J. (2003). Looking in classrooms (9th ed.). Boston, MA: Allyn \& Bacon.

Grigal, M., Neubert, D., Moon, M., \& Graham, S. (2003). Self-determination for students with disabilities: Views of parents and teachers. Exceptional Children, 70, 97112.

Gulchak, D. (2008). Using a mobile handheld computer to teach a student with an emotional and behavioral disorder to self-monitor attention. Education and Treatment of Children, 31, 567581.

Gureasko-Moore, S., DuPaul, G., \& White, G. (2007).Self-management of classroom preparedness and homework: Effects on school functioning of adolescents with attention deficit hyperactivity disorder. School Psychology Review, 36, 647-664.

Hallahan, D. P., \& Kauffman, J. M. (2000). Exceptional learners: Introduction to special education (8thed.). Boston, MA: Allyn and Bacon.

Hanson, M. (1996). Self-management through self-monitoring. In K. Jones \& T. Charlton (Eds.), Overcoming learning and behavior difficulties: Partnership with pupils (pp. 173-191). London: Routledge.

Hardman, M., Drew, C., \& Egan, M. (2006). Human exceptionality: School, community, and family (8th ed.). Boston, MA: Allyn and Bacon.

Harris, K., Friedlander, B., Saddler, B., Frizzelle, R., \& Graham, S. (2005). Selfmonitoring of attention versus self-monitoring of academic performance: Effects among students with ADHD in the general education classroom. Journal of Special Education, 39, 45-156.

Harvey, M. (2002). Comparison of postsecondary transitional outcomes between students with and without disabilities by secondary vocational education participation: Findings from the national education longitudinal study. Career Development for Exceptional Individuals, 25(2), 99-122.

Hathaway, W., \& Barkley, R. (2003).Self regulation, ADHD, \&child religiousness. Journal of Psychology \& Christianity, 22(2), 101. 
Hayes, S. R. (2002). Improving student performance in fifth grade band through the use of student self-monitoring. Unpublished doctoral dissertation, Saint Xavier University, Chicago. (ERIC Document Reproduction Service No. ED471585)

Heins, E. D., Lloyd, J. W., \& Hallahan, D. P. (1986). Cued and non-cued self-recording of attention to task. Behavior Modification, 10(2), 235-254.

Hill, N., \& Tyson, D. F. (2009). Parental Involvement in middle school: A meta-analytic assessment of the strategies that promote achievement. Developmental Psychology, 45(3), 740-763.

Hill, S., Spencer, R., Alston, A., \& Fitzgerald, J. (1986). Homework policies in the schools. Education, 107(1), 58-70.

Hong, E., Peng, Y., \& Rowell, L. L. (2009). Homework self-regulation: Grade, gender, and achievement-level differences. Learning and Individual Differences, 19(2), 269-276.

Hoover, C. (2006). Research-based instructional strategies. School Library Media Activities Monthly, 22(8), 26-28.

Hoover-Dempsey, K., Battiato, A., Walker, J., Reed, R., DeJong, J., \& Jones, K. (2001). Parental Involvement in Homework. Educational Psychologist, 36, 195-209.

Hughes, C., \& Boyle, J. (1991). Effects of self-monitoring for on-task behavior and task productivity on elementary students with moderate mental retardation. Education and Treatment of Children, 14(2), 96-111.

Hughes, C., Copeland, S., Agran, M., Wehmeyer, M., Rodi, M., \& Presley, J. (2002). Using self-monitoring to improve performance in general education high school classes. Education and Training in Mental Retardation and Developmental Disabilities, 37, 262-272.

Hughes, C. A., Ruhl, K. L., Schumaker, J. B., \& Deshler, D. D. (2002). Effects of instruction in an assignment completion strategy on the homework performance of students with learning disabilities in general education classes. Learning Disabilities Research \& Practice, 17, 1-18.

Hunt, P., \& Goetz, L. (1997). Research on inclusive educational programs, practices, and outcomes for students with severe disabilities. Journal of Special Education, 31, $3-29$.

Individuals with Disabilities Education Act of 2004. (2004). In GovTrack.us (database of federal legislation). Retrieved from http://www.govtrack.us/congress/bill.xpd?bill=h108-1350 
Janney, R., \& Snell, M. (2000). Teachers' guide to inclusive practices: Behavioral support. Baltimore, MD: Paul H. Brookes.

Johnston, J., \& Pennypacker, H. (1993). Strategies and tactics of behavior research (2nd ed.). Hillsdale, NJ: Lawrence Erlbaum Associates.

Kamps, D., \& Kay, P. (2002). Preventing problems through social skills instruction. In B. Algozzine, \& P. Kay (Eds.), Preventing problem behaviors: A handbook of successful prevention strategies (pp. 57-84). Thousand Oaks, CA: Corwin Press.

Karvonen, M., Test, D., Wood, W., Browder, D., \& Algozzine, B. (2004). Putting selfdetermination into practice. Exceptional Children, 71(1), 23.

Kazdin, A. (1982). Single-case research designs: Methods for clinical and applied settings. New York, NY: Oxford Press.

Kehle, T. J., Clark, E., Jenson, W. R., \& Wampold, B. E. (1986). Effectiveness of selfobservation with behavior-disordered elementary school children. School Psychology Review, 15(2), 289-295.

Keith, T. (1986). Homework. West Lafayette, IN: Kappa Delta Phi.

Keith, T., Diamond-Hallam, C. \& Fine, J. (2004). Longitudinal effects of in-school and out-of-school homework on high school grades. School Psychology Quarterly, 19, $187-211$.

Keith, T., \& Keith, P. (2006). Homework. In G. Bear, \& K. Minke (Eds.),Children's needs III: Development, prevention, and intervention.(pp. 615-629). Washington, DC: National Association of School Psychologists.

Kim, H., \& Sugai, G. (1995). The effects of self-evaluation, self-observation, and selfobservation plus recording on the occurrence of disruptive behaviors in classroom: Extension study. (ERIC Document Reproduction Service No. ED385028)

King-Sears, M. (1999). Teacher and researcher co-design self-management content for an inclusive setting: Research training, intervention, and generalization effects on student performance. Education and Training in Mental Retardation and Developmental Disabilities, 34, 134-56.

King-Sears, M. (2006).Self-Management for students with disabilities: The importance of teacher follow-up. International Journal of Special Education, 21, 94-108. 
Kralovac, E., \& Buell, J. (2001). End homework now. Educational Leadership, 58, 3942.

Lannie, A. L., \& Martens, B. K. (2008). Targeting performance dimensions in sequence according to the instructional hierarchy: Effects on children's math work within a self-monitoring program. Journal of Behavioral Education, 17(4), 356-375.

Lee, S., Palmer, S., \& Wehmeyer, M. (2009). Goal setting and self-monitoring for students with disabilities: Practical tips and ideas for teachers. Intervention in School and Clinic, 44, 139.

Lieberman, L. (1983). The homework solution. Journal of Learning Disabilities, 16, 435.

Madaus, M., Kehle, T., Madaus. J., \& Bray, M. (2003). Mystery motivator as an intervention to promote homework completion and accuracy. School Psychology International, 24, 369-377.

Maertens, D., \& Johnson, K. (1972). Effects of arithmetic homework upon the attitudes and achievement of 5 th and $6^{\text {th }}$ grade pupils. School Science and Mathematics, 72, $117-126$.

Marzano, R.J. (2003). What works in schools: Translating research into action. Alexandria, VA: Association for Supervision and Curriculum Development.

Mastropieri, M., Scruggs, I., Craetz, J., Norland, W., Gardizi, \& McDuffie, K. (2005). Case studies in co-teaching in the content areas: Successes, failures, and challenges. Intervention in School and Clinic, 40, 260-70.

Mathes, M., \& Bender, W. (1997). The effects of self-monitoring on children with attention-deficit/hyperactivity disorder who are receiving pharmacological interventions. Remedial and Special Education, 18, 121-128.

McCarl, J. J. \& Hallahan, D. (1991). Self-recording in a classroom for students with mild to moderate mental handicaps: Effects on productivity and on-task Behavior. Education and Training in Mental Retardation, 26(1), 79-88.

McDougall, D., \& Brady, M. (1998). Initiating and fading self-management interventions to increase math fluency in general education classes. Exceptional Children, 64, 151-166.

McMillan, J. (2004). Classroom assessment: Principles and practice for effective instruction. Boston, MA: Pearson. 
Mendicino, M., Razzaq, L., \& Heffernan, N. (2009). A comparison of traditional homework to computer-supported homework. Journal of Research on Technology in Education, 41, 331-359.

Meyer, K., \& Kelley, M. (2007). Improving homework in adolescents with attentiondeficit/hyperactivity disorder: Self- vs. parent-monitoring of homework behavior and study skills. Child \& Family Behavior Therapy, 29, 25-42.

Miller, D., \& Kelley, M. (1991). Interventions for improving homework performance: A critical review. School Psychology Quarterly, 6, 174-185.

Miller, S., Heafner, T., \& Massey, D. (2009). High-School Teachers' Attempts to Promote Self-Regulated Learning: "I May Learn from You, Yet How Do I Do It?". Urban Review: Issues and Ideas in Public Education, 41. (2), 121-140.

Minzner, K. (2003). Using self-management to improve homework completion and grades of students with learning disabilities. Cincinnati, $\mathrm{OH}$ : University of Cincinnati.

Moore, D., Prebble, S., Robertson, J., Waetford, R., \& Anderson, A. (2001). Selfrecording with goal setting: A self-management programmed for the classroom. Educational Psychology, 21, 255-265.

Olympia, D., Sheridan, S., \& Jenson,W. (1994a). Homework: A natural means of home school collaboration. School Psychology Quarterly, 9, 60-80.

Olympia, D., Sheridan, S., Jenson, W., \& Andrews, D. (1994b). Using student-managed interventions to increase homework completion and accuracy. Journal of Applied Behavior Analysis, 27, 85-99.

Palmer, S., Wehmeyer, M., Gipson, K., \& Agran, M. (2004). Promoting access to the general curriculum by teaching self-determination skills. Exceptional Children, 70, 427-439.

Patton, B., Jolivette, K., \& Ramsey, M. (2006). Students with emotional and behavioral disorders can manage their own behavior. Teaching Exceptional Children, 39(2), $14-21$.

Peterson, L. D., Young, K. R., Salzberg, C. L., West, R. P., \& Hill, M. (2006). Using selfmanagement procedures to improve classroom social skills in multiple general education settings. Education and Treatment of Children, 29(1), 1-21.

Porter, L. (2002). Cognitive skills. In L. Porter (Ed.), Educating young children with special needs. Crow's Nest, Australia: Allen \& Unwin. 
Power, T., Karustis, J., \& Habboushe, D. (2001). Homework success for children with ADHD: A family-school intervention program. New York, NY: Guilford Press.

Power T., Werba, B., Watkins, M., Angelucci, J., \& Eiraldi, R. (2006). Patterns of parentreported homework problems among ADHD-referred and non-referred children. School Psychology Quarterly, 21, 13-33.

Redmon, R. (2007, October). Impact of teacher preparation upon teacher efficacy. Paper presented at the Annual Meeting of the American Association for Teaching and Curriculum, Cleveland, $\mathrm{OH}$.

Reinhardt, D., Theodore, L., Bray, M., \& Kehle, T. (2009). Improving homework accuracy: Interdependent group contingencies and randomized components. Psychology in the Schools, 46(5), 471-488.

Remmers, H., Gage, N., \& Shimberg, B. (1948). Youth looks at schools and jobs. (as referenced in Davis, Allison Papers, Box \# 18, Folder \# 1, Special Collections Research Center, University of Chicago Library). Purdue Opinion Panel.

Robin, A. (1998). ADHD in adolescents: Diagnosis and treatment. New York, NY: Guilford.

Rock, M. (2005). Use of strategic self-monitoring to enhance academic engagement, productivity, and accuracy of students with and without exceptionalities. Journal of Positive Behavioral Interventions, 7, 3-17.

Rock, M., \& Thead, B. (2007). The effects of fading a strategic self-monitoring intervention on students' academic engagement, accuracy, and productivity. Journal of Behavioral Education, 16, 389-412.

Rooney, K., Hallahan, D., \& Lloyd, J. (1984). Self-recording of attention by learning disabled students in the regular classroom. Journal of Learning Disabilities, 17, 360-364.

Rutherford, R., Quinn, M., \& Mathur, S. (1996). Effective strategies for teaching appropriate behaviors to children with emotional/behavioral disorders. Reston, VA: Council for Children with Behavioral Disorders.

Salend, S., Duhaney, D., Anderson, D., \& Gottschalk, C. (2004). Using the internet to improve homework communication and completion. Teaching Exceptional Children, 36(3), 64-73.

Salend, S., \& Gajria, M. (1995). Homework practices of students with and without learning disabilities: A comparison. Journal of Learning Disabilities, 25, 285297. 
Santangelo, T., Harris, K., \& Graham, S. (2007). Self-regulated strategy development: A validated model to support students who struggle with writing. Learning Disabilities: A Contemporary Journal, 5(1), 1-20.

Schunk, D. (1997, March). Self-monitoring as a motivator during instruction with elementary school students. Paper presented at the Annual Meeting of the American Educational Research Association, Chicago, IL.

Shimabukuro, S., Prater, M., Jenkins, A., \& Edelen-Smith, P. (1999). The effects of selfmonitoring of academic performance on students with learning disabilities and ADD/ADHD. Education and Treatment of Children, 22, 397-406.

Smith, D., \& Young, R. K. (1992). The effect of a self-management procedure on the classroom and academic behavior of students with mild handicaps. School Psychology Review, 21(1), 59.

Smith, S. (2002). Applying cognitive-behavioral techniques to social skills instruction. Arlington, VA: ERIC Clearinghouse on Disabilities and Gifted Education. (ERIC Document Reproduction Service No. ED 469 2790)

Stainback, S., \& Stainback, W. (1980).Educating children with severe maladaptive behaviors. New York, NY: Grune \& Stratton.

Stronge, J. (2002). The qualities of effective teachers. Alexandria, VA: Association for Curriculum and Curriculum Development.

Tam, K., Heward, W., \& Heng, M. (2006). A reading instruction intervention program for English-language learners who are struggling readers. Journal of Special Education, 40, 79-93

Todd, A., Horner, R., \& Sugai, G. (1999). Self-monitoring and self-recruited praise: Effects on problem behavior, academic engagement, and work completion in a typical classroom. Journal of Positive Behavior Interventions, 4, 445-459.

Toney, L., Kelley, M., \& Lanclos, N. (2003). Self- and parental monitoring of homework in adolescents: Comparative effects on parents' perceptions of homework behavior problems. Child \& Family Behavior Therapy, 25, 35-51.

Trammel D., Schloss, P., \& Alper, S. (1994). Using self-recording, evaluation, and graphing to increase completion of homework assignments. Journal of Learning Disabilities, 27, 75-81. 
U.S. Department of Education. (1986). What works: research on teaching and learning. Washington, DC: Department of Education.

U.S. Department of Education. (2003). Office of Intergovernmental and Interagency Affairs, Educational Partnerships and Family Involvement Unit, Homework Tips for Parents. Retrieved from http://www.ed.gov/parents/academic/ involve/homework/homeworktips.pdf

U. S. Department of Education. (2008a). Office of Special Education Programs, NAEP Inclusion Policy. Inclusion of Special Needs Students. Retrieved from http://nces.ed.gov/nationsreportcard/about/inclusion.asp

U. S. Department of Education. (2008b). Institute of Education Sciences. Expectations and reports of homework for public school students in the first, third, and fifth grades. Retrieved from http://nces.ed.gov/pubsearch/pubsinfo. asp?pubid=200903

Vaughn, S., Bos, C., \& Schumm, J. (2000). Teaching exceptional, diverse, and at risk students in the general education classroom (2nd ed.). Boston, MA: Allyn and Bacon.

Walberg, H., Paschal, R., \& Weinstein, T. (1985). Homework's powerful effects on learning. Educational Leadership, 42, 76-79.

Wallace, G., \& Kauffman, J. M. (1986). Teaching students with learning and behavior problems. Columbus, $\mathrm{OH}$ : Merill.

Wehmeyer, M., Agran, M., \& Hughes, C. (1998). Teaching self-instruction skill: Teaching self-determination to students with disabilities. Baltimore, MD: Paul H. Brookes.

Wehmeyer, M., Yeager, D., Bolding, N., Agran, M., \& Hughes, C. (2003). The effects of self-regulation strategies on goal attainment for students with developmental disabilities in general education classrooms. Journal of Developmental and Physical Disabilities, 15, 79-91.

Whitby, P., \& Miller, K. J. (2009). Using eKidtools software tools to provide behavior support in general education settings. TEACHING Exceptional Children Plus, 5(3) Article 5. Retrieved from http://escholarship.bc.edu/education/tecplus/vol5/iss3/art5

Wood, S., Murdock, J., \& Cronin, M. (2002). Self-Monitoring and at-risk middle school students: Academic performance improves, maintains, and generalizes. Behavior Modification, 26, 605-626 
Xu, J. (2007).Middle-School homework management: More than just gender and family involvement. Educational Psychology, 27, 173-189.

Zlomke, K., \& Zlomke, L. (2003). Token economy plus self-monitoring to reduce disruptive classroom behaviors. Behavior Analyst Today, 4, 177-182. 


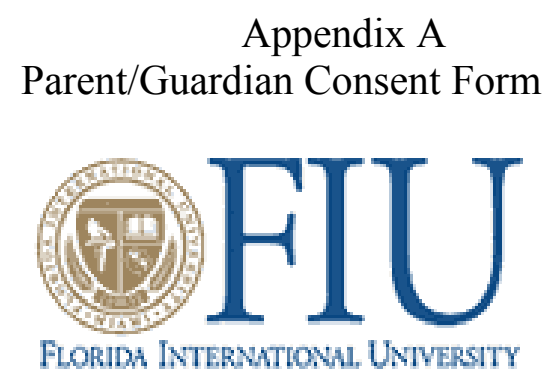

Parent/Guardian Consent Form

Your child, , is being considered for participation in a research study. The investigator of this study is Carol Ann Falkenberg and she is a student at Florida International University (FIU). The data collected will be identified by a pseudonym and not your child's name. All of the information is private and will not be shared with anyone unless required by law. The data will be presented in a graph like table. You or your child may ask questions at any time. Of course, you may choose not to allow your child to participate in this research project without any pressure. Please read below and sign and return to your child's teacher.

You freely and voluntarily give consent for your child to be a participant in the study entitled, "The Effects of Self-monitoring on the Accuracy and Completion Rate of Homework of Students with Disabilities in Inclusive Setting" to be conducted by Carol Ann Falkenberg, a doctoral candidate at the Florida International University in Miami-Dade County and a full time teacher at Vineyards Elementary School in Collier County Florida.

You fully understand that the purpose of this research is to observe the effects of self-monitoring on completion and accuracy of homework. You are aware that your child's personal information may be reviewed in order to establish descriptive data, and that his/her identity will be kept completely confidential. You are also aware that your child will be involved self-monitoring of their homework while they are at home as well as on a computer at school. You understand that your child's participation in the study will last for approximately 20 minutes each school day for 16 weeks. The researcher does not expect any harm to your child by being in the study. If he or she becomes frustrated or upset at any point in the study he or she may ask to take a break. You may withdraw your child from the study at any time if you feel in any way uncomfortable. There is no cost to you for your child's participation in the study. This study will provide him or her with additional homework completion strategies.

Consent for your child to participate in this study is entirely voluntary and your decision will involve no penalty or loss of benefits to your child, you, or to the school. You understand that if you have any questions regarding the study, you can contact Carol Ann Falkenberg at (239) 377-8714, Dr. Patricia Barbetta at (305)-348-2552, and Dr. Patricia Price, Chairman of the FIU Institutional Review Board at $305-$ 348-2618.

Please circle one of the following choices and sign the statement:

I GIVE/DO NOT GIVE permission for my child to participate in this study.

Signature of Parent

Date

Your participation in this project is greatly and sincerely appreciated.

Carol Ann Falkenberg 


\section{Appendix B}

\section{Homework Self-Monitoring Sheet}

Self-Monitoring Sheet for Math and Spelling Homework Completion and Accuracy Directions: Read the questions and answer by coloring, shading or circling a smiley face for "yes" response or a sad face for a "no" response. If there was not an assignment for that subject, circle N/A. Have an adult look at and initial the form when you have completed it.

Name/Date

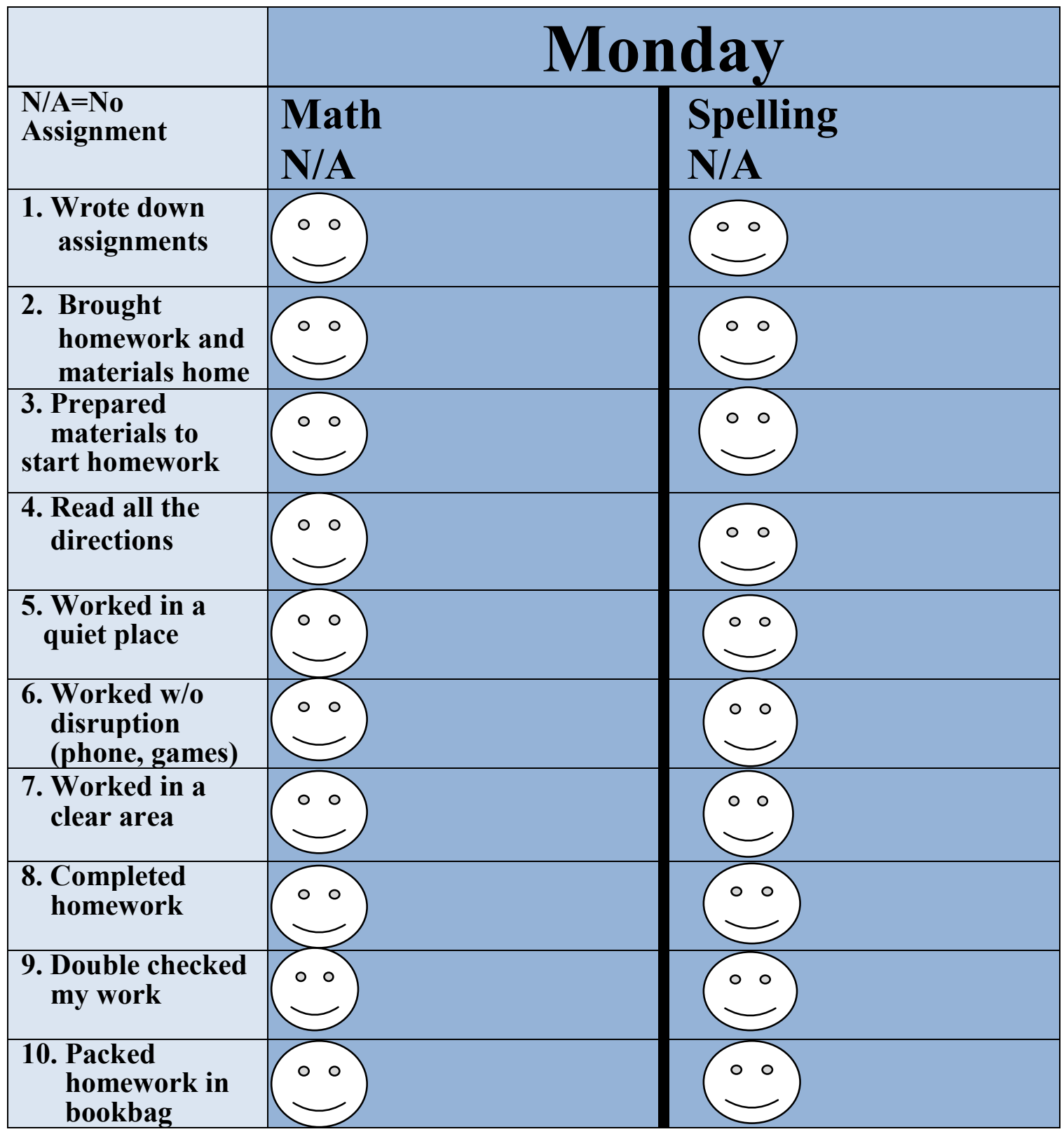

\section{Initials:}


Appendix C

Sample Self-Monitoring Sheet From KidTools

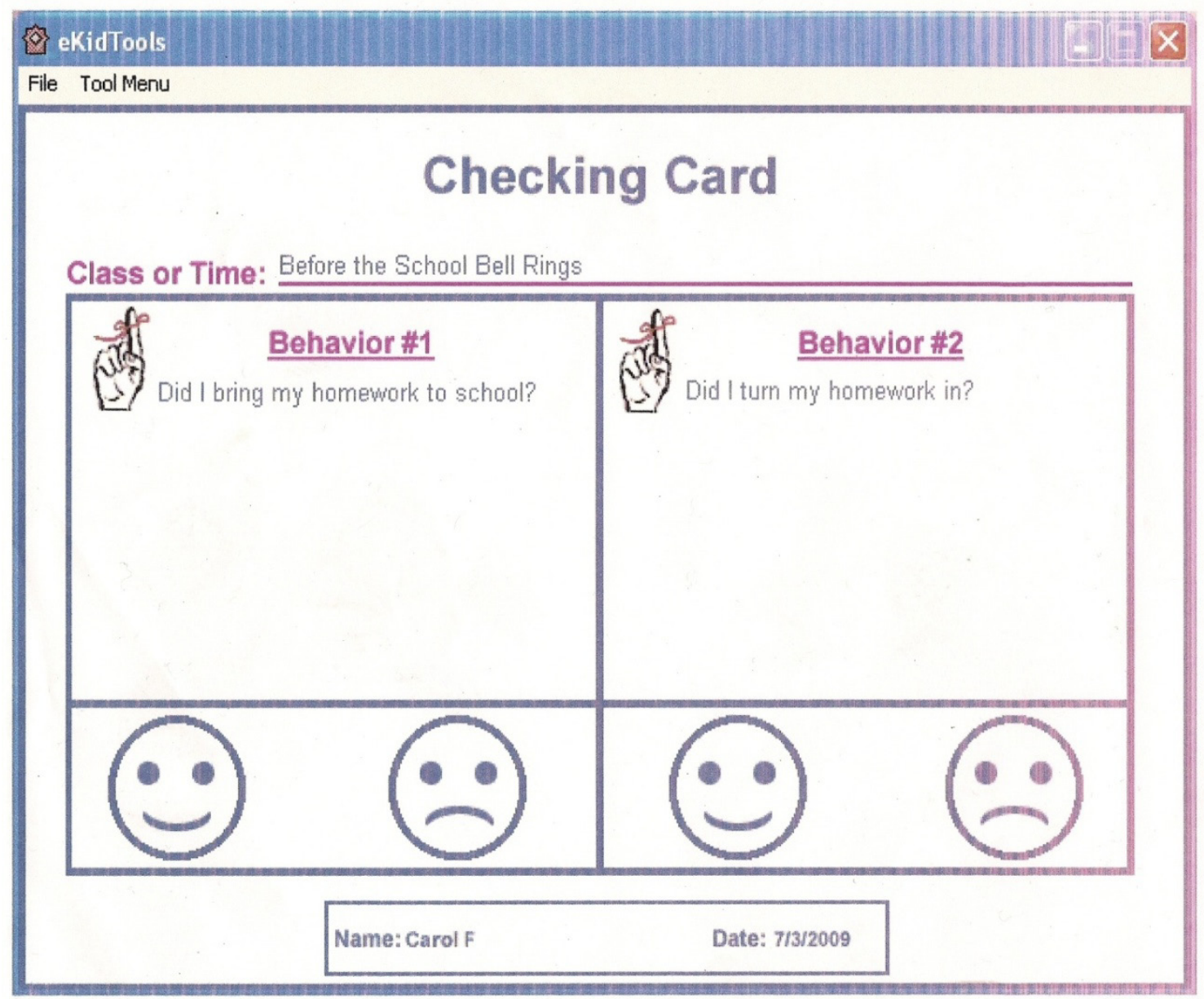




\section{Appendix D}

\section{Participant Assent}

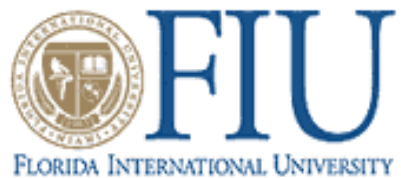

\section{ASSENT TO PARTICIPATE IN A RESEARCH STUDY}

Title: Effects of Self-Monitoring On Completion And Accuracy Rate Of Homework Of Students With Disabilities Included In General Education.

My name is Carol Ann Falkenberg and I am a student at Florida International University (FIU) and a teacher here at Vineyards Elementary School. You and some of your classmates are being asked to participate in a research study. This study will look at whether self-monitoring your homework will help you complete it more often and accurately.

Your parent/guardian must give you permission to take part in the study. If you do take part, you will be meeting with me for about 5-10 minutes a day. We will meet in school.

1. You will bring your self-monitoring sheet to school.

2. You will use the computer to answer a few questions.

3. You will discuss your answers with me.

4. I will review your self-monitoring sheet and your homework.

There is no charge for being a part of this study. Participating will not harm you in any way. Taking part in this study will not help or hurt your grades. You or your parent can ask to stop taking part in the study at any time. There is no reason to expect any harm to come to you by being in the study. If you become frustrated or upset at any point in the study you may ask to take a break. You may withdraw from the study at any time if you feel in any way uncomfortable. There is no cost to you for participating in the study. This study will provide you with additional homework completion strategies.

None of the information I collect will have your name on it. I will write about this research in my research paper using a letter or number. If you decide not to take part in this study no one will be upset with you.

If you have any questions you can ask anytime. You and your parents may contact me at (239) 3778714. You may also contact my teacher at FIU, Dr. Patricia Barbetta at (305) 348-2552. If you or your parent feels that you are not being treated fairly in this study, you may contact Dr. Patricia Price, the Chairperson of the FIU Institutional Review Board at 305-348-2618 or 305-348-2494.

If you would like to be in the study, sign below. You will have a copy of this form.

Sign Here

Investigator: Carol Ann Falkenberg

\section{Date}

Date 
Appendix E

\author{
Homework Quiz for Meeting With \\ Participants Prior to Baseline
}

Name:

Date:

1. Should you do homework in a loud area with the television on? Y N

2. Do you need to have materials available such as paper, pencils and a dictionary before you begin your homework? Y N

3. Should you do your homework just before bed time? $\mathrm{Y} \quad \mathrm{N}$

4. Is texting, talking to others and playing games a good idea while you are doing your homework? Y N

5. If you do not understand your homework, should you ask someone for the answers? Y N

6. If you do not understand your homework, should you ask someone to explain what to do? $\mathrm{Y} \quad \mathrm{N}$

7. Should you start your homework without reading all the directions first? Y N

8. If you are having trouble staying focused, is it okay to take a short break? Y N

9. Should you double check your work to make sure it's all completed? $\quad \mathrm{Y} \quad \mathrm{N}$ 


\section{Appendix F}

Interrater Agreement Form

\section{Inter-Rater Agreement Recording Sheet}

\section{Participant's Name}

Mark the item number in red with a + if there is agreement between raters, and mark the item number in another color with $\mathrm{a}-$ if there is disagreement between the raters

Phase: Circle one: baseline intervention I II III maintenance

\begin{tabular}{|l|l|l|l|}
\hline Date & Date & Date & Date \\
\hline Date & Date & Date & Date \\
\hline Date & Date & Date & Date \\
\hline Date & Date & Date & Date \\
\hline Date & Date & Date & Date \\
\hline Date & Date & Date & Date \\
\hline Date & Date & Date & Date \\
\hline Date & Date & Date & Date \\
\hline Date & Date & Date & Date \\
\hline Date & Date & Date & Date \\
\hline Date & Date & Date & Date \\
\hline Date & Date & Date & Date \\
\hline
\end{tabular}

Number of agreements $\mathrm{X} 100 \%=$ $\%$

Number of agreements + Number of disagreements $=$ 


\section{Appendix G}

Treatment Integrity Checklist

Participant Psydeonym:

Observer Filling Out This Form:

Date :

Time:

Phase of Study: (Check One)

Baseline

Maintenance

Intervention I II III

Directions: Check off whether the researcher performs the following tasks.

\begin{tabular}{|c|c|c|c|}
\hline \multirow{2}{*}{$\begin{array}{c}\text { Description of Procedure } \\
\text { For Phase I }\end{array}$} & \multicolumn{3}{|c|}{ Implemented } \\
\hline & $\mathrm{N} / \mathrm{A}$ & Yes & No \\
\hline $\begin{array}{l}\text { 1. The researcher welcomes participant and introduces the self- } \\
\text { monitoring sheet to the participant, how it will be used and } \\
\text { where it needs to be kept and how it should be turned in. }\end{array}$ & & & \\
\hline $\begin{array}{l}\text { 2. The researcher explains the first item on the self-monitoring } \\
\text { sheet "worked in a clear area" and shows what a clear area } \\
\text { looks like by making room on the table and explaining that } \\
\text { you need room for the book, paper, pencil etc. }\end{array}$ & & & \\
\hline $\begin{array}{l}\text { 3. The researcher asks the participant to explain in their own } \\
\text { words what was just said and/or demonstrate their } \\
\text { understanding. If they understand, the next item is addressed. } \\
\text { If they do not, then another demonstration is provided until the } \\
\text { participant shows understanding. }\end{array}$ & & & \\
\hline $\begin{array}{l}\text { 4. The researcher explains the second item on the self- } \\
\text { monitoring sheet "worked in a quiet place" and shows what } \\
\text { that sounds like by listening to the quiet room. }\end{array}$ & & & \\
\hline $\begin{array}{l}\text { 5. The researcher asks the participant to explain in their own } \\
\text { words what was just said and/or demonstrate their } \\
\text { understanding. If they understand, the next item is addressed. } \\
\text { If they do not, then another demonstration is provided until the } \\
\text { participant shows understanding. }\end{array}$ & & & \\
\hline $\begin{array}{l}\text { 6. The researcher explains the next item on the self-monitoring } \\
\text { sheet "worked without disruption" and explains what that } \\
\text { means, no phone, no games, to talking to others unless it's for } \\
\text { assistance etc. }\end{array}$ & & & \\
\hline
\end{tabular}




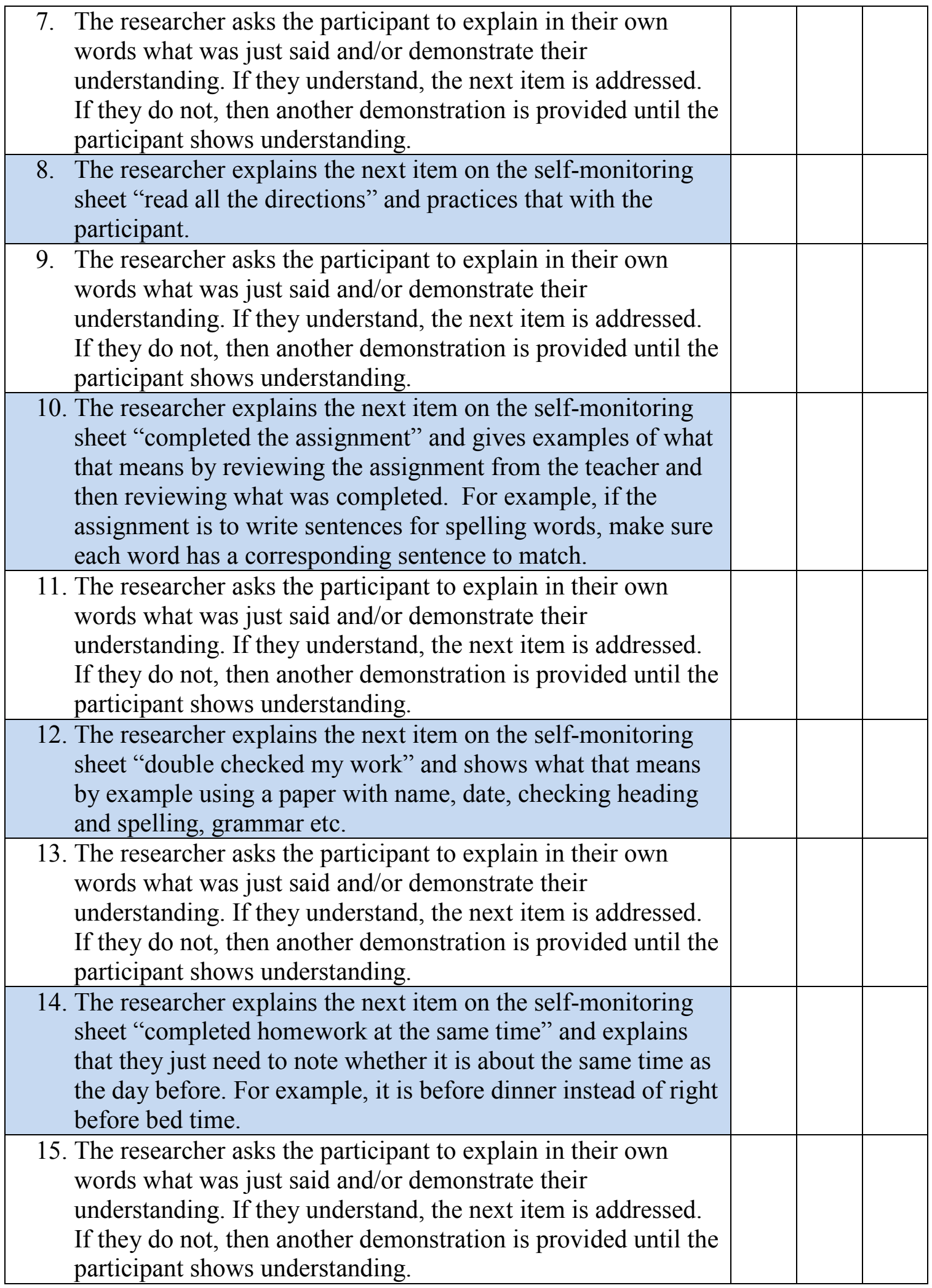


16. The researcher explains the next item on the self-monitoring sheet "packed it up to go to school" and shows by packing up a book bag with papers and zipping up the bag.

17. The researcher asks the participant to explain in their own words what was just said and/or demonstrate their understanding. If they understand, the next item is addressed. If they do not, then another demonstration is provided until the participant shows understanding.

18. Next, the researcher walks to the student computers and opens up the KidTools application and guides the participant through the steps of the program (See appendix G for sample).

19. The researcher asks the participant to show what they just learned by going through the application on their own or with the help of the guide. If they are able to do this, the next item is addressed, if not then another demonstration is provided until the participant demonstrates understanding.

20. The researcher explains to the participant that this will be completed everyday and asks if they have any questions about what to do. If not, they are excused.

\begin{tabular}{|c|c|c|c|}
\hline \multirow{2}{*}{$\begin{array}{c}\text { Description of Procedure } \\
\text { For Phase II }\end{array}$} & \multicolumn{3}{|c|}{ Implemented } \\
\hline & $\mathrm{N} / \mathrm{A}$ & Yes & No \\
\hline $\begin{array}{l}\text { 1. Good morning. You have been doing an excellent job self- } \\
\text { monitoring your spelling and math homework. Today we are } \\
\text { going to discuss a change in the procedure that you have been } \\
\text { doing so far. Okay? }\end{array}$ & & & \\
\hline 2. Address any questions or concerns. & & & \\
\hline $\begin{array}{l}\text { 3. Since you began self-monitoring, we have met every school } \\
\text { day. One day for you to receive your self-monitoring sheet, } \\
\text { and the other days for you to review the self-monitoring sheet } \\
\text { with me. }\end{array}$ & & & \\
\hline $\begin{array}{l}\text { 4. From now on, we will still meet the first day of the week for } \\
\text { you to receive your self-monitoring sheet. However, we will } \\
\text { only meet on two other days of the week to review your self- } \\
\text { monitoring sheet together. }\end{array}$ & & & \\
\hline $\begin{array}{l}\text { 5. You will continue to self-monitor as you have been doing all } \\
\text { along. I will only be calling for you to meet with me to review } \\
\text { your self-monitoring sheet on two days a week. You will not } \\
\text { know which days we will meet until that day. }\end{array}$ & & & \\
\hline $\begin{array}{l}\text { 6. You will know when I call for you that we will be reviewing } \\
\text { your self-monitoring sheet together. }\end{array}$ & & & \\
\hline
\end{tabular}




\begin{tabular}{|c|c|c|c|}
\hline $\begin{array}{l}\text { 7. Ask the participant if they understand, by having them explain } \\
\text { in their own words what was said. If they cannot give an } \\
\text { explanation, then provide another description until the } \\
\text { participant shows understanding. }\end{array}$ & & & \\
\hline \multirow{2}{*}{$\begin{array}{c}\text { Description of Procedure } \\
\text { For Phase III }\end{array}$} & \multicolumn{3}{|c|}{ Implemented } \\
\hline & $\mathrm{N} / \mathrm{A}$ & Yes & No \\
\hline $\begin{array}{l}\text { 1. Good morning. You have been doing an excellent job self- } \\
\text { monitoring your spelling and math homework. Today we are } \\
\text { going to discuss a change in the procedure that you have been } \\
\text { doing so far. Okay? }\end{array}$ & & & \\
\hline 2. Address any questions or concerns. & & & \\
\hline $\begin{array}{l}\text { 3. Since you began the second phase of self-monitoring, we have } \\
\text { met twice a week. One day for you to receive your self- } \\
\text { monitoring sheet, and the other day for you to review the self- } \\
\text { monitoring sheet with me. }\end{array}$ & & & \\
\hline $\begin{array}{l}\text { From now on, we will still meet the first day of the week for } \\
\text { you to receive your self-monitoring sheet. However, we will } \\
\text { only meet on one other day of the week to review your self- } \\
\text { monitoring sheet together. }\end{array}$ & & & \\
\hline $\begin{array}{l}\text { 5. You will continue to self-monitor as you have been doing all } \\
\text { along. I will only be calling for you to meet with me to review } \\
\text { your self-monitoring sheet one day a week. You will not know } \\
\text { which day we will meet until that day. }\end{array}$ & & & \\
\hline $\begin{array}{l}\text { 6. You will know when I call for you that we will be reviewing } \\
\text { your self-monitoring sheet together. }\end{array}$ & & & \\
\hline $\begin{array}{l}\text { 7. Ask the participant if they understand, by having them explain } \\
\text { in their own words what was said. If they cannot give an } \\
\text { explanation, then provide another description until the } \\
\text { participant shows understanding. }\end{array}$ & & & \\
\hline
\end{tabular}

\begin{tabular}{|c|c|c|c|}
\hline \multirow{2}{*}{$\begin{array}{l}\text { Description of Procedure } \\
\text { For Conferences }\end{array}$} & \multicolumn{3}{|c|}{ Implemented } \\
\hline & N/A & Yes & No \\
\hline $\begin{array}{l}\text { 1. The researcher welcomes participant and asks to see their self- } \\
\text { monitoring sheets. They review them together. }\end{array}$ & & & \\
\hline $\begin{array}{l}\text { 2. The researcher asks how they feel about completing their } \\
\text { sheets and if they have any questions. If so, all questions are } \\
\text { answered. }\end{array}$ & & & \\
\hline
\end{tabular}


Appendix $\mathrm{H}$

\section{Social Validity Questionnaire}

\section{Parent Survey}

Date: __ June 3.2010_ Interview completed by:_Falkenberg

1. Do you think it was helpful for your child to self-monitor their spelling and math homework? Why or why not?

Sam's Mom: Without a doubt! Sam was excited about it and it assisted in keeping her on track.

Rio's Mom: Yes. Rio was less confused about what he needed to do and how. It calmed him down. He's usually very anxious about the homework.

Mike's Mom: It meant something to him to have the sheet completed every day. He was proud of himself that he remembered. It was like the teacher was there reminding him.

That was good for me too, so I don't feel like a nag to him.

Brandy's Mom: I think anything we can do which results in improving her performance on homework is helpful. Her homework grades were a disaster.

2. Was it easy or difficult to assist with? Why?

Sam's Mom: Extremely easy to do. Sam did it on her own and I just needed to review it and initial each night. Took 30 seconds, tops!

Rio's Mom: Rio was pretty good at keeping track of his paper, so it really wasn't a big deal at all.

Mike's Mom: It was easier than bugging him about doing his homework! That used to be difficult. Sometimes I would remind him about his paper, but he never gave me a hard time.

Brandy's Mom: Anything was easier than what we were doing before, which was mostly arguing about homework. This was simple and she enjoyed it. Thank God.

3. Will you continue to support their self-monitoring of homework? Why or why not?

Sam's Mom: Without a doubt!

Rio's Mom: I'm glad to help with this.

Mike's Mom: He will not have a choice, I'm making sure he continues it.

Brandy's Mom: Next year I'm talking to all her teachers at the beginning of the year about this. I hope you can help us with that. I really want her to keep up with her selfmonitoring. It's good for her independence and self-esteem. Thanks for your assistance.

4. Is there something you would change about the self-monitoring? If yes, what would it be? Sam's Mom: No, I think it was wonderful. Thank you.

Rio's Mom: He love it, so I don't see anything that would really improve what was done. You saw his grades, right??

Mike's Mom: Nothing about the school aspect of it. We may tie it into some extra things at home though.

Brandy's Mom: Not that I can see at the moment. I may include some rewards at home.

\section{Thank you for your support and input.}


Appendix I

Social Validity Questionnaire

Participant Survey

Date: $\_\underline{6 / 2 / 10}$ Interview completed by:

Falkenberg

1. Do you think self-monitoring helped you with your spelling and math homework? If so, how did it help you?

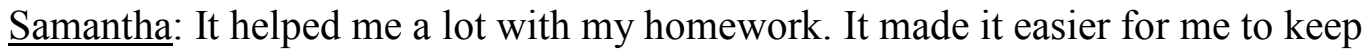
track of my work.

Rio: Yes, it reminded me what to do every day, so that was easy. The computer program was fun, so I remembered to do that.

Mike: Yes, It helped me with my math to stay focused. My mom would remind me to follow the sheet and that was a good thing, don't you think so?

Brandy: Yes, it was good and useful because it helped me double check my work and my father reminded me to check my sheet at night.

2. If not, why not?

3. Was it easy or difficult? How?

Samantha: Very easy. I kept the sheet in my planner and I liked doing the other one on the computer.

Rio: Easy. Read, color, bring it to school. Easy, KidTools, print.

Mike: It was easy to do, and the smiley faces were happy. Sometimes I just used a pencil.

Brandy: So easy, just had to read it, and check then do the chart on the computer at school, simple.

4. What did you like best about it? Why?

Samantha: The computer. It was fun and I liked the song.

Rio: I liked having better grades and my teacher was glad and my mother was glad and my sister was glad.

Mike: I liked bringing the paper in to class and I liked going on KidTools to make the other sheet. The other kids asked me about it too, so that's cool right?

Brandy: I really liked meeting with you and talking about my progress. Are we going to do that again? 
5. Will you continue to self-monitor your homework? Why or why not?

Samantha: I will do it. It was simple. Plus, I can listen to the song.

Rio: I will see next year about that, maybe my grades will just be better now.

Mike: I think my mom will make me keep doing it because it helped my homework grades a lot, didn't you see?

Brandy: I think I will keep doing the chart on the computer because that was fun. The song was fun.

6. Is there something you would change about the way you self-monitored? If yes, what would it be?

Samantha: I liked meeting with you. Also, I would like to compete against the other kids.

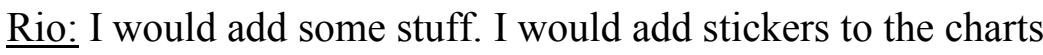

Mike: Yes, I would like to get paid or have extra computer time for good grades. Maybe you could talk to my mom about it.

Brandy: We could have the whole class do a sheet and graph it! 
Appendix $\mathbf{J}$

\section{Criteria for Selection of Participants}

\section{Student Name} Teacher Name

The following form will be utilized in the selection process of participants for a research study. The study will examine the effects of self-monitoring completion and accuracy of homework for students with disabilities who are educated in a general education classes. Your assistance in this endeavor is extremely beneficial since you know the children, and it is greatly appreciated.

\begin{tabular}{|c|l|}
\hline \multicolumn{2}{|c|}{ Must Meet Both of the Criteria Below } \\
\hline 1. & Exceptional Education Student \\
\hline 2. & Included in the general education classes \\
\hline 1. & Homework turned in late $70 \%$ of the time in a week \\
\hline 2. & Homework not turned in at all $70 \%$ of the time in a week \\
\hline 3. & Homework scores are below $70 \%$ two times a week \\
\hline 4. & \\
\hline
\end{tabular}


Appendix K

Teacher Checklist for Math and Spelling HW

\begin{tabular}{|l|l|l|l|l|}
\hline Student ID & Assignment & Due Date & $\begin{array}{c}\text { \% } \\
\text { Correct }\end{array}$ & $\begin{array}{c}\text { On } \\
\text { Time }\end{array}$ \\
\hline & & & & \\
\hline & & & & \\
\hline & & & & \\
\hline & & & & \\
\hline & & & & \\
\hline & & & & \\
\hline & & & & \\
\hline & & & & \\
\hline & & & & \\
\hline & & & & \\
\hline & & & & \\
\hline & & & & \\
\hline & & & & \\
\hline & & & & \\
\hline & & & & \\
\hline & & & & \\
\hline & & & & \\
\hline
\end{tabular}


Appendix L

\section{GENERAL HOMEWORK TIPS FOR PARENTS}

$>$ Make sure your child has a quiet, well-lit place to do homework-Avoid having your child do homework with the television on or in places with other distractions, such as people coming and going.

$>$ Make sure the materials your child needs, such as paper, pencils and a dictionary, are available-Ask your child if special materials will be needed for some projects and get them in advance.

$>$ Help your child with time management-Establish a set time each day for doing homework. Don't let your child leave homework until just before bedtime. Think about using a weekend morning or afternoon for working on big projects, especially if the project involves getting together with classmates.

$>$ Be positive about homework-Tell your child how important school is. The attitude you express about homework will be the attitude your child acquires.

$>$ When your child asks for help, provide guidance, not answers-Giving answers means your child will not learn the material. Too much help teaches your child that when the going gets rough, someone will do the work for him or her.

$>$ When the teacher asks that you play a role in homework, do it-Cooperate with the teacher. It shows your child that the school and home are a team.

$>$ If homework is meant to be done by your child alone, stay away-Too much parent involvement can prevent homework from having some positive effects. Homework is a great way for kids to develop independent, lifelong learning skills.

$>$ Stay informed-Talk with your child's teacher. Make sure you know the purpose of homework and what your child's class rules are.

$>$ Help your child figure out what is hard homework and what is easy homework-Have your child do the hard work first. This will mean he will be most alert when facing the biggest challenges. Easy material will seem to go fast if fatigue begins to set in.

$>$ Watch your child for signs of failure and frustration-Let your child take a short break if she is having trouble keeping her mind on an assignment.

$>$ Set a schedule, including both a beginning and an ending time-Most kids need some time to unwind after school before they tackle their homework. Doing it too close to bedtime may make it difficult due to fatigue.

$>$ Encourage your child to divide the homework assignment- "What I can do myself" and "What I need help with." You should help only with that part of the homework your child cannot do independently, such as using flashcards, practicing spelling tests, and clarifying assignments. This

$>$ Use direct praise for doing the homework and even more for accomplishment- "You've spelled 18 out of 20 words correctly--that's the best you've done this semester!"

$>$ Look over the homework when it is completed- Do not correct it unless you have checked with the teacher. Seeing the pattern of errors is often helpful to a teacher.

Allow bathroom, drink, and/or snack breaks-but insist on completion of tasks.

U.S. Department of Education

Office of Intergovernmental and Interagency Affairs

May 2003 


\section{Intervention for Self-Monitoring Training Script}

1. Good morning. Today we are going to discuss and learn about a new tool that will assist you in doing your homework and remembering to turn it in.

2. Give the participant a sample self-monitoring sheet to follow along.

3. Point to the first item on the self-monitoring sheet "worked in a clear area" and show what a clear area looks like by making room on the table and explaining that you need room for the book, paper, pencil etc.

4. Ask the participant if they understand by having them show you, if they say are able to do this, address the next item. If they do not give an appropriate example, then provide another demonstration until the participant shows understanding.

5. Explain the second item on the self-monitoring sheet "worked in a quiet place" and show what that sounds like by listening to the quiet room. Talk about the lack of telephones ringing or the television blaring etc.

6. Ask the participant if they understand by having them give an example, if they say give an appropriate example, the next item is addressed. If they do not give an appropriate example, then another demonstration is provided until the participant shows understanding.

7. Explain the next item on the self-monitoring sheet "worked without disruption" and explain what that means, no games, no texting, no talking to others unless it's for assistance etc.

8. Ask the participant if they understand, by having them give an example, if they say give an appropriate example address the next item. If they cannot give an explanation, then provide another demonstration until the participant shows understanding.

9. Explain the next item on the self-monitoring sheet "read all the directions" and practice that with the participant using a sample homework sheet.

10. Ask the participant if they understand by showing you, if they can do it, address the next item. If they say no, then provide another demonstration until the participant shows understanding.

11. Explain the next item on the self-monitoring sheet "completed the assignment" and give examples of what that means by reviewing an assignment from the teacher and then reviewing what need to be completed. For example, if the assignment is to write sentences for spelling words, make sure each word has a corresponding sentence to match, along with their name and date.

12. Ask the participant to explain what you just said, if they give an appropriate explanation, address the next item. If they do not, then provide another demonstration until the participant shows understanding.

13. Explain the next item on the self-monitoring sheet "double checked my work" and show what that means by example using a paper with name, date, checking heading and spelling, grammar etc. 
14. Ask the participant to explain what you just said, if they give an appropriate explanation, address the next item. If they do not, then provide another demonstration until the participant shows understanding.

15. Explain the next item on the self-monitoring sheet "completed homework at the same time" and explain that they need to think about whether it's about the same time as the day before. For example, it's before dinner instead of right before bed time.

16. Ask the participant to explain what you just said, if they give an appropriate explanation, address the next item. If they do not, then provide another demonstration until the participant shows understanding.

17. Explain the next item on the self-monitoring sheet "packed it up to go to school" and demonstrate by packing up a book bag with papers and zipping it up.

18. Ask the participant to explain or show you what you just said, if they give an appropriate explanation or demonstration, address the next item. If they do not, then provide another demonstration until the participant demonstrates understanding.

19. Next, walk over to the student computers in the classroom, click on the KidTools icon. There the child guide asks you to type in your name, type in your first and last name, then press the enter key and click "save to computer". Next, choose the "Self-Monitoring" card, then click on the "checking" card. Type in your name and the two behaviors of "Did I bring my homework to school today?" and "Did I turn my homework in?". There are happy and sad faces next to the questions, explain that a happy face means yes and a sad face means no. Then save this to the computer (See appendix ? for sample).

20. Ask the participant to show you what you just did, if they cannot remember what to do, show them that there is a guide that will help them if they click on the guide. Continue with the assistance until the participant can do it on their own and/or with the help of the guide.

21. Explain to the participant that this will be completed everyday and ask if they have any questions about what to do. If not, excuse them. 
Appendix N

\section{Script for Self-Monitoring Phase II}

8. Good morning. You have been doing an excellent job self-monitoring your spelling and math homework. Today we are going to discuss a change in the procedure that you have been doing so far. Okay?

9. Address any questions or concerns.

10. Since you began self-monitoring, we have met every school day. One day for you to receive your self-monitoring sheet, and the other days for you to review the self-monitoring sheet with me.

11. From now on, we will still meet the first day of the week for you to receive your self-monitoring sheet. However, we will only meet on two other days of the week to review your self-monitoring sheet together.

12. You will continue to self-monitor as you have been doing all along. I will only be calling for you to meet with me to review your self-monitoring sheet on two days a week. You will not know which days we will meet until that day.

13. You will know when I call for you that we will be reviewing your self-monitoring sheet together.

14. Ask the participant if they understand, by having them explain in their own words what was said. If they cannot give an explanation, then provide another description until the participant shows understanding. 
Appendix $\mathrm{O}$

\section{Script for Self-Monitoring Phase III}

8. Good morning. You have been doing an excellent job self-monitoring your spelling and math homework. Today we are going to discuss a change in the procedure that you have been doing so far. Okay?

9. Address any questions or concerns.

10. Since you began the second phase of self-monitoring, we have met twice a week. One day for you to receive your self-monitoring sheet, and the other day for you to review the self-monitoring sheet with me.

11. From now on, we will still meet the first day of the week for you to receive your self-monitoring sheet. However, we will only meet on one other day of the week to review your self-monitoring sheet together.

12. You will continue to self-monitor as you have been doing all along. I will only be calling for you to meet with me to review your self-monitoring sheet one day a week. You will not know which day we will meet until that day.

13. You will know when I call for you that we will be reviewing your self-monitoring sheet together.

14. Ask the participant if they understand, by having them explain in their own words what was said. If they cannot give an explanation, then provide another description until the participant shows understanding. 


\section{Appendix P}

\section{Script for Self-Monitoring Maintenance}

1. Good morning. You have been doing an excellent job self-monitoring your spelling and math homework. Today we are going to discuss a change in the procedure that you have been doing so far. Okay?

2. Address any questions or concerns.

3. Since you began the third phase of self-monitoring, we have met once a week. One day for you to receive your self-monitoring sheet, and the other day for you to review the self-monitoring sheet with me.

4. From now on, you can complete your KidTools sheet on the computer if you wish, but we will not review the self-monitoring sheet together. You will not be reminded in any way.

5. Ask the participant if they understand, by having them explain in their own words what was said. If they cannot give an explanation, then provide another description until the participant shows understanding. 
VITA

CAROL ANN FALKENBERG

1987

$1987-1988$

$1988-1993$

1993

1993-2003

2003-2006
B.S., Special Education and Psychology Central Connecticut State University

New Britain, Connecticut

Teacher of children with Severe Emotional Disturbance Lindsay Hopkins Technical Education Center Miami, Florida

Teacher of children with Emotional Handicaps Miami Heights Elementary School

Miami, Florida

Creative Writing for Summer Enrichment Program Wilton Public Schools

Wilton, Connecticut

M.S., Diagnostic Teaching

Florida International University

Miami, Florida

Educational Specialist

School Board Administration

Miami, Florida

Behavior Management Teacher

Dade County Public Schools District Position

Miami, Florida

Graduate Certificate in Guidance and Counseling Florida International University

Miami, Florida

Summer School Teacher Students with Autism Trumbull Public Schools

Trumbull, Connecticut

Adjunct Professor

Florida International University

Miami, Florida 
Behavior Management Specialist Claude Pepper Elementary School

Miami, Florida

Adjunct Professor

Miami-Dade Community College

Miami, Florida

2006-Present

ESE Specialist,1st Grade Teacher, Inclusion Teacher Vineyards Elementary School

Naples, Florida

\section{PUBLICATIONS AND PRESENTATIONS}

Barbetta, P., Leong-Norona, K., Silió, M., \& Falkenberg, C. (2002, May). Response cards and computers: Low-tech meets high-tech. Paper presented at the annual conference of Linking Forces, Miami, Florida.

Nevin, A. (Ed.) (2004). Reviews of single subject research designs: Applications to special education and school psychology. ERIC Document Reproduction Service No. ED489930

Salazar, L., Falkenberg, C., Nullman, S., Silio, M., \& Nevin, A., (2004). Universal design and differentiated instruction: A position paper to resolve potentially competing mandates of the Individuals with Disabilities Education Act and No Child Left Behind. ERIC Document Reproduction Service No. ED490358

\section{CURRENT MEMBERSHIPS}

Council for Exceptional Children

Florida School Counselor Association 